\title{
A 250 plastome phylogeny of the grass family (Poaceae): Topological support under different data partitions
}

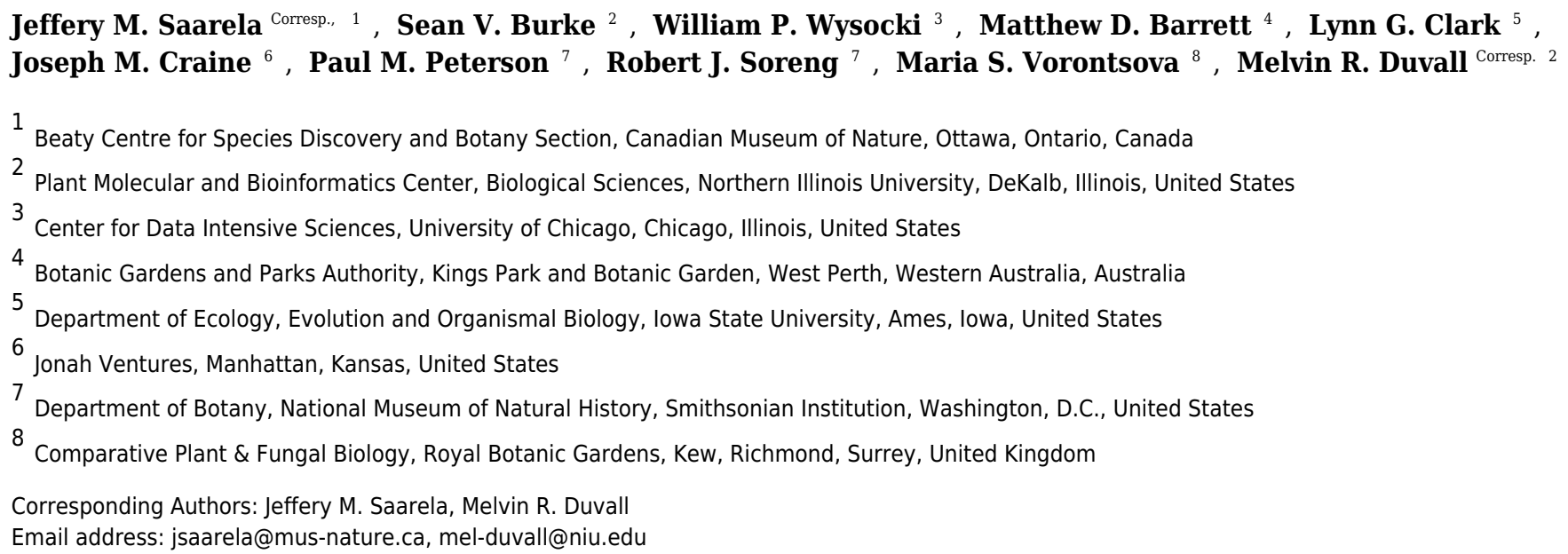

The systematics of grasses has advanced through applications of plastome phylogenomics, although studies have been largely limited to subfamilies or other subgroups of Poaceae. Here we present a plastome phylogenomic analysis of 250 complete plastomes ( 180 genera) sampled from 44 of the 52 tribes of Poaceae. Plastome sequences were determined from high throughput sequencing libraries and the assemblies represent over 28.7 Mbases of sequence data. Phylogenetic signal was characterized in 14 partitions, including 1) complete plastomes; 2) protein coding regions; 3 ) noncoding regions; and 4) three loci commonly used in single and multi-gene studies of grasses. Each of the four main partitions was further refined, alternatively including or excluding positively selected codons and also the gaps introduced by the alignment. All 76 protein coding plastome loci were found to be predominantly under purifying selection, but specific codons were found to be under positive selection in 65 loci. The loci that have been widely used in multi-gene phylogenetic studies had among the highest proportions of positively selected codons, suggesting caution in the interpretation of these earlier results. Plastome phylogenomic analyses confirmed the backbone topology for Poaceae with maximum bootstrap support (BP). Among the 14 analyses, 82 clades out of 309 resolved were maximally supported in all trees. Analyses of newly sequenced plastomes were in agreement with current classifications. Five of seven partitions in which alignment gaps were removed retrieved Panicoideae as sister to the remaining PACMAD subfamilies. Alternative topologies were recovered in trees from partitions that included alignment gaps. This suggests that ambiguities in aligning these uncertain regions might introduce false signal. Resolution of 
these and other critical branch points in the phylogeny of Poaceae will help to better understand the selective forces that drove the radiation of the BOP and PACMAD clades comprisingmore than $99.9 \%$ of grass diversity. 
1 A 250 plastome phylogeny of the grass family (Poaceae): Topological support under

2 different data partitions

3

4 Jeffery M. Saarela ${ }^{1,}$, Sean V. Burke ${ }^{2}$, William P. Wysocki ${ }^{3}$, Matthew D. Barrett ${ }^{4}$, Lynn G.

5 Clark $^{5}$, Joseph M. Craine ${ }^{6}$, Paul M. Peterson ${ }^{7}$, Robert J. Soreng ${ }^{7}$, Maria S. Vorontsova ${ }^{8}$, and

6 Melvin R. Duvall ${ }^{*}$

$8 \quad{ }^{1}$ Beaty Centre for Species Discovery and Botany Section, Research and Collections, Canadian

9 Museum of Nature, PO Box 3443 Stn. D, Ottawa, ON, Canada K1P 3P4

102 Plant Molecular and Bioinformatics Center, Biological Sciences, Northern Illinois University,

111425 W. Lincoln Hwy, DeKalb, IL 60115-2861, USA

$12{ }^{3}$ Center for Data Intensive Sciences, University of Chicago, 5454 S. Shore Dr., Chicago IL

1360615

$14{ }^{4}$ Botanic Gardens and Parks Authority, Kings Park and Botanic Garden, West Perth, WA 6005,

15 Australia

$16{ }^{5}$ Department of Ecology, Evolution and Organismal Biology, Iowa State University, 251 Bessey

17 Hall, Ames, Iowa, 50011-1020, USA

18 'Jonah Ventures, Manhattan, KS 66502, USA.

$19{ }^{7}$ Smithsonian Institution, Department of Botany, National Museum of Natural History,

20 Washington, D.C. 20013-7012, USA

$21{ }^{8}$ Comparative Plant \& Fungal Biology, Royal Botanic Gardens, Kew, Richmond, Surrey, TW9

$223 \mathrm{AE}, \mathrm{UK}$ 
24 *Corresponding authors’ e-mail addresses: jsaarela@mus-nature.ca, mel-duvall@niu.edu

\section{Abstract}

26 The systematics of grasses has advanced through applications of plastome phylogenomics,

27 although studies have been largely limited to subfamilies or other subgroups of Poaceae. Here

28 we present a plastome phylogenomic analysis of 250 complete plastomes (180 genera) sampled

29 from 44 of the 52 tribes of Poaceae. Plastome sequences were determined from high throughput

30 sequencing libraries and the assemblies represent over 28.7 megabases of sequence data.

31 Phylogenetic signal was characterized in 14 partitions, including 1) complete plastomes; 2)

32 protein coding regions; 3) noncoding regions; and 4) three loci commonly used in single and

33 multi-gene studies of grasses. Each of the four main partitions was further refined, alternatively

34 including or excluding positively selected codons and also the gaps introduced by the alignment.

35 All 76 protein coding plastome loci were found to be predominantly under purifying selection,

36 but specific codons were found to be under positive selection in 65 loci. The loci that have been

37 widely used in multi-gene phylogenetic studies had among the highest proportions of positively

38 selected codons, suggesting caution in the interpretation of these earlier results. Plastome

39 phylogenomic analyses confirmed the backbone topology for Poaceae with maximum bootstrap

40 support. Among the 14 analyses, 85 clades out of 309 resolved were maximally supported in all

41 trees. Analyses of newly sequenced plastomes were in agreement with current classifications.

42 Five of seven partitions in which alignment gaps were removed retrieved Panicoideae as sister to

43 the remaining PACMAD subfamilies. Alternative topologies were recovered in trees from

44 partitions that included alignment gaps. This suggests that ambiguities in aligning these uncertain

45 regions might introduce false signal. Resolution of these and other critical branch points in the 
46 phylogeny of Poaceae will help to better understand the selective forces that drove the radiation

47 of the BOP and PACMAD clades comprising more than $99.9 \%$ of grass diversity.

\section{Introduction}

Grasses (Poaceae) are the fifth largest family of flowering plants in the world, with some

11,500 species and about 768 genera (Soreng et al., 2017), and the family is economically

51 important because it includes wheat (Triticum L.), rice (Oryza L.) and corn (Zea L.), as well as numerous forage, bamboo and biofuel species. Grasses grow on all continents in tropical, temperate and Arctic zones. Grasses are common and often dominant components of open ecosystems (prairies, pampas, steppes, veldts), but also occur in association with forests, and they have diversified to inhabit wet to dry habitats. The deep phylogenetic framework for Poaceae is well established (Grass Phylogeny Working Group, 2001; Duvall et al., 2007; Bouchenak-Khelladi et al., 2008; Saarela \& Graham, 2010; Grass Phylogeny Working Group II, 2012). Three small, deeply diverging subfamilies (Anomochlooideae, Pharoideae, Puelioideae) are the successive sister groups of a major clade comprising two lineages, the BOP and PACMAD clades. The BOP clade consists of three subfamilies: Bambusoideae (bamboos or

61 bambusoids), Oryzoideae (rices or oryzoids) and Pooideae (cool season or pooids). The

62 PACMAD clade consists of six subfamilies: Panicoideae (panicoids), Arundinoideae

63 (arundinoids), Chloridoideae (chloridoids), Micrairoideae (micrairoids), Aristidoideae

64 (aristidoids) and Danthonioideae (danthonioids).

65 The systematics of grasses have been studied throughout the history of botany, with the 66 first dedicated classification by Brown (1814), and classifications of the whole family or parts

67 thereof have been continually proposed through time as new information has accumulated. The 
68 current subfamily classification was proposed by Grass Phylogeny Working Group (2001) and

69 modified by Sánchez-Ken et al. (2007) and Sánchez-Ken \& Clark (2010). The phylogenetic

70 structure of the family was synthesised and reconciled with morphological and developmental

71 genetic data by Kellogg (2015). A recent worldwide classification of grasses based explicitly on

72 molecular phylogenetic evidence recognized 12 subfamilies, 6 supertribes, 52 tribes and 90

73 subtribes of grasses, with 21 genera unplaced to tribe and 39 unplaced to subtribe (Soreng et al.,

74 2017); this is an update of a classification proposed two years earlier by Soreng et al. (2015b).

Complete plastid genomes from across the land plant tree of life are being sequenced

rapidly (e.g., Tonti-Filippini et al., 2017), including those from grasses. Saarela et al. (2015)

summarized all publications of grass plastomes published as of September 2014, and many new

plastomes have since become available. Recent grass plastome sequences have been variously

published in short contributions (Myszczyński et al., 2015; Wang \& Gao, 2015, 2016; Lu et al.,

2016; Perumal et al., 2016) or in the context of detailed phylogenomic analyses of different grass lineages, including the PACMAD clade (Cotton et al., 2015; Teisher et al., 2017), Bambusoideae

(Wu et al., 2015; Wysocki et al., 2015; Attigala et al., 2016; Vieira et al., 2016; Zhang \& Chen, 2016), Brachypodieae (Sancho et al., 2017), early-diverging grasses (Burke et al., 2016a),

Panicoideae (Burke et al., 2016b), Chloridoideae (Duvall et al., 2016), Zea (Orton et al., 2016),

Micrairoideae (Duvall et al., 2017), Pooideae (Saarela et al., 2015) and Oryzeae (Kim et al.,

87 plastomes have contributed increased resolution and support for many relationships within and 
$91 \quad$ One issue of plastome phylogenomics relates to data partitioning. A few plastome

92 phylogenomic studies of grasses have investigated different ways to partition complete plastome

93 sequences, primarily by comparing analyses of coding, noncoding, and coding plus noncoding

94 regions. These studies failed to find unambiguous evidence to support any specific partitioning

95 strategy, but this may reflect insufficient taxonomic sampling (Zhang et al., 2011; Burke et al.,

96 2012; Ma et al., 2014; Saarela et al., 2015). Gapped sites in an alignment are another partition

97 that can analyzed, and that may be problematic for phylogenetic inference (Warnow, 2012). The

98 effects of including vs. excluding gapped sites on phylogenetic reconstruction has not been fully

99 explored in grass phylogenomic analyses. Some gapped sites in an alignment reflect evolutionary

100 history (e.g., indels), but others may represent suboptimal alignment possibly resulting in

101 spurious phylogenetic results. Indeed, as plastome-scale data sets rapidly increase in size, manual

102 curation of alignments is increasingly difficult, especially as phylogenetic breadth of taxon

103 sampling increases. Generating alignments automatically for these large data sets is practical, but

104 such alignments are likely to include some ambiguously aligned regions, particularly among the

105 most rapidly-evolving parts of the plastome for which it is necessary to introduce alignment

106 gaps.

107

Yet another way to partition plastomes for phylogenetic reconstruction is through

108 comparison of positively-selected vs. non-selected nucleotide sites. The plastome is a mosaic of

109 selected and non-selected nucleotide sites. Sites under selection are found in polycistronic

110 protein and RNA coding regions together with their associated promoter and intron-processing

111 regions. These regions constitute approximately $45 \%$ of the grass plastome, although many third

112 codon positions in protein coding loci are unconstrained by selection. Positive selection can bias

113 reconstruction of phylogenetic relationships (Christin et al., 2012). In grasses, positive selection 
114 has been characterized in $r b c L$ (Christin et al., 2008b) and in all plastome protein genes across

115 the PACMAD clade (Piot et al., 2017). The latter study identified positive selection in 25 of 76

116 plastid genes, and found that the multiple origins of $\mathrm{C}_{4}$ photosynthesis in the PACMAD clade

117 were accompanied by positive selection in $r b c L$ but not in other plastid genes. Potential bias in

118 plastome phylogenetic reconstruction when positively selected sites are included in analysis has

119 not been explored previously in grasses.

120 Here, we report a phylogenomic study of 250 plastomes broadly representing the

121 subfamilies, families, tribes and subtribes of grasses, including 15 new plastomes. We

122 characterize phylogenetic signal in 14 plastome partitions, including a three-gene partition,

123 coding regions, noncoding regions, and complete plastomes, each variously including or

124 excluding gapped sites and positively selected sites in the alignment. With these analyses we test

125 the hypotheses that selection, alignment ambiguities, or other characteristics of specific partitions

126 contribute to difficulties in retrieving consistent topologies in grass phylogenies when taxonomic

127 sampling is consistent. In particular, the problematic deep relationships among the PACMAD

128 subfamilies are investigated (i.e., what is the branching order among Aristidoideae, Panicoideae,

129 Chloridoideae + Danthonioideae, and Arundinoideae + Micrairoideae). We also compare and

130 contrast the results of our phylogenomic analyses with current grass classifications and with

131 existing knowledge of phylogenetic relationships in grasses derived from plastid/plastome and

132 nuclear analyses. 


\section{Materials and Methods}

\section{Taxon Sampling}

135 Taxon sampling includes 15 new (Table 1) and 235 plastomes obtained from GenBank

136 (Asano et al., 2004; Saski et al., 2007; Bortiri et al., 2008; Diekmann et al., 2009; Leseberg \&

137 Duvall, 2009; Wu et al., 2009, 2012; Morris \& Duvall, 2010; Nock et al., 2011; Young et al.,

138 2011; Zhang et al., 2011, 2016; Burke et al., 2012, 2014, 2016a, 2016b; Waters et al., 2012;

139 Besnard et al., 2013; Hand et al., 2013; Gornicki et al., 2014; Jones et al., 2014; Lee et al., 2014;

140 Ma et al., 2014, 2015; Mariac et al., 2014; Middleton et al., 2014; Ye et al., 2014; Cotton et al.,

141 2015; Gogniashvili et al., 2015; Kim et al., 2015; Lundgren et al., 2015; Rousseau-Gueutin et al.,

142 2015; Saarela et al., 2015; Wambugu et al., 2015; Wang \& Gao, 2015; Wysocki et al., 2015;

143 Attigala et al., 2016; Duvall et al., 2016, 2017; Gao \& Gao, 2016; Gao et al., 2016; Nah et al.,

144 2016) (Supplemental Table 1). Plastomes not available on GenBank as of 19 November 2015

145 were not included in our analyses, unless generated by us. The voucher specimen for the

146 plastome published as Microstegium vimineum (Trin.) A. Camus (GRIN, PI 659331) in Burke et

147 al. (2016b) was mis-identified; its correct identity is Arthraxon prionodes (Steud.) Dandy (E.

148 Kellogg, pers. comm.). The same seed accession was sequenced in Estep et al. (2014), as

149 Arthraxon prionodes, and in Liu et al. (2014), as Microstegium vimineum. We have corrected

150 this error on GenBank (accession KU291471). For new plastomes, we obtained DNA from either

151 fragments of herbarium mounted leaf tissues or silica-dried seedlings germinated in the

152 greenhouse. For the latter, voucher specimens were prepared from greenhouse material when it

153 reached a flowering stage suitable for identification, and these were deposited in the herbarium

154 (DEK) of the Biological Sciences Department, Northern Illinois University, DeKalb, Illinois. 
155 Tissue was homogenized manually in liquid nitrogen before extraction. The DNA extraction

156 protocol was followed using the Qiagen DNeasy Plant Mini Kit (Qiagen Inc., Valencia, CA, 157 USA).

158 We follow the subdivisional classification of Poaceae by Soreng et al. (2017) with one

159 exception: following the results of Burke et al. (2016b), we consider Whiteochloa C.E. Hubb. as

160 part of Panicinae rather than Cenchrinae. Genus classification also follows Soreng et al. (2017),

161 including for plastomes published under different names, as noted in Supplemental Table 1.

162 Major lineages in the bamboo tribe Arundinarieae have been referred to as clades I to XII

163 (Triplett \& Clark, 2010; Zeng et al., 2010; Yang et al., 2013; Attigala et al., 2014; Zhang et al.,

164 2016c), and we here follow this informal naming system. The plastome sampling represents all

16512 subfamilies, 44 tribes, 63 subtribes, 179 genera and 250 species of grasses.

\section{Plastome sequencing, assembly, annotation and alignment}

167 Plastome sequencing methods generally followed those of Burke et al. (2016b). Single end

168 libraries were prepared depending on different starting quantities of DNA with the Nextera or

169 Nextera XT methods (Illumina, San Diego, CA, USA). All sequencing was done on the Illumina

170 HiSeq 2500 platform at the core DNA Facility, Iowa State University, Ames, IA, USA. Details

171 are given (Table 1). Illumina reads were assembled into complete plastid chromosomes with de

172 novo assembly methods. For Nextera data the Velvet software package (Zerbino \& Birney,

173 2008) was used iteratively, loading contigs from the previous step into the assembler multiple

174 times with stepwise increasing kmer lengths (see details in Wysocki et al. 2014). For Nextera XT

175 data, SPAdes v.3.5.0 (http://bioinf.spbau.ru/spades) was used for de novo assembly (Bankevich

176 et al., 2012). Contigs were scaffolded with the anchored conserved region extension method

177 (Wysocki et al., 2014), which queries contig sets for regions that are invariant across Poaceae. 
178 Any remaining gaps in the scaffolds were resolved by in silico genome walking. A final

179 verification was performed by mapping reads to the newly assembled plastome to detect and

180 correct inconsistencies. Annotations were determined in Geneious Pro v9.1.6 (Biomatters Ltd.,

181 Auckland, NZ) (Kearse et al., 2012) initially using the pairwise align function. A published

182 reference for each new plastome was obtained from a closely related grass species. Annotations

183 from the reference were transferred to the newly assembled plastome. The boundaries of coding

184 sequences were adjusted to preserve reading frames. The endpoints of the large inverted repeats

185 (IR) were located using the methods of Burke et al. (2012). Data partitions were aligned in

186 Geneious Pro with the MAFFT v7.017 (Katoh \& Standley, 2013) plugin using the auto function

187 for the algorithm and other settings as defaults. In the interest of reproducibility no manual

188 adjustments were made to the alignments. This approach may have discarded informative

189 microstructural mutations or possibly allowed regions with micro inversions to be misaligned.

190 However, in the context of whole plastome alignments, these events are overwhelmed by

191 unambiguously aligned coding and noncoding regions and so have minimal effect.

192

193 Purifying/positive selection

194 Purifying/positive selection detection and the removal of positively selected sites were as

195 follows: alignments for each of the 76 protein coding sequences (CDS), excluding duplicated

196 copies of loci in one of the IRs, for the 250 taxa were individually extracted. Each extracted CDS

197 was imported into Mega6 v6.06 (Tamura et al., 2013) and aligned by codon via Muscle (Edgar,

198 2004). The computed overall mean distance function determined the mean non-synonymous

199 substitutions per non-synonymous site $(\mathrm{dN})$ and the mean synonymous substitutions per

200 synonymous site (dS) values for each CDS based on default parameters. Each CDS was then 
201 tested for positive or purifying selection using the codon-based Z test of selection (Nei \& Kumar,

202 2000) on default parameters (Supplemental Dataset 1).

203 After the predominant type of selection for each locus was identified, the specific number

204 of positively selected codons in each locus was determined using the following methods. Each

205 extracted CDS was then first analyzed with the codon alignment tool in HYPHY

206 v2.22016030beta (MP) (Pond \& Frost, 2005), under the 'Data File Tools' (option 4), under the

207 following encoded conditions: 1 (coding sequence aligned to reference using protein

208 translations), 1 (default BLAST BLOSUM62 matrix), 1 (prefix and suffix indels were not

209 penalized), 2 (the longest sequence in the data file was used as the reference), and 1 (there were

210 no reference coordinate sequences; i.e., no external standard). Each alignment was then analyzed

211 with 'Data File Tools' (option 4) following the options of: 6 (convert sequence names to HyPhy

212 valid identifiers if needed and replace stop codons with gaps in codon data if any are present),

213 and 1 (Universal Code), to remove stop codons and convert sequence names just for the

214 following analysis. Each CDS alignment was then tested for positive selection at individual

215 codon sites using mixed effects model of evolution (MEME) (Murrell et al., 2012). This was

216 done through the 'Positive Selection' option in HyPhy following the options of 9 (quickly test

217 for positive selection using several approaches), 1 (universal code), 1 (new analysis), 1 (default,

218 use HKY85 and MG94xHKY85), 1 (neutral dN/dS=1), and 11 (MEME, mixed effects model of

219 evolution to search for evidence of episodic selection at individual sites). Based on this output,

220 for each data partition that had positively selected sites removed, these sites were manually

221 removed for each CDS. 


\section{Phylogeny estimation}

223

224

225

226

227

228

229

230

231

232

233

234

235

236

237

238

239

240

241

242

243

244

We analysed 14 different data partitions (Table 2), which variously included a subset of plastome coding regions (partitions $\mathrm{A}-\mathrm{D})$, all plastome coding regions $(\mathrm{E}-\mathrm{H})$, plastome noncoding regions $(\mathrm{Q}-\mathrm{R})$ and complete plastomes (coding and noncoding partitions) (W-Z). The subset of coding regions ( $r b c L, n d h F, \operatorname{mat} K$, and the $\operatorname{trn} K$ intron) was selected to compare against previously published family-wide analyses such as Grass Phylogeny Working Group II (2012). In each of these four core partitions we variously included or excluded gapped sites in the alignment and positively selected sites in partitions including coding regions when applicable, so that each core partition had four variants except the noncoding partition, from which there were no positively selected sites to exclude. Alignment gaps found in one or more sequences were removed using the "remove gaps" command in Geneious. Alignment files are presented in Supplemental Datasets 2-15. We refer to the four trees based on the reduced datasets as "three-gene trees", and to the ten trees based on large partitions of whole plastomes as "plastome trees".

We conducted only maximum likelihood (ML) analyses, given the extensive partitioning that was conducted and the large number of comparisons that needed to be made among the many clades in trees from different partitions. Since our study is focused on plastome phylogeny of the entire grass family, it would be ideal to root the tree with non-grass taxa. The closest relatives of grasses are the families Joinvilleaceae, Ecdeiocolaceae and Flagellariaceae. Plastome data based on 77 coding regions and some smaller data sets identify Ecdeiocolaceae and grasses as sister taxa (Bremer, 2002; Chase et al., 2006; Graham et al., 2006; Givnish et al., 2010; Barrett et al., 2016), while other studies have identified a clade of Ecdeiocolaceae + Joinvilleaceae as the grass sister group (Marchant \& Briggs, 2007; Christin et al., 2008a; Saarela \& Graham, 2010). 
245 Of these three non-grass graminid families, complete plastome data are available only for

246 Joinvilleaceae (Wysocki et al., 2016a). Moreover, there are major rearrangements in the large

247 single copy (LSC) regions of grass plastomes compared to other Poales and all other

248 angiosperms (Doyle et al., 1992; Katayama \& Ogihara, 1996; Michelangeli et al., 2003; Burke et

249 al., 2016a; Wysocki et al., 2016a). In a recent plastome phylogenomic study of grasses, including

250 a highly rearranged Poales outgroup (Joinvillea Gaudich. ex Brongn. \& Gris) resulted in the loss

251 of substantial data, especially in noncoding regions (Burke et al., 2016a). Using Joinvillea as an

252 outgroup in the current study would similarly result in a loss of data, which would be detrimental

253 to our partitioned analyses. Thus, considering the difficulty of aligning grasses with non-grasses,

254 and consistent with the purpose of the present analysis, we opted to root our trees along the

255 branch leading to Anomochlooideae (Anomochloa marantoidea Brong. and Streptochaeta

256 spicata Scrad. ex Nees), given the well-established sister group relationship of Anomochlooideae

257 to the rest of the grasses

258 A substitution model was selected using jModelTest v. 2.1 .3 (Guindon \& Gascuel, 2003;

259 Darriba et al., 2012). For all partitions, the GTR + I + G model was selected under the Akaike

260 information criterion (Akaike, 1974). ML analyses were performed using RAxML-HPC2 on

261 XSEDE v. 8.1.11 (Stamatakis, 2014) at the CIPRES Science Gateway (Miller et al., 2010). The

262 number of bootstrap replicates was automatically halted by the "autoMRE" function. All model

263 parameters were estimated.

264 To compare and contrast the phylogenetic trees generated from each of the 14 partitions,

265 we compared branch support for identical (i.e., shared) clades across all trees (Supplemental

266 Dataset 16). First, we chose a reference tree, named all clades on that tree by assigning a unique

267 number to each branch subtending a clade, and then recorded, in a spreadsheet, bootstrap support 
268 for each clade when $\geq 50 \%$. Second, we recorded bootstrap support $\geq 50 \%$ for the same clades in

269 all other trees. When we encountered a clade in a non-reference tree not present in the reference

270 tree, we named that clade and recorded bootstrap support for it, when $\geq 50 \%$, across all trees. We

271 chose the tree resulting from analysis of partition $\mathrm{X}$ as our reference tree, for the following

272 reasons: (1) A priori partition exclusion is minimized in X (i.e., it includes coding and noncoding

273 regions), so we are not arbitrarily choosing one of those two major partitions for our reference

274 tree; (2) Stripping gapped sites is necessary since accurate ML estimation cannot be guaranteed,

275 even with long sequences, when indels are included and treated as missing data (Warnow 2012);

276 (3) Erring on the side of including more data, as found in complete plastomes, keeps our large

277 analysis from running into an insufficient phylogenetic information wall. We present the ML

278 reference tree $(\mathrm{X})$ in multiple figures, including a summary tree showing relationships among

279 subfamilies, with within-subfamily sampling collapsed to a single branch.

280 We performed six pairwise comparisons of trees generated from data partitions differing

281 only by the inclusion or exclusion of positively selected codons, to gain insight into the relative

282 effect of these characters on the inferred phylogenies. We conducted similar comparisons of trees

283 differing only by the inclusion or exclusion of gapped sites. To characterize the effect of datasets

284 comprising three-genes and all plastome coding genes on tree topology and support we

285 conducted pairwise comparisons of trees A vs. E, B vs. F, C vs. G and D vs. H.

286 Descriptions of phylogenetic results focus on the plastome trees (not the three-gene

287 trees), and clades with support $<50 \%$ are not discussed. We use the terms 'weak or poor',

288 'moderate', and 'strong' in reference to clades that received bootstrap support values of $50-70 \%$,

$28971-90 \%$ and $91-100 \%$, respectively, and 'unsupported' for clades with bootstrap support $<50 \%$. 
290 Results

\section{Purifying/positive selection}

292 Selection analyses of 76 protein coding loci in the grass plastome indicated that all were

293 under selection. The predominate selective force identified for all loci was purifying selection

294 (all 76 significant at $\mathrm{p}<0.05$ ). However, positively selected codons could be identified in 65 out

295 of the 76 loci (Fig. 1). Loci without positively selected codons included two subunits of the

296 cytochrome b6/f complex (petL, pet $N$ ), seven photosystem II proteins (psbE, psbF, psbI, psbL,

$297 p s b N, p s b T, p s b Z)$ and two ribosomal proteins (rpL36, rps 19). All 11 were relatively short loci

298 (mean length $<150$ bases). Of the 65 loci with positively selected codons, the greatest number

299 were found in rpoC2 (184 codons), matK (74), ndhF (67) and rbcL (47).

300

301

302

303

304

305

306

307

308

309

310

311

\section{Comparison of phylogenetic trees from partitioned datasets}

The entire 250 plastome alignment, including gapped sites, is 197,529 bp in length, and there is considerable variation in the lengths of the plastome partitions considered (Table 2). The plastome coding, plastome noncoding and complete plastome alignments including gapped sites are $24-32 \%, 445 \%$ and $151-177 \%$ longer, respectively, than when gapped sites are excluded. The plastome coding and complete plastome alignments including positively selected sites are $5.8 \%$ and $0.1 \%$ greater in length than when positively selected sites are excluded.

Maximum likelihood cladograms and phylograms of all 14 analyses are provided in

Supplemental Figure 1. Mean bootstrap support across all branches with support $\geq 50 \%$ in each of the 14 trees ranges from $90.1 \%$ to $97.9 \%$. Support is generally lower in the three-gene trees than in the plastome trees (Fig. 2). Among the four three-gene trees, mean support is highest in tree A, and that support is significantly different from mean support in trees B to D (Fig. 2). 
312 Among the 10 plastome trees, support is generally lower in tree $\mathrm{R}$ compared to the others, but

313 mean support in tree $\mathrm{R}$ is not significantly different than that in trees $\mathrm{E}$ to $\mathrm{H}$. Mean branch

314 support is highest in trees Q and $\mathrm{W}$ to $\mathrm{Z}$, but is not significantly different among these trees (Fig.

$3152)$.

316 The reference tree X (Figs. 3-8) includes 242 clades with bootstrap support $\geq 50 \%$, and

317 the 14 trees include 309 clades with support $\geq 50 \%$ in at least one tree (Supplemental Dataset

318 16). Eighty-five clades are maximally supported in all 14 trees and 144 in all plastome trees, 231

319 clades are maximally supported in at least one plastome tree, and 78 clades are not maximally

320 supported in any tree. There are 197 clades with support $\geq 50 \%$ in at least one plastome tree and

32124 clades with support $\geq 50 \%$ in only single plastome trees. The number of clades in each tree

322 with support $\geq 50 \%$ ranges from 206 to 246 . There are fewer clades with support $\geq 50 \%$ in the

323 three-gene trees (206 to 215 clades, $\bar{x}=212)$ than in the plastome trees $(224$ to $246, \bar{x}=239)$.

324 In pairwise comparisons of trees generated from data partitions differing by the inclusion

325 or exclusion of positively selected codons (Table 3), the number of shared clades (i.e., identical

326 clades with support $\geq 50 \%$ ) ranges from 192 to 238 and the number of shared clades with

327 maximal support from 90 to 203 . When positively selected sites are excluded, the number of

328 shared clades with increased support in one of the compared trees ranges from 11 to $46(\overline{\mathrm{x}}=22 \pm$

329 12), with identical support in the compared trees from 100 to $205(\overline{\mathrm{x}}=166 \pm 42)$, and with

330 decreased support in one of the compared trees from 12 to $58(\overline{\mathrm{x}}=32 \pm 15)$. In all comparisons,

331 the ranges of support differences for shared clades are considerable (up to $48 \%$ ), and some clades

332 identified in each tree with bootstrap support $\geq 50 \%$ are unsupported in the other. Overall,

333 however, excluding positively selected codons has relatively little effect on support values, with

334 average support differences for shared clades in each comparison ranging from 1 to $4 \%$. The 
335 largest effect of positively selected sites is in comparison B vs. D. These are three-gene data sets,

336 with all genes known to have positively selected sites.

337 In pairwise comparisons of trees generated from data partitions differing only by

338 inclusion or exclusion of gapped sites (Table 3), the number of shared clades ranges from 197 to

339230 and the number of shared clades with maximal support from 95 to 200 . When gapped sites

340 are excluded, the number of shared clades with increased support in one of the compared trees

341 ranges from 3 to $32(\overline{\mathrm{x}}=15 \pm 9)$, with identical support in the compared trees from 103 to $201(\overline{\mathrm{x}}$

$342=164 \pm 38)$, and with decreased support in one of the compared trees from 19 to $68(\overline{\mathrm{x}}=38 \pm$

343 13). In all comparisons, the ranges of support differences for shared clades are considerable (up

344 to $44 \%$ ), and, as in the comparisons excluding positively selected sites, some clades identified in

345 each tree with bootstrap support $\geq 50 \%$ are unsupported in the other. Overall, excluding gapped

346 sites has relatively little effect on support values, with average support differences for shared

347 clades in each comparison ranging from 2 to $4 \%$. The largest effect of gapped sites are in

348 comparisons Y vs. Z (complete plastome data sets excluding positively selected sites) and Q vs.

$349 \mathrm{R}$ (noncoding plastome data).

350 In each comparison of three-gene vs. plastome coding trees, 103 to 119 shared clades are

351 maximally supported (Table 4). Three to six shared clades are more strongly supported in the

352 three-gene trees than the plastome coding trees; the difference in support is $\geq 10 \%$ in 0 to 4 of

353 these clades. Reciprocally, 71 to 91 shared clades are more strongly supported in the plastome

354 coding trees than the three-gene trees; the difference in support is $\geq 10 \%$ in 26 to 50 of these

355 clades. Two to eight clades are identified with support $\geq 70 \%$ in the three-gene trees that are

356 unsupported in the plastome coding trees. Reciprocally, 30 to 34 clades are identified with

357 support $\geq 70 \%$ in the plastome coding trees that are unsupported in the three-gene trees. Twenty- 
358 seven clades not supported in any of the three-gene trees are supported (BP $\geq 50 \%)$ in one or

359 more of the plastome coding trees, and 25 clades identified with $\mathrm{BP} \geq 50 \%$ in one or more three-

360 gene trees are not supported in the plastome coding trees (Supplemental Dataset 16). Ten of the

361 latter have support $\geq 70 \%$ in at least one three-gene tree: PCMAD [aristidoid sister],

362 Monachather + Micrairoideae, Dactyloctenium + Tripogoninae, Trichoneurinae + Eleusininae,

363 Amphicarpum + Thyridolepis, Otachyriinae + Paspalinae, Bambusinae + Greslaninae +

364 Dinochloinae, Bambusa multiplex + Bambusa oldhemii + Bambusa emeiensis + Bambusa

365 bambos + Dendrocalamus, Diarrhena + Bromeae + Poeae + Triticeae, and Agrostidinae +

366 Brizinae + Anthoxanthinae + Aveninae.

367 We define conflicting clades as those with moderate to strong support $(\mathrm{BP} \geq 70 \%)$ in two

368 or more trees and different but overlapping sets of species. In 22 instances one or more taxa are

369 part of two conflicting clades, and in five instances one or more taxa are part of three conflicting

370 clades (Table 5). Nineteen conflicting clades are present in a single tree, 20 in two to four trees,

371 and 18 in five or more trees. Conflicts occur in Bambusoideae, Chloridoideae, Oryzoideae,

372 Panicoideae and Pooideae, among subfamilies of the PACMAD clade and among taxa of the

373 Arundinoideae + Micrairoideae clade. There are four instances of conflict among congeneric

374 species in Aegilops L., Bambusa Schreb., Oryza and Triticum.

375 Phylogenetic Relationships

376 The following descriptions of phylogenetic relationships refer only to the ten plastome

377 trees unless otherwise indicated. In all plastome trees, Pharoideae and Puelioideae are

378 successively diverging sisters of a lineage comprising the BOP and PACMAD clades (Figs. 3-

379 8). The BOP clade is maximally supported in all plastome trees except $\mathrm{Y}(\mathrm{BP}=88 \%)$, and the

380 PACMAD clade is maximally supported in all plastome trees. 
381

382 In the plastome trees, Bambusoideae $(\mathrm{BP}=100 \%)$, Oryzoideae $(\mathrm{BP}=87-100 \%)$ and Pooideae

$383(\mathrm{BP}=100 \%)$ are strongly supported, and Bambusoideae and Pooideae form a maximally

384 supported clade (Figs. 3, 5, Supplemental Figure 1).

Pooideae

386

Brachyelytrum aristosum (Michx.) P. Beauv. ex Trel. (Brachyelytreae), Lygeum spartum

387

L. (Lygeae) + Nardus stricta L. (Nardeae), Phaenosperma globosum Munro ex Benth.

388 (Phaenospermateae), Melica L. (two species; Meliceae), and Stipeae-Ampelodesmeae diverge

389 successively with respect to the rest of the Pooideae clade in all trees $(\mathrm{BP}=88-100 \%)$. Within

390 Stipeae-Ampelodesmeae ( $\mathrm{BP}=100 \%)$, Eriocoma hymenoides (Roem. \& Schult.) Rydb. +

391 Nassella hyalina (Nees) Barkworth (BP $=100 \%)$ and Piptatherum songaricum (Trin. \& Rupr.)

392 Roshev. ex Nikitina form a clade (BP $=100 \%)$, and Oryzopsis asperifolia Michx. +

393 Ampelodesmos mauritanicus (Poir.) T. Durand \& Schinz (Ampelodesmeae) (BP = 88-100\%)

394 and Piptochaetium avenaceum (L.) Parodi form a clade (BP $=88-100 \%)$.

395 Seven trees identify a clade comprising Brachypodium distachyon (L.) P. Beauv.

396 (Brachypodieae), Bromus vulgaris (Hook.) Shear (Bromeae), Poeae and Triticeae, with varying

397 support. Gapped sites in the plastome noncoding alignments contribute strongly to support for

398 the clade. In tree Q, based on noncoding regions including gapped sites, and in the two complete

399 plastome trees including gapped sites (W, Y), support for the clade is $100 \%$, whereas in tree R,

400 based on noncoding regions excluding gapped sites, support for the clade is less than $50 \%$.

401 Plastome coding regions also identify the clade, but with weaker support, when gapped sites are

402 included (G, E; BP $=80 \%, 85 \%)$ and excluded (F, H; BP $=62 \%$, 55\%). When gapped sites are

403 excluded from the complete plastome datasets, however, Diarrhena obovata (Gleason) 
404 Brandenburg (Diarrheneae) and Brachypodieae are sister taxa with weak (X, BP = 55\%) and 405 moderate $(\mathrm{Z}, \mathrm{BP}=72 \%)$ support. In all trees, Bromeae and Triticeae are maximally supported 406 sister taxa, and Bromeae + Triticeae and Poeae form a maximally supported clade.

407 Within Triticeae, Hordeum L. (two species sampled), Connorochloa tenuis (Buchanan) 408 Barkworth, S.W.L. Jacobs \& H.Q. Zhang, Secale cereale L. and Taeniatherum caput-medusae 409 (L.) Nevski diverge successively with respect to the rest of the clade, with all branches strongly 410 supported in most trees. An Aegilops L. + Triticum clade is variously supported (BP $=60-100 \%)$

411 (Fig. 4) and divided into two subclades. One subclade comprises Triticum macha Dekapr. \&

412 Menabde + Triticum turgidum L. + Triticum aestivum L. $(\mathrm{BP}=100 \%)$ sister to Aegilops

413 speltoides Tausch + Triticum timopheevii (Zhuk.) Zhuk. (BP =100\%). Relationships among taxa

414 in the former clade conflict among trees (Table 5). The other subclade comprises Triticum urartu

415 Thumanjan ex Gandilyan + Triticum monococcum L. $(\mathrm{BP}=100 \%)$ sister to an eight-species

416 Aegilops clade $(\mathrm{BP}=98-100 \%)$ in which relationships are mostly strongly supported; however,

417 relationships among Aegilops kotschyi Boiss., Aegilops sharonensis Eig and Aegilops longissima

418 Schweinf. \& Muschl. conflict among trees (Table 5).

419 Within Poeae, maximally supported clades correspond to Poeae chloroplast groups 1 and 4202 (Fig. 4). In group 1, Phalaris arundinacea L. (Phalaridinae) and Torreyochloa pallida (Torr.)

421 G.L. Church (Torreyochloinae) are sister taxa (BP =100\%); Agrostidinae, comprising Agrostis L. 422 (two species sampled), Calamagrostis breviligulata (Fernald) Saarela [syn. Ammophila 423 breviligulata Fernald (Saarela et al., 2017)] and Gastridium ventricosum (Gouan) Schinz \& 424 Thell., is monophyletic; Agrostidinae + Briza maxima L. (Brizinae) form a clade $(\mathrm{BP}=80$ 425 100\%); and Agrostidinae + Brizinae + Anthoxanthum L. (two species; Anthoxanthinae) form a 426 clade $(\mathrm{BP}=100 \%)$. There is conflict among trees for the relative branching order of Phalaridinae 
427 + Torreyochloinae and Aveninae (Avena sativa L. and Trisetum cernuum Trin.) with respect to 428 the remainder of the clade (Table 5).

429 Poeae chloroplast group 2 is divided into two subclades (Fig. 4). One comprises

430 Puccinellia nuttalliana (Schult.) Hitchc. + Zingeria biebersteiniana (Claus) P.A. Smirn.

431 (Coleanthinae) $(\mathrm{BP}=100 \%)$ and Alopecurus arundinaceus Poir. (Alopecurinae) + Phleum

432 alpinum L. (Phleinae) + Poa palustris L. (Poinae) (=supersubtribe Poodinae; BP = 100\%).

433 Relationships among Phleum, Alopecurus and Poa conflict among trees (Table 5). The other

434 subclade of group 2 is recovered in all trees $(\mathrm{BP}=77-100 \%)$ but $\mathrm{R}$ and comprises Cynosurus

435 cristatus L. (Cynosurinae), Catapodium rigidum (L.) C.E. Hubb. (Parapholiinae), Holcus lanatus

436 L. (Holcinae), Deschampsia antarctica E. Desv. (Aristaveninae), Helictochloa hookeri (Scribn.)

437 Romero-Zarco (Airinae), Dactylis glomerata L. and Lamarckia aurea (L.) Moench

438 (Dactylidinae) and Festuca ovina L., Drymochloa sylvatica (Pollich) Holub and Lolium L. (four

439 species) (Loliinae). Holcinae and Airinae are sister taxa in six trees $(\mathrm{E}, \mathrm{G}, \mathrm{Q}, \mathrm{W}-\mathrm{Y}, \mathrm{BP}=50-$

440 100\%). In all trees, Cynosurinae and Parapholiinae are sister taxa $(\mathrm{BP}=100 \%)$ and form a clade

441 with Dactylidinae ( $\mathrm{BP}=83-100 \%)$, and in all trees except $\mathrm{R}$ these subtribes form a clade with

442 Loliinae $(\mathrm{BP}=92-100 \%)$.

443 Bambusoideae

Within Bambusoideae (Figs. 3, 5), Arundinarieae, Bambuseae and Olyreae are each 445 monophyletic $(\mathrm{BP}=100 \%)$, and Bambuseae and Olyreae are sister taxa $(\mathrm{BP}=100 \%)$. Within 446 Olyreae, Buergersiochloa bambusoides Pilg. (Buergersiochloinae) is sister to a clade of Eremitis

447 Döll sp. + Pariana Nakai (three accessions and at least two species) (Parianinae; BP $=100 \%$ ) 448 and Diandrolyra Stapf sp., + Raddia brasiliensis Bertol. + Olyra latifolia L. + Cryptochloa 
449 strictiflora (E. Fourn.) Swallen + Lithachne pauciflora (Sw.) P. Beauv. (Olyrinae; BP = 100\%).

450 Relationships within Parianinae and Olyrinae are strongly supported.

451 Within Bambuseae, two major clades are identified (Fig. 5). The paleotropical woody

452 bamboo clade comprises Hickelia madagascariensis A. Camus (Hickeliinae), Neololeba atra

453 (Lindl.) Widjaja (Dinochloinae) + Greslania Balansa sp. (Greslaninae) and Bambusa spp. +

454 Dendrocalamus latiflorus Munro (Bambusinae) $(\mathrm{BP}=100 \%)$. Dinochloinae and Greslaninae

455 form a clade $(\mathrm{BP}=98-100 \%)$, but relationships among Dinochloinae + Greslaninae,

456 Bambusinae and Hickeliinae conflict among trees (Table 5). The five species of Bambusa form a

457 clade in seven trees (E, Q, R, W, X, Y, Z, BP = 50-93\%), with a maximally supported subclade

458 comprising Bambusa emeiensis L.C. Chia \& H.L. Fung and Bambusa multiplex (Lour.) Raeusch.

459 ex Schult. \& Schult. f. + Bambusa oldhamii Munro. Relationships among this latter clade,

460 Bambusa bambos (L.) and Bambusa arnhemica Voss vary among trees (Table 5). The

461 neotropical woody bamboo clade (BP = 88-100\%) comprises Chusquea Kunth (four accessions

462 representing at least three species; Chusqueinae; BP =100\%), Rhipidocladum pittieri (Hack.)

463 McClure (Arthrostylidiinae), and Guadua weberbaueri Pilg., Olmeca reflexa Soderstr. and

464 Otatea acuminata (Munro) C.E. Calderón \& Soderstr. (Guaduinae; BP = 100\%). Within

465 Chusqueinae, Chusquea spectabilis L.G. Clark is robustly resolved as sister to the remainder of

466 the genus. Arthrostylidiinae and Guaduinae are sister taxa $(\mathrm{BP}=100 \%)$. Relationships among

467 the three sampled genera of Guaduinae conflict among trees (Table 5).

468 Within Arundinarieae (Fig. 5), Ampelocalamus calcareus C.D. Chu \& C.S. Chao (clade

$469 \mathrm{X}$; see Methods for details of informal clade names in this tribe) is sister to the rest of the

470 subtribe. Gelidocalamus tessellatus T.H. Wen \& C.C. Chang and Ferrocalamus rimosivaginus

471 T.H. Wen are sister taxa in all but two trees (G, H, Q-Y, BP $=72-100 \%)$, and these plus 
472 Shibataea kumasaca (Zoll. ex Steud.) Makino form a clade (clade IV; BP $=80-100 \%$ ). Sasa

473 veitchii (Carrière) Rehder, Arundinaria Michx. (three species; BP =73-100\%), Pseudosasa

474 japonica (Siebold \& Zucc. ex Steud.) Makino ex Nakai, Pleioblastus maculatus (McClure) C.D.

475 Chu \& C.S. Chao, Acidosasa purpurea (Hsueh \& T.P. Yi) Keng f., Indosasa sinica C.D. Chu \&

476 C.S. Chao and Oligostachyum shiuyingianum (L.C. Chia \& P. But) G.H. Ye \& Z.P. Wang form a 477 clade (clade VI) in all trees $(\mathrm{BP}=95-100 \%)$. Indocalamus wilsonii (Rendle) C.S. Chao \& C.D.

478 Chu (clade VIII) forms a clade with clades IV and VI in two trees (Q, Y, BP $=67,82 \%)$ and is

479 sister to clade IV in two trees (W, Y, BP $=98,75 \%)$. Within clade VI, Sasa veitchii and

480 Arundinaria form a clade ( $\mathrm{BP}=63-98 \%$ ) in all plastome trees except $\mathrm{R}$, in which Sasa veitchii

481 is sister to the rest of the subtribe ( $\mathrm{BP}=68 \%$ ). The remaining taxa form a strongly supported

482 clade, in which Pseudosasa japonica is sister to the rest of the lineage. However, relationships

483 among Pleioblastus maculatus, Acidosasa purpurea, Indosasa sinica and Oligostachyum

484 shiuyingianum are discordant among trees (Table 5).

485

A deep lineage of Arundinarieae is recovered in five trees $(\mathrm{H}, \mathrm{W}-\mathrm{Z}, \mathrm{BP}=50-92 \%)$

486

comprising Chimonocalamus longiusculus Hsueh \& T.P. Yi (clade III), Thamnocalamus

487 spathiflorus (Trin.) Munro (clade VII), Gaoligongshania megalothyrsa (Hand.-Mazz.) D.Z. Li,

488 Hsueh \& N.H. Xia (clade IX), Sarocalamus faberi (Rendle) Stapleton, Drepanostachyum

489 falcatum (Nees) Keng f., Indocalamus longiauritus Hand.-Mazz., Yushania Keng. F. (two

490 species), Bashania fargesii (E.G. Camus) Keng f. \& T.P. Yi, Fargesia Franch. (two species) and

491 Phyllostachys Siebold \& Zucc. (five species) (clade V). Clades III, IX and V form a clade in all

492 trees except $\mathrm{R}(\mathrm{BP}=55-85 \%)$, and clades III and IX are sisters in all trees except $\mathrm{Q}$ and $\mathrm{R}(\mathrm{BP}=$

493 60-93\%). Within clade V, Indocalamus longiauritus and Yushania form a clade in all trees

494 except G, H and R. Fargesia nitida (Mitford ex Anonymous) Keng f. ex T.P. Yi and Fargesia 
495 murielae (Gamble) T. P. Yi form a clade $(\mathrm{BP}=55-100 \%)$ in all trees except R. In all trees, the

496 five species of Phyllostachys form a clade $(\mathrm{BP}=65-100 \%)$, Phyllostachys aurea Carrière ex

497 Rivière \& C. Rivière and Phyllostachys propinqua McClure form a clade $(\mathrm{BP}=68-100 \%)$, and

498 Phyllostachys sulphurea (Carrière) Rivière \& C. Rivière and Phyllostachys nigra var. henonis

499 (Mitford) Stapf ex Rendle form a clade (BP = 87-100\%). In subsets of trees, Phyllostachys

500 edulis (Carrière) J. Houz. and Phyllostachys aurea + Phyllostachys propinqua form a clade (Q,

501 W, Y, BP = 82-100\%), and Phyllostachys aurea, Phyllostachys propinqua, Phyllostachys

502 sulphurea and Phyllostachys nigra var. henonis form a clade (E, X, Z, BP = 58-68\%).

503 Phyllostachys and Fargesia are sister taxa in two trees (X, Y, BP =68, 58\%), and a broader

504 clade including these genera and Bashania is recovered in all trees $(\mathrm{BP}=52-100 \%)$.

505 Oryzoideae

506

Oryzoideae is monophyletic and moderately to strongly supported in all trees $(\mathrm{BP}=87-$

507 100\%) (Fig. 6). Streptogyna americana C.E. Hubb. (Streptogyneae), Ehrharta bulbosa Sm. +

508 Microlaena stipoides (Labill.) R. Br. (Ehrharteae; BP =100\%) and Humbertochloa

509 bambusiuscula A. Camus \& Stapf (Phyllorachideae) are successively diverging sisters to

510 Oryzinae + Zizaniinae, with strong support for all branches. Within Oryzinae, Leersia tisserantii

511 (A. Chev.) Launert and Prosphytochloa prehensilis (Nees) Schweick. are sister taxa (BP =

$512100 \%)$, and the multiple species of Oryza form a clade $(\mathrm{BP}=100 \%)$. Relationships among most

513 species of Oryza are strongly supported in most trees; however, relationships among Oryza

514 sativa L., Oryza nivara Sharma \& Shastry and Oryza rufipogon Griff. conflict among trees

515 (Table 5). Within Zizaniinae, Rhynchoryza subulata (Nees) Baill. and Zizania aquatica L. are

516 sister taxa $(\mathrm{BP}=100 \%)$, and relationships among this clade, Chikusichloa aquatica Koidz. and

517 Potamophila parviflora $\mathrm{R}$. Br. are discordant among trees (Table 5). 


\section{PACMAD clade}

519 The deepest split in the PACMAD clade varies among complete plastome trees (Figs. 3, 8, Table

520 4, Supplemental Figure 1). In two trees, Panicoideae are sister to the rest of PACMAD clade,

521 with weak $(Z, B P=58 \%)$ and strong $(\mathrm{R}, \mathrm{BP}=93 \%)$ support for the ACMAD subclade. In three

522 trees, Aristidoideae are sister to the rest of PACMAD clade, with moderate (W, BP $=87 \%)$ and

523 strong $(\mathrm{Q}, \mathrm{Y}, \mathrm{BP}=93 \%$ and $100 \%)$ support for the PCMAD subclade. In one tree, Aristidoideae

$524+$ Panicoideae $(\mathrm{F}, \mathrm{BP}=52 \%)$ are the sister to the rest of the PACMAD clade. In the three other

525 trees $(\mathrm{E}, \mathrm{G}, \mathrm{H})$, no deep topology receives support $\geq 50 \%$. The four remaining PACMAD

526 subfamilies - Arundinoideae, Micrairoideae, Chloridoideae and Danthonioideae — form a clade

527 in all trees (BP = 96-100\%; Figs. 3, 8). Chloridoideae and Danthonioideae are sister taxa in all

528 trees $(\mathrm{BP}=78-100 \%)$. All taxa of Arundinoideae and Micrairoideae form a clade $(\mathrm{BP}=100 \%)$.

529 Arundinoideae is not consistently resolved as monophyletic, however, because in one three-gene

530 tree Monachather forms a clade with Micrairoideae (D, BP = 72\%) (Table 5).

531 Panicoideae

532 At the base of the Panicoideae subtree, Zeugites pittieri Hack. (Zeugiteae) and

533 Chasmanthium sessiliflorum (Poir.) H.O. Yates (Chasmanthieae) form a clade (BP = 57-100\%).

534 Loudetiopsis kerstingii (Pilg.) Conert + Danthoniopsis dinteri (Pilg.) C.E. Hubb. (Tristachyideae;

$535 \mathrm{BP}=100 \%)$ and Thysanolaena latifolia (Roxb. ex Hornem.) Honda (Thysanolaeneae) +

536 Centotheca lappacea (L.) Desv. (Centotheceae) $(\mathrm{BP}=100 \%)$ are sister groups. Paniceae,

537 Paspaleae, Andropogoneae and Arundinelleae are each monophyletic, and relationships among

538 these four tribes, which compose the core Panicoideae, are maximally supported in all trees:

539 Paniceae is sister to Paspaleae + (Andropogoneae + Arundinelleae) (Fig. 7). However, deep

540 relationships among Zeugiteae + Chasmanthieae, Tristachyideae, Centotheceae + 
541 Thysanolaeneae and Paniceae + Paspaleae + Andropogoneae + Arundinelleae vary among trees 542 (Table 5).

543 Within Andropogoneae, most aspects of relationships are strongly supported, including

544 the successive branching of Arthraxon prionodes (Arthraxoninae) and Zea mays L. (Tripsacinae)

545 sister to the rest of the tribe. Coix lacryma-jobi L. (Coicinae) and Rottboellia cochinchinensis

546 (Lour.) Clayton (Rottboelliinae) are sister taxa (BP =93-100\%), Coicinae + Rottboelliinae and

547 Ischaemum afrum (J.F. Gmel.) Dandy (Ischaeminae) form a clade (BP = 87-100\%), and this

548 three-subtribe clade is sister to the rest of Andropogoneae. The two species of Sorghum Moench

549 are sister taxa $(\mathrm{BP}=100 \%)$, Sorghum and Saccharum cv. NCo310 are sister taxa in all trees (BP

$550=87-100 \%)$ except R, and these plus Imperata cylindrica (L.) P. Beauv. form a clade $(\mathrm{BP}=72-$

551 100\%). Eulalia aurea (Bory) Ku and Sorghastrum nutans (L.) Nash are sister taxa in all trees

$552(\mathrm{BP}=62-100 \%)$ except $\mathrm{F}$, but relationships among these species, the rest of Saccharinae, and

553 Andropogoninae are discordant among trees (Table 5). Saccharinae, comprising Sorghum,

554 Saccharum, Imperata, Eulalia and Sorghastrum, is monophyletic only in trees G, Q, W and Z

$555(\mathrm{BP}=75-93 \%)$. Within Andropogoninae, the following lineages diverge successively with

556 strong support: Diheteropogon amplectens var. catangensis (Chiov.) Clayton + Hyparrhenia

557 subplumosa Stapf, Themeda Forssk. sp., Iseilema macratherum Domin and Capillipedium

558 venustum (Thwaites) Bor + Bothriochloa alta (Hitchc.) Henrard.

559 Within Paniceae, Digitaria exilis (Kippist) Stapf (Anthephorinae) is sister to the rest of

560 the tribe (BP =88-100\%) (Fig. 7). Alloteropsis J. Presl (three species), Amphicarpum

561 muhlenbergianum (Schult.) Hitchc., Echinochloa P. Beauv. (two species) and Oplismenus

562 hirtellus (L.) P. Beauv. form a clade (Boivinellinae; BP $=100 \%$ ) in all trees except $\mathrm{Y}$, in which

563 Amphicarpum muhlenbergianum and Thyridolepis xerophila (Domin) S.T. Blake (Neurachninae) 
564 form a clade $(\mathrm{BP}=97 \%)$. Within Boivinellinae, relationships among the four genera are

565 discordant among trees (Table 5). Alloteropsis angusta Stapf and Alloteropsis semialata (R. Br.)

566 Hitchc. are sister taxa $(\mathrm{BP}=100 \%)$. The remaining taxa of Paniceae form a clade in all trees $(\mathrm{BP}$

$567=80-100 \%$; Fig. 7). Dichanthelium acuminatum (Sw.) Gould \& C.A. Clark (Dichantheliinae)

568 and Thyridolepis xerophila (Neurachninae) are sister taxa $(\mathrm{BP}=98-100 \%)$ in all trees except $\mathrm{Y}$

569 (see above). The two species of Panicum L. and Whiteochloa capillipes (Benth.) Lazarides form

570 a clade (Panicinae; $\mathrm{BP}=100 \%$ ), but Panicum is not monophyletic because Panicum capillare L.

571 and Whiteochloa capillipes are sister taxa $(\mathrm{BP}=97-100 \%)$. Eriochloa meyeriana (Nees) Pilg.

572 and Urochloa reptans (L.) Stapf are sister taxa $(\mathrm{BP}=100 \%)$, and these species plus Megathyrsus

573 maximus (Jacq.) B.K. Simon \& S.W.L. Jacobs form a clade (Melinidinae; BP = 100\%).

574 Cenchrus americanus (L.) Morrone and the three species of Setaria P. Beauv. form a clade

575 (Cenchrinae; $\mathrm{BP}=100 \%)$ in all trees, but Setaria is monophyletic only in trees $\mathrm{E}$ and $\mathrm{F}(\mathrm{BP}=$

576 98-100\%). In all other trees, Setaria geminata (Forskk.) Veldkamp is sister to Cenchrus

577 americanus + (Setaria italica (L.) P. Beauv. + Setaria viridis (L.) P. Beauv.). Cenchrinae and

578 Melinidinae are sister taxa $(\mathrm{BP}=100 \%)$, and Panicinae and Cenchrinae + Melinidinae form a

579 broader clade $(\mathrm{BP}=98-100 \%)$.

580 Within Paspaleae, Axonopus fissifolius (Raddi) Kuhlm. and Paspalum L. (three species)

581 form a clade (Paspalinae; BP =100\%). Otachyrium versicolor (Döll) Henrard and Steinchisma

582 laxum (Sw.) Zuloaga are sister taxa $(\mathrm{BP}=100 \%)$, and these plus Plagiantha tenella Renvoize

583 form a clade (Otachyriinae; BP =100\%). Coleataenia prionitis (Nees) Soreng and Oncorachis

584 ramosa (Zuloaga \& Soderstr.) Morrone \& Zuloaga form a clade (Arthropogoninae; BP = 98-

585 100\%; Fig. 7). Arthropogoninae and Otachyriinae are sister groups (BP = 98-100\%). 
586

587

588

589

590

591

592

593

594

595

596

597

598

599

600

601

602

603

604

605

606

607

\section{Chloridoideae}

Within Chloridoideae, Centropodia glauca (Nees) Cope (Centropodieae), Neyraudia reynaudiana (Kunth) Keng ex Hitchc. (Triraphideae), Eragrostideae, Zoysieae and Cynodonteae diverge successively, with maximum support for all branches (Fig. 8). Eragrostideae (BP = 100\%) comprises Eragrostis Wolf (two species; Eragrostidinae) and Uniola paniculata L.

(Unioliinae). Zoysieae $(\mathrm{BP}=100 \%)$ comprises Zoysia macrantha Desv. (Zoysiinae) and three species of Sporobolus R. Br. nom. cons. (Sporobolinae; BP =100\%). Sporobolus michauxianus (Hitchc.) P.M. Peterson \& Saarela and Sporobolus maritimus (Curtis) P.M. Peterson \& Saarela are sister taxa $(\mathrm{BP}=100 \%)$. The eight sampled subtribes of Cynodonteae form a clade in all trees $(\mathrm{BP}=100 \%)$. Bouteloua Lag. (two species; Boutelouinae; $\mathrm{BP}=100 \%)+$ Distichlis Raf. (two species; Monanthochloinae; $\mathrm{BP}=100 \%$ ) and Hilaria Kunth (two species; Hilariinae; BP = $100 \%$ ) form a clade corresponding to supersubtribe Boutelouodinae. Melanocenchris abyssinica (R. Br. ex Fresen.) Hochst. and Halopyrum mucronatum (L.) Stapf form a clade (Tripogoninae; $\mathrm{BP}=100 \%$.), as do the two species of Triodia $\mathrm{R} . \mathrm{Br}$. (Triodiinae; BP $=100 \%$ ). Trichoneura grandiglumis (Nees) Ekman (Trichoneurinae) and Dactyloctenium aegyptium (L.) Willd. (Dactylocteniinae) are sister taxa $(\mathrm{BP}=68-100 \%)$. Within Eleusininae $(\mathrm{BP}=100 \%)$, Oxychloris scariosa $(\mathrm{F}$. Muell. $)$ Lazarides + Eustachys glauca Chapm. $(\mathrm{BP}=100 \%)$ and Chloris barbata Sw. form a clade $(\mathrm{BP}=100 \%)$, and relationships among this clade, Astrebla pectinata (Lindl.) F. Muell. ex Benth and Leptochloa pluriflora (E. Fourn.) P.M. Peterson \& N. Snow are discordant among trees (Table 5). Eleusininae, Triodiinae, Dactylocteniinae and Trichoneurinae form a clade in all trees $(\mathrm{BP}=65-97 \%)$, but relationships vary both within the clade and among the four-subtribe clade, Tripogoninae and Boutelouodinae (Table 5). 
We conducted plastome phylogenomic analyses of 250 species of grasses, many of which

610 have not previously been combined in a single study, including 15 newly generated plastomes

611 from six subfamilies. Deep relationships among grass subfamilies are fully congruent with most

612 previous few-gene plastid and plastome studies that identified Anomochlooideae, Pharoideae and

613 Puelioideae as successive sisters to a clade comprising the BOP and PACMAD clades (Clark et

614 al., 1995; Grass Phylogeny Working Group, 2001; Duvall et al., 2007; Bouchenak-Khelladi et

615 al., 2008; Saarela \& Graham, 2010; Grass Phylogeny Working Group II, 2012; Jones et al.,

616 2014; Burke et al., 2016a, 2016b). The plastome phylogeny represents $85 \%$ of the lineages of

617 grasses currently recognized as tribes, $67 \%$ as subtribes, $23 \%$ as genera and ca. $2 \%$ as species

618 (Peterson et al., 2017; Soreng et al., 2017), and our results corroborate many aspects of

619 relationships among tribes, subtribes, genera and species identified in previous plastid studies, in

620 most cases with increased support here. Indeed, over 230 clades are identified with maximum

621 support in at least one plastome tree, 85 clades are maximally supported in all 14 trees, and 144

622 clades are identified with maximum support in all plastome trees. Clades that are maximally

623 supported in all trees are distributed from the deepest to the shallowest levels of the grass tree of

624 life, including the branches defining the spikelet clade (all Poaceae excluding

625 Anomochlooideae), the BOP + PACMAD clade, the PACMAD clade, as well as clades

626 comprising subfamilies, tribes, subtribes, genera and even multiple congeneric species.

627 Comparison of three-gene vs. complete plastome coding trees

628 We compared trees inferred from three plastome coding regions and all plastome coding

629 regions, the former being more representative of, and comparable to, the numerous few- 
630 gene/region phylogenetic studies of grasses conducted previously. If phylogenetic signal among

631 plastome coding sequences is congruent, support for a topology, when less than maximal in a

632 few-gene tree, would be expected to increase as the number of coding sequences and

633 phylogenetically informative characters in an analysis increase. More than 100 shared clades are

634 maximally supported in each of the compared three-gene and plastome coding trees. For these

635 clades, there is sufficient phylogenetic signal in the three-gene datasets to robustly resolve

636 relationships, and recovery of the same maximally supported clades in the plastome coding trees

637 indicates there is either no conflict among plastome coding regions, or minimal conflict that does

638 not affect support levels; the current data do not distinguish between these two possibilities. On

639 the other hand, there is increased support for many clades in plastome coding trees compared to

640 three-gene trees, consistent with our expectations and with results of earlier phylogenomic

641 studies of grasses (Jones et al., 2014; Cotton et al., 2015; Saarela et al., 2015; Burke et al., 2016a,

642 2016b; Duvall et al., 2016, 2017; Orton et al., 2016), confirming the utility of plastome

643 phylogenomic studies for clarifying phylogenetic relationships at multiple hierarchical levels of

644 the grass family.

645 However, we also found some differences in resolution and support among three-gene

646 and plastome coding trees. Twenty-three clades identified in one or more of the three-gene trees

647 are not present in the plastome coding trees (Supplemental Dataset 16). Thirteen of these are

648 only weakly supported in one to three of the three-gene trees, but the remaining ten are

649 moderately to strongly supported ( $\mathrm{BP} \geq 70 \%$ ) in one or more of the trees; these clades represent

650 relationships among subfamilies, tribes, subtribes and species of a bamboo genus. In most cases,

651 the plastome coding trees identify alternative moderately to strongly supported topologies,

652 indicative of character conflict among the three-gene data and the complete plastome coding 
653 data. In the plastome coding trees, the differing signal in the three-gene data, whatever its origin,

654 may be "swamped" by the stronger signal in the much larger plastome coding dataset. Similar

655 conflict was identified among few-gene vs. plastome coding partitions in a study of monocot

656 phylogeny (Davis et al., 2013). Overall, these results indicate that supported clades in few-gene

657 plastid trees may sometimes be misleading, such that well-supported and few-gene phylogenies

658 should not necessarily be accepted as the "final word" on plastome phylogenetic relationships,

659 until compared with whole plastome phylogenies that maximize available phylogenetic

660 information in the plastome.

661

662 Comparison of coding, noncoding and complete plastome partitions

663 We also identified some strongly conflicting topologies among our analyses of coding,

664 noncoding and complete plastome partitions variously including and excluding coding gapped

665 sites and positively selected sites (Table 4). Of these conflicting relationships, only one, or

666 possibly none, is likely to be an accurate representation of the evolutionary history of the

667 plastome, which is uni-parentally inherited. Although at least one instance of conflict was

668 identified among each of the 14 trees, conflicting clades (relative to the majority topology) were

669 more common in trees derived from partitions including gapped sites, noncoding data or both.

670 For example, three of the four conflicting clades in tree R (plastome noncoding partition

671 excluding gapped sites) are not present in any other trees, indicating the conflicting signal is

672 restricted in these alignments to noncoding regions, whereas most other conflicting clades are

673 present in two or more trees inferred from datasets including gapped sites. 


\section{Effects of gapped sites on tree topology and support}

675 The complete 250 plastome alignment includes many gapped sites, given that it is

676 approximately $45 \%$ longer than the length of an average unaligned grass plastome (ca. 136,000

677 bp; Saarela et al. 2015). Gapped sites in an alignment of plastome sequences often reflect

678 evolutionary history and may result from microstructural changes (indels, inversions) in specific

679 lineages and from gene transfers. Such rare genomic changes are generally straightforward to

680 align, at least among close relatives, and may be phylogenetically informative, as demonstrated

681 for several grass lineages (Jones et al., 2014; Burke et al., 2016a; Orton et al., 2016). However,

682 gapped sites may also be introduced in an alignment when portions of the plastome are difficult

683 to align across divergent taxa, and poorly-aligned regions may represent noise in an analysis. As

684 such, unique clades in trees inferred from datasets including ambiguously aligned gapped sites

685 may reflect systematic error. A particular challenge in phylogenomics is differentiating data

686 signal reflecting evolutionary history from non-phylogenetic signal reflecting systematic error

687 (Rodríguez-Ezpeleta et al., 2007).

688 Options for dealing with gapped sites in a phylogenetic analysis include removing them,

689 assigning an additional state for each gap, coding gaps and treating them as binary characters,

690 and treating gaps as missing data; the latter option is the most common approach (Warnow,

691 2012), and is what we did in a subset of analyses. Warnow (2012) demonstrated, however, that

692 ML analyses may be statistically inconsistent when gaps are treated as missing data (but see

693 Truszkowski \& Goldman, 2016), and other studies have similarly shown that treating gaps as

694 missing data can result in incorrect tree topologies in varying phylogenetic contexts (Roure et al.,

695 2013; Shavit Grievink et al., 2013; McTavish et al., 2015). Therefore, as an alternative treatment

696 for another subset of analyses we removed possibly-ambiguously aligned nucleotides by 
697 excluding all sites with a gap in at least one taxon (Jones et al., 2014; Cotton et al., 2015; Saarela

698 et al., 2015; Attigala et al., 2016; Burke et al., 2016a, 2016b; Duvall et al., 2016; Orton et al.,

699 2016). This allowed us to compare the effects on topology of including vs. excluding gapped

700 sites. A limitation of this approach, however, is that potentially phylogenetically informative

701 gapped sites or characters within alignment portions including gapped sites are also excluded

702 from consideration. Differentiating between phylogenetically informative gaps and non-

703 informative gaps in an alignment would require manual characterization of all alignment gaps,

704 which we did not explore.

705 Another strategy for minimizing potential systematic error in plastome phylogenomic

706 analyses caused by gapped sites is to exclude all noncoding data from consideration because the

707 majority of gapped sites in plastome alignments are present in the noncoding partition. This

708 would also exclude potential conflicting signal in the unambiguously aligned subset of

709 noncoding data, like we found in a few instances in tree R. Researchers routinely exclude

710 noncoding data from phylogenomic analyses, especially when generating phylogenies spanning

711 multiple families and orders, where it is often difficult or impossible to align the more rapidly-

712 evolving noncoding regions among distantly related taxa. On the other hand, plastome noncoding

713 regions are usually straightforward to align among closely-related species and genera with little

714 overall plastome divergence, and branch support from noncoding data alone or when combined

715 with coding data is sometimes stronger than from coding data for relationships among closely-

716 related taxa (Ma et al., 2014; Saarela et al., 2015). Examples in the current study of shared clades

717 with higher support in noncoding compared to coding trees include Trichoneurinae +

718 Dactylocteniinae + Triodiinae + Eleusininae, Trichoneurinae + Dactylocteniinae, Oryza sativa + 
719 Oryza nivara + Oryza rufipogon, the Bambusa clade, the Phyllostachys clade, and

720 Gelidocalamus + Shibataea (Supplemental Dataset 16).

721 Effect of positively selected sites on tree topology and support

722

723

724

725

726

727

728

729

730

731

732

733

734

735

736

737

738

739

740

741

Positively selected codons have been shown to impact phylogenies inferred from single

loci, and widely used phylogenetic methods do not automatically identify or correct for such

bias. For example, in grasses in which photosynthetic genes, such as $r b c L$ or $P E P C$, converge

under selection for $\mathrm{C}_{4}$ photosynthesis, misleading phylogenies can result (Christin et al., 2008a,

2008b). Multi-gene analyses should be somewhat less susceptible to selection bias since loci

under different selective regimes would not be expected to reinforce an erroneous phylogenetic signal. Four protein coding loci commonly used for phylogenetic inference in grasses are $r b c L$,

matK, $n d h F$, and rpoC2 (Clark et al., 1995; Duvall et al., 2003, 2007; Grass Phylogeny Working

Group II, 2012). We find the highest numbers of selected codons in these four loci among all of

the protein coding loci in the grass plastome. Piot et al. (2017) identified these same four genes

as having the greatest signature of positive selection in plastomes of 113 PACMAD species. The considerable range in support for clades, differing by up to $41 \%$, among three-gene trees that

include and exclude positively selected sites indicates that the possibility of selection-induced bias in multi-gene analyses of these loci cannot be discounted.

Including positively selected sites in complete plastome analyses did not considerably

affect topology and support for the majority of clades in our trees. However, like in the threegene trees, we found a considerable range of bootstrap support for some clades in analyses including or excluding positively selected sites, indicating these sites influence phylogenetic reconstruction. In several instances clades identified when positively selected sites were included were not identified when those sites were excluded. This is most evident in the complete 
742 plastome trees: in tree W (including positively selected sites) there are 10 clades with support $\geq$

$74370 \%$ that in tree $\mathrm{Y}$ (excluding positively selected sites) are unsupported. Reciprocally, in tree $\mathrm{Y}$

744 there are 11 clades with support $\geq 70 \%$ that in tree $\mathrm{W}$ are unsupported. Furthermore, two cases of

745 strong conflict between trees $\mathrm{W}$ and $\mathrm{Y}$ can be attributed specifically to inclusion or exclusion of

746 positively selected sites: relationships among Oplismenus P. Beauv., Amphicarpum Kunth,

747 Alloteropsis and Echinochloa, and among Triticum turgidum, Triticum aestivum and Triticum 748 macha.

749 Among our analyses, we also compared phylogenies inferred from partitions with all

750 plastome coding loci against exclusively noncoding partitions. This diversity of loci across the

751 functional groups of the plastome would again be expected to reduce any particular selection

752 bias, but possibly at the expense of increasing the noise to signal ratio. Consistent with this

753 observation is that the removal of selected sites in our analyses did not introduce extensive

754 topological incongruities and that a greater range of support values for the included clades was 755 observed.

756

757 Comparison of plastome trees with previous phylogenetic studies of

plastomes, subsets of plastid regions, and nuclear genes

759

BOP Clade

760 The robust sister group relationship between Pooideae and Bambusoideae is congruent with most

761 previous studies of multiple plastid genes and plastomes (Bouchenak-Khelladi et al., 2008;

762 Saarela \& Graham, 2010; Zhang et al., 2011; Grass Phylogeny Working Group II, 2012; Wu \&

763 Ge, 2012) as well as nuclear genes (Zhao et al., 2013; Wysocki et al., 2016b). However, in a 
764 recent plastid study Oryzoideae and Pooideae were recovered as sister taxa, although with

765 uneven sampling throughout the family (Pimentel et al., 2017).

\section{Bambusoideae}

767 Bambusoideae is divided into two tribes of woody bamboos (the tropical Bambuseae with 768 eleven subtribes and two genera incertae sedis, and the temperate Arundinarieae with a single

769 subtribe) and one of herbaceous bamboos (Olyreae, with three subtribes) (Bamboo Phylogeny

770 Group, 2012; Soreng et al., 2017). Bamboo taxonomy is complicated by the fact that bamboos

771 are polyploid. Many genera are paraphyletic or polyphyletic, and in many cases revised generic

772 classifications have not yet been proposed. The plastome sampling includes six subtribes of

773 Bambuseae, subtribe Arundinariinae and each subtribe of Olyreae (Buergersiochloinae, Olyrinae,

774 Parianinae). Wysocki et al. (2015) identified an insertion of approximately 500 bp in the rps 16-

$775 \operatorname{trn} Q$ intergenic spacer in the 10 members of Arundinarieae they sampled that was not present in

776 taxa of the other bamboo tribes, and we confirm this insertion is present in all members of

777 Arundinarieae sampled here, with the single exception of Pseudosasa japonica. A 150 bp

778 inversion in the trnD-psbM intergenic spacer defines the Olyrinae clade (Wysocki et al., 2015).

779 In the plastome trees, Arundinarieae is sister to Bambuseae + Olyreae, congruent with other

780 studies of plastid data that identified paraphyly of woody bamboos (Clark et al., 2007;

781 Bouchenak-Khelladi et al., 2008; Sungkaew et al., 2008; Bamboo Phylogeny Group, 2012;

782 Kelchner, 2013). Phylogenetic studies of nuclear genes, however, identify Bambuseae and

783 Arundinarieae as sister taxa, supporting monophyly of woody bamboos (Triplett et al., 2014;

784 Wysocki et al., 2016b). 
785 Olyreae

786 Species of Olyreae fall on long branches relative to species of Arundinarieae and

787 Bambuseae, indicating a faster mutation rate in plastomes of Olyreae than in woody bamboos.

788 Within Olyreae, the robustly resolved relationships among Buergersiochloinae, Parianinae and

789 Olyrinae in the plastome trees are congruent with previous plastid studies (Oliveira et al., 2014;

790 Wysocki et al., 2015). Although the three sampled species of Pariana form a maximally

791 supported clade in our trees, the genus is not monophyletic in plastid and ITS trees in Oliveira et

792 al. (2014) because two species of Eremitis, including one now recognized in Parianella

793 Hollowell, F.M. Ferreira \& R.P. Oliveira (Ferreira et al., 2013; Soreng et al., 2017), are nested

794 within it. A molecular phylogenetic analysis of these three genera is in progress (L. Clark, pers.

795 comm.). The robustly supported topology within Olyrinae is congruent with trees based on six

796 plastid regions (Zhang et al., 2016c) and plastome-scale data (Wysocki et al., 2015), and better

797 resolved and supported than in a tree based on the trnD-trnT intergenic spacer (Oliveira et al., 798 2014).

799 Arundinarieae

800 Seven of the twelve major lineages (clades I to XII) of Arundinarieae are represented in

801 the plastome trees, which in many cases are better resolved and supported than trees based on a

802 few plastid regions. Within the tribe, only 12 clades of two or more taxa are weakly to strongly

803 supported in all plastome trees, indicating weak or conflicting signal in some of the plastome

804 partitions analyzed. Placement of Ampelocalamus calcareus (clade XI) as sister to the rest the

805 tribe is congruent with other studies (Ma et al., 2014; Attigala et al., 2016; Zhang \& Chen, 2016;

806 Zhang et al., 2016c), but some deep relationships among the other lineages of Arundinarieae are

807 variously unsupported or discordant. In previous phylogenies based on complete plastomes, a 
808 lineage comprising clades IV, VI and VIII was identified, with strong support only in Bayesian

809 trees (Ma et al., 2014; Attigala et al., 2016). This same clade is identified in two ML trees here

810 (plastome noncoding including gapped sites and complete plastome including gapped sites) with

811 weak to moderate support. Within the clade, the Chinese species Indocalamus wilsonii (clade

812 VIII) is moderately to strongly supported as sister to clade IV in the two complete plastome trees

813 including gapped sites but is unsupported in all other trees. In the earlier plastome trees,

814 Indocalamus wilsonii is also sister to clade IV (Ma et al., 2014; Attigala et al., 2016), but again

815 with support only in the Bayesian trees. In few-gene plastid trees, placement of Indocalamus

816 wilsonii is unresolved within Arundinarieae (Zeng et al., 2010; Zhang et al., 2016c). In the

817 plastome noncoding tree, however, clades IV and VI are strongly supported as sister taxa, a

818 topology that conflicts with the trees that identify clades VIII and IV as sister taxa. All known

819 taxa that are part of the clade comprising clades VI, VIII and IV have leptomorph rhizomes

820 (Attigala et al., 2016), but we are not aware of morphological characters that would favor one or

821 the other of the topologies among the three clades. Resolution of relationships among these

822 clades is likely complicated by the short branches that define each of them.

823 The robustly supported clade IV has been recovered in other studies, many of which are

824 more broadly sampled than our analyses (Triplett \& Clark, 2010; Zeng et al., 2010; Attigala et

825 al., 2014; Zhang et al., 2016c). The plastome tree here includes three of the five genera

826 recognized in the clade compared to two genera included in earlier plastome studies (Ma et al.,

827 2014; Attigala et al., 2016). The sister relationship between Gelidocalamus tessellatus and

828 Shibataea kumasaca is congruent with the plastid tree in Zeng et al. (2010), but contrasts with a

829 plastid tree in which species of Ferrocalamus Hsueh \& Keng f., Shibataea Makino ex Nakai and

830 Sasa Makino \& Shibata form a clade that excludes Gelidocalamus tessellatus (Zhang et al. 
831 2016c). In other few-gene plastid studies, relationships among taxa of clade IV are mostly

832 unresolved (Triplett \& Clark, 2010; Attigala et al., 2014).

833 The strongly supported clade VI (also called the Arundinaria clade) was similarly

834 resolved in earlier plastome trees (Ma et al., 2014; Attigala et al., 2016). It includes subclades

835 referred to as the Japan-North American clade (here including Arundinaria spp. and Sasa

836 veitchii) and Sino-Japanese clade (Pseudosasa japonica, Pleioblastus maculatus, Acidosasa

837 purpurea, Indosasa sinica and Oligostachyum shiuyingianum) (Zhang et al., 2016c). Support for

838 the Japan-North American clade varies from weak to strong in all trees except R, in which the

839 clade is not resolved because Sasa veitchii is sister to the rest of the subtribe. In other studies,

840 support for the clade is moderate in maximum parsimony (MP) and ML trees based on plastomes

841 and taxon sampling comparable to the current study (Attigala et al., 2016), and weak in MP and

842 ML trees based on four plastid regions and denser taxon sampling (Triplett \& Clark, 2010). The

843 clade was not, however, identified in the eight-region plastid tree in Zeng et al. (2010). The

844 generally strong support for the three-species New World Arundinaria clade in the current and

845 earlier plastome trees (Burke et al., 2014; Attigala et al., 2016), in which Arundinaria tecta and

846 Arundinaria appalachiana are sister taxa, is an improvement on few-gene plastid trees, in which

847 the three species do not form a clade (Triplett \& Clark, 2010) or form a clade with support only

848 in BI trees (Zeng et al., 2010) and in BI and MP trees (Zhang et al., 2012). The three species

849 formed an unsupported clade in a nuclear GBSII phylogeny, with a differing but weakly

850 supported internal topology (Zhang et al., 2012). Recovery of the Sino-Japanese clade in all

851 plastome trees, and placement of Pseudosasa japonica as sister to the rest of the lineage (a four-

852 taxon strongly supported clade), is congruent with other plastid trees (Triplett \& Clark, 2010;

853 Zhang et al., 2012; Attigala et al., 2016; Zhou et al., 2016) but not with a nuclear phylogeny 
854 (Zhang et al., 2012). In plastid trees with better taxon sampling, Pseudosasa japonica is part of a

855 deep lineage referred to as the "Medake subclade" (Triplett \& Clark, 2010; Zeng et al., 2010).

856 The Acidosasa purpurea + Indosasa sinica + Oligostachyum shiuyingianum clade, strongly

857 supported in two trees $(\mathrm{R}, \mathrm{W})$ and with Pleioblastus maculatus resolved as its sister group, is

858 also identified in the plastome tree in Zhang \& Chen (2016), based on 'complete cp genomes'

859 (they did not indicate how they dealt with gapped sites, although there were likely fewer gapped

860 sites in their alignments than ours because they analyzed only plastomes of bamboos), and in the

861 complete plastome tree in Ma et al. (2014), and congruent with the tree in Attigala et al. (2016).

862 In six trees, however, Pleioblastus maculatus + Indosasa sinica + Oligostachyum shiuyingianum

863 form a moderately to strongly supported clade $(\mathrm{E}-\mathrm{H}, \mathrm{Y}, \mathrm{Z})$. Neither of these conflicting clades is

864 identified in other plastid trees (Yang et al., 2013; Zhang et al., 2016c). We are not aware of

865 morphological characters that would support one of these competing topologies, as

866 morphological variation of the genera of clade VI, none of which is monophyletic, is

867 insufficiently known.

868 The deep lineage of Arundinarieae comprising clades III, V, VII and IX recovered in

869 three complete plastome trees with weak to moderate support is weakly supported or

870 unsupported in other multi-region plastid trees (Triplett \& Clark, 2010; Zeng et al., 2010; Yang

871 et al., 2013; Zhang et al., 2016c), and variously supported (depending on method of phylogenetic

872 inference) to strongly supported in earlier plastome trees (Ma et al., 2014; Attigala et al., 2016).

873 Placement of Thamnocalamus spathiflorus (clade VII) sister to the rest of the clade in nine

874 plastome trees here is congruent with one earlier plastome tree (Attigala et al., 2016) but not the

875 other, in which clades III + IX are sister to the rest of the clade (Ma et al., 2014). The deep

876 placement of Thamnocalamus spathiflorus in the plastome trees here was not recovered in 
877 broadly sampled few-gene plastid trees (Triplett \& Clark, 2010; Zeng et al., 2010; Yang et al.,

878 2013; Zhang et al., 2016c). The sister relationship between Gaoligongshania megalothyrsa

879 (clade IX) and Chimonocalamus longiusculus (clade III) in all plastome trees except the two

880 based on noncoding data, one of which weakly supports clades III and VII as sister taxa, is

881 congruent with other studies (Zeng et al., 2010; Yang et al., 2013; Ma et al., 2014; Attigala et al.,

882 2016; Zhang et al., 2016c). In a better sampled plastome study also including clades II and XII,

883 however, clades II, III, IX and XII form a clade and clades III and XII are sister taxa (Attigala et

884 al., 2016).

885 The strongly supported clade V, the Phyllostachys clade (Zeng et al., 2010; Kellogg,

886 2015), has been recovered in other few-gene plastid and plastome trees with varying support

887 (Triplett \& Clark, 2010; Zeng et al., 2010; Yang et al., 2013; Ma et al., 2014; Attigala et al.,

888 2016; Zhang et al., 2016c), but not in a nuclear GBSSI phylogeny in which most deep branches

889 of Arundinarieae are unresolved or poorly supported (Zhang et al., 2012). Most genera currently

890 recognized in clade $\mathrm{V}$ are not monophyletic (Kellogg, 2015). Overall, resolution and support for

891 relationships in clade $\mathrm{V}$ are better and stronger in the plastome trees here compared to few-gene

892 plastid trees (Triplett \& Clark, 2010; Zeng et al., 2010; Zhang et al., 2012, 2016c). The varying

893 support we find for Sarocalamus faberi being sister to the rest of clade V is congruent with the

894 plastome tree in Ma et al. (2014), whereas its affinities in clade V are unresolved in the tree in

895 Triplett \& Clark (2010). Affinities of Drepanostachyum falcatum (type species of the genus)

896 within clade V are poorly supported in the plastome trees, as in previous studies of plastid and

897 GBSSI sequences in which species of Drepanostachyum Keng f. and Himalayacalamus Keng. f.,

898 neither of which is monophyletic, form a clade of unresolved affinity within clade V (Triplett \&

899 Clark, 2010; Zeng et al., 2010; Zhang et al., 2012, 2016). The Drepanostachyum falcatum 
900 plastome is the first one sequenced for the genus, which comprises ten species from the

901 Himalayan regions of Bhutan, China, India and Nepal (Kellogg, 2015). No plastomes have been

902 published from Himalayacalamus, comprising eight species also from Bhutan, China, India and

903 Nepal (Kellogg, 2015). Relationships among the remaining taxa of clade V are mostly congruent

904 with those found by Ma et al. (2014). The five species of Phyllostachys included here have not

905 previously been combined in a phylogenetic analysis. They form a clade in all plastome trees, an

906 improvement compared to few-gene trees here and elsewhere (Triplett \& Clark, 2010; Zeng et

907 al., 2010; Zhang et al., 2016c). Within Phyllostachys, the affinities of Phyllostachys edulis, a

908 species that grows rapidly and is of critical ecological, economic and cultural value in Asia (Peng

909 et al., 2013), vary among analyses.

910 Bambuseae

911 Two major clades have been identified in Bambuseae: the paleotropical woody bamboo

912 clade and the neotropical woody bamboo clade (Kelchner, 2013; Zhang et al., 2016c). Our

913 plastome sampling in the paleotropical woody bamboo clade represents four of the eight

914 subtribes that are part of the lineage (Sungkaew et al., 2009; Goh et al., 2010; Kelchner, 2013;

915 Zhang et al., 2016c). Plastomes representing subtribes Racemobambosinae, Holttumochloinae

916 and Temburongiinae have not yet been published. The sister group relationship between

917 Dinochloinae and Greslaninae and the monophyly of Bambusinae are congruent with earlier

918 plastome trees (Wysocki et al., 2015) and with better sampled few-gene plastid trees (Yang et al.,

919 2008; Sungkaew et al., 2009; Chokthaweepanich, 2014; Zhou et al., 2017). However,

920 relationships among Hickeliinae, Bambusinae, Dinochloinae and Greslaninae vary among our

921 plastome trees, as they do among other studies. Relationships among these lineages in an 18-

922 region plastid tree are unresolved (Zhou et al., 2017). Hickeliinae forms a strongly supported 
923 clade with Dinochloinae + Greslaninae in seven trees (E-H, Q, W, Y), a topology found in an

924 earlier plastome study (Wu et al., 2015), and congruent with a six-gene plastid tree in which

925 Dinochloinae is not sampled (Zhang et al., 2016c). On the other hand, Hickeliinae is sister to a

926 strongly supported Bambusinae + Dinochloinae + Greslaninae clade in three trees (R, X, Z), a

927 topology recovered with moderate support in analyses of a plastome matrix equivalent to $\mathrm{X}$ here

928 (Wysocki et al., 2015) and of plastomes excluding gapped sites (Vieira et al., 2016). Plastome

929 sampling from the eight additional genera included in Hickeliinae, all distributed in Africa and/or

930 Madagascar (Soreng et al., 2017), may help resolve ambiguity in affinities of the subtribe within

931 Bambuseae, as well as from Melocanninae, Racemobambosinae, Temburongiinae and

932 Holttumochloinae, the subtribes of the paleotropical woody bamboo clade not represented in our

933 plastome trees.

934 The neotropical woody bamboo clade includes subtribes Chusqueinae, Arthrostylidiinae

935 and Guaduinae. Placement of Chusqueinae (Chusquea) sister to a maximally supported clade

936 comprising Arthrostylidiinae and Guaduinae is congruent with other studies (Sungkaew et al.,

937 2009; Kelchner, 2013; Chokthaweepanich, 2014; Vieira et al., 2016; Zhang et al., 2016c). Within

938 Guaduinae, Olmeca reflexa and Otatea acuminata are strongly supported sister taxa in most

939 trees, but in tree R, Olmeca reflexa and Guadua weberbaueri form a moderately supported clade.

940 The former topology was previously identified in a plastome study (Wu et al., 2015) and is

941 congruent with a few-gene plastid study (Ruiz-Sanchez et al., 2011). A morphological character

942 supporting a close relationship between Olmeca and Otatea is absence of infra-and supranodal

943 bands of hairs and thorns in branches. These bands of hairs are also absent in Eremocaulon

944 Soderstr. \& Londoño and Apoclada McClure, the two other genera of Guaduinae, but are present

945 in Guadua (Ruiz-Sanchez et al., 2011). Relationships among the four samples of Chusquea are 
946 congruent with a more detailed study of Chusquea phylogeny (Fisher et al., 2014). Chusquea

947 spectabilis used to be included in Neurolepis Meisn., a genus that lacked elongated woody culms

948 of Chusquea as historically applied (Fisher et al., 2009).

949 Pooideae

950

Relationships among subtribes

951 The successive divergences of Brachyelytreae, Lygeae + Nardeae, Phaenospermateae,

952 Meliceae and Stipeae (including Ampelodesmeae) with respect to the rest of the subfamily in the

953 plastome trees is congruent with previous few-gene plastid studies, and the robust support in the

954 plastome trees for the respective branches is in many instances stronger than in few-gene trees

955 (Catalán et al., 1997; Soreng \& Davis, 1998, 2000; Mathews et al., 2000; Grass Phylogeny

956 Working Group, 2001; Davis \& Soreng, 2007, 2010; Döring et al., 2007; Duvall et al., 2007;

957 Bouchenak-Khelladi et al., 2008; Schneider et al., 2011; Grass Phylogeny Working Group II,

958 2012; Blaner et al., 2014; Hochbach et al., 2015; Pimentel et al., 2017). Morphological

959 synapomorphies supporting most of these deep splits in Pooideae have been identified (Kellogg

960 et al., 2013; Kellogg, 2015). Of the early-diverging lineages of Pooideae, the only tribes from

961 which plastomes have not been sampled are Brylkinieae and Duthieae (Soreng et al., 2017). The

962 three plastomes of Stipeae newly sampled here (Eriocoma hymenoides, Nassella hyalina,

963 Piptatherum songaricum) form a clade sister to a lineage of Oryzopsis asperifolia,

964 Ampelodesmos mauritanicus (Ampelodesmeae), which is a polyploid reticulate species with

965 Duthieeae and Stipeae that obtained its plastome from a stipoid grass (Romaschenko et al.,

966 2014), and Piptochaetium avenaceum. The strongly supported relationships within both clades

967 are congruent with a tree based on fewer plastid regions but denser taxon sampling

968 (Romaschenko et al., 2012). 

supported clade in all trees here, as in numerous other studies of plastid and nuclear ribosomal DNA (Catalán et al., 1997; Davis \& Soreng, 2007; Bouchenak-Khelladi et al., 2008; Schneider et al., 2011; Pimentel et al., 2017; Sancho et al., 2017). Diarrheneae is unique in the clade in having non-distichous two-ranked inflorescence phyllotaxy, a character-state reversion in this taxon following the origin of distichous phyllotaxis in the ancestor of the clade including Phaenospermateae and the rest of the subfamily (Kellogg et al., 2013). The maximally supported relationships among Bromeae, Poeae and Triticeae are congruent with a recent plastome study

977 (Saarela et al., 2015) and numerous few-gene plastid studies. Monophyly of Triticeae is maximally supported in all plastome trees here. However, when plastid data for Psathyrostachys Nevski are included in analysis, Triticeae is paraphyletic because Bromeae is included within it (Bernhardt et al., 2017). We have not sampled the monogeneric tribe Littledaleae (Soreng et al., 981 2017), which is sister to Bromeae + Triticeae in plastid trees (Soreng et al., 2007; Schneider et 982 al., 2012) and sister to Triticeae in nuclear trees (Hochbach et al., 2015). A plastome from a species of Littledalea Hemsl. was recently published (Liu et al., 2017). important because the annual species Brachypodium distachyon is a model system for grasses

986 (International Brachypodium Initiative, 2010). Relationships and support levels among

987 Diarrheneae, Brachypodieae and Bromeae + Poeae + Triticeae vary among plastome trees and 988 are affected particularly by inclusion or exclusion of gapped sites in the noncoding data partition. 989 Relationships among these taxa inferred from different plastome partitions were similarly 990 variable in an earlier plastome study, which also found differences among ML, BI and MP trees

991 (Saarela et al., 2015). Presence of parallel-sided subsidiary cells is a putative synapomorphy for a 
992 Brachypodieae + Bromeae + Poeae + Triticeae clade (Kellogg, 2015), found in a subset of our

993 trees. Some analyses of low copy nuclear genes also identify a Brachypodieae + Bromeae +

994 Poeae + Triticeae clade (Hochbach et al., 2015), but in others relationships among these lineages

995 are either unresolved or Diarrhena and Brachypodium are sister taxa (Hochbach et al., 2015;

996 Minaya et al., 2015), like in the trees here based on complete plastomes excluding gapped sites.

997 In a recent study including plastomes from three Brachypodium species, Diarrhena,

998 Brachypodium, and Bromeae + Poeae + Triticeae diverged successively, with strong support for

999 the topology. Those trees were based on a dataset that excluded poorly aligned regions but

1000 included "robust gaps".

1001 Variation in topology and support among Diarrheneae, Brachypodieae and Bromeae +

1002 Poeae + Triticeae in the plastome trees might be related to the long branch subtending

1003 Brachypodium distachyon - the longest one in Pooideae in our trees - relative to the lengths of

1004 nearby branches (Supplemental Figure 1). This long branch might be attributable to one or a

1005 combination of an accelerated plastome substitution rate in the genus or the one annual species

1006 of the genus we sampled, long persistence of the lineage since its divergence from the common

1007 ancestor it shares with its sister group, or extinction(s) of closely-related taxa (none of which is

1008 known). Substitution rates in plastid coding regions are significantly lower in lineages of

1009 Triticum and Aegilops compared to Brachypodium (Gornicki et al., 2014), supporting an

1010 accelerated rate of evolution along the Brachypodium branch. Combined plastid and nuclear

1011 ribosomal data do not support an older age for the Brachypodium crown clade than for the Poeae

1012 + Triticeae crown clade (Catalán et al., 2012), whereas in a plastome-based nested dating

1013 analysis of the grass family and Brachypodium, the ages of the Brachypodium and Poeae +

1014 Bromeae-Triticeae crown clades were estimated at 10.1 Ma and 27.8 Ma, respectively (Sancho et 
1015 al., 2017). Plastomes from the other two annual species of Brachypodium, when analyzed

1016 phylogenetically with Brachypodium distachyon in analyses including some gapped sites in the

1017 alignment, resulted in a slightly shortened stem branch of the Brachypodium clade, which may

1018 have contributed to the strongly resolved relationships among Brachypodieae, Diarrheneae and

1019 Bromeae-Poeae-Triticeae in those analyses (Sancho et al. 2017). Plastomes from the perennial

1020 species Brachypodium mexicanum (Roem. \& Schult.) Link and Brachypodium boissieri Nyman,

1021 based on their affinities to the annual species and the core perennial clade in a two-gene plastid

1022 tree (Catalan et al. 2012, 2016), might further break up the long stem branch, which may help

1023 clarify relationships among Brachypodieae, Diarrheneae and Bromeae-Poeae-Triticeae from

1024 different plastome partitions. Plastome sampling of Neomolinia Honda, the other genus of

1025 Diarrheneae, might also help clarify these relationships. Neomolinia, with five species and

1026 sometimes treated as a synonym of Diarrhena (e.g., Kellogg, 2015), has been sampled in only

1027 three studies (Schneider et al., 2011; Romaschenko et al., 2012; Hochbach et al., 2015).

1028 Triticeae

1029 Within Triticeae, the strongly supported successive divergences of Hordeum,

1030 Connorochloa tenuis, Secale cereale, Taeniatherum caput-medusae and Aegilops/Triticum in the

1031 plastome trees are congruent with (or at least not in conflict with) and better supported than few-

1032 gene plastid trees (Petersen \& Seberg, 1997; Mason-Gamer et al., 2002; Petersen et al., 2006;

1033 Seberg \& Petersen, 2007) and some nuclear trees (Mason-Gamer, 2001; Petersen et al., 2006;

1034 Escobar et al., 2011). However, conflict is well known among plastid and nuclear trees,

1035 reflecting hybridization in the origins of many genera and species in the tribe (Petersen \&

1036 Seberg, 2002; Mason-Gamer, 2005; Petersen et al., 2006; Seberg \& Petersen, 2007; Escobar et

1037 al., 2011). The plastome topology here is congruent with the plastome tree in Bernhardt et al. 
1038 (2017). Connorochloa tenuis, an octoploid endemic to New Zealand and the only species in its

1039 genus (Barkworth et al., 2009), has apparently not been included in any previous phylogenetic

1040 study.

1041 Our sampling includes plastomes from additional species of Aegilops and Triticum

1042 (Gornicki et al., 2014; Gogniashvili et al., 2015) compared to an earlier study (Saarela et al.,

1043 2015). Although all species of Aegilops and Triticum form a clade in the plastome trees, other

1044 studies have demonstrated that genera not sampled here (e.g., Amblyopyrum (Jaub. \& Spach)

1045 Eig, Thinopyrum Á. Löve, Lophopyrum Á. Löve, Crithopsis Jaub. \& Spach.) are part of the

1046 lineage (Petersen et al., 2006). Despite our incomplete genus-level sampling of the Aegilops and

1047 Triticum lineage, recovery of major subclades in the lineage is congruent with other studies

1048 (Petersen et al., 2006; Gornicki et al., 2014; Bernhardt et al., 2017). The Aegilops speltoides +

1049 Triticum timopheevii sublineage has been found in other studies (Golovnina et al., 2007;

1050 Gornicki et al., 2014; Gogniashvili et al., 2015), as has the lineage comprising Triticum macha

1051 (= Triticum aestivum subsp. macha (Dekapr. \& Menabde) MacKey), Triticum turgidum and

1052 Triticum aestivum 'Chinese Spring', whose relationships conflict strongly among the plastome

1053 trees. Close relationships among multiple subspecies of Triticum turgidum (sometimes

1054 recognized at species level) and Triticum aestivum 'Chinese Spring' were found in earlier

1055 plastome (Gornicki et al., 2014) and nuclear (Petersen et al., 2006; Nasernakhaei et al., 2015)

1056 trees, but none of those studies sampled the Georgian endemic Triticum macha. Golovnina et al.

1057 (2007) sampled one individual of Triticum macha in their matK tree, which was identical to

1058 multiple other taxa, including Triticum durum Desf. and Triticum aestivum, congruent with our

1059 results. The subclade comprising Triticum urartu + Triticum monococcum and the eight-species

1060 Aegilops clade is congruent with other plastid trees with similar sampling (Petersen et al., 2006; 
1061 Golovnina et al., 2007; Gornicki et al., 2014; Middleton et al., 2014; Gogniashvili et al., 2015).

1062 The sister relationship between Aegilops cylindrica Host and Aegilops tauschii Coss. has been

1063 found in other studies (Middleton et al., 2014; Gogniashvili et al., 2015), as has the five-species

1064 clade comprising Aegilops bicornis (Forssk.) Jaub. \& Spach, Aegilops sharonensis, Aegilops

1065 longissima, Aegilops kotschyi and Aegilops searsii Feldman \& Kislev (Gornicki et al., 2014).

1066 Poeae

1067 The maximally supported clades in the plastome trees recognized as Poeae chloroplast 1068 groups 1 and 2 have been recovered in other plastid-based studies (Quintanar et al., 2007;

1069 Saarela et al., 2010, 2015, 2017; Pimentel et al., 2017; Sancho et al., 2017), but not in studies

1070 based on nuclear ribosomal DNA, in which Scolochloinae and Sesleriinae, both part of Poeae

1071 chloroplast group 2 and not sampled here, are closely related to taxa of Poeae chloroplast group

10721 (Quintanar et al., 2007; Saarela et al., 2010, 2015, 2017). Six of the eight subtribes of Poeae

1073 chloroplast group 1 (Soreng et al., 2017) are represented in our trees. Relationships among the

1074 four taxa of Agrostidinae and the sister-group relationship between Agrostidinae and Brizinae in

1075 the plastome trees are congruent with other plastid studies, with the caveat that studies with

1076 broader sampling of these subtribes and related taxa have identified problems with generic

1077 circumscriptions and conflicts between plastid and nuclear data (Quintanar et al., 2007; Soreng et

1078 al., 2007; Saarela et al., 2017). The maximally supported sister group relationship between

1079 Anthoxanthinae and Agrostidinae + Brizinae is also congruent with other plastome and few-gene

1080 plastid studies (Saarela et al., 2015, 2017). In a recent five region plastid study, however,

1081 Anthoxanthinae is strongly supported as sister to Aveninae/Koeleriinae and Lagurus (Pimentel et 1082 al., 2017), a topology conflicting with our results. 

identified in a previous plastome study (Saarela et al., 2015); however, these subtribes are not

1085 sister taxa in combined ITS+ETS trees, possibly indicative of ancient hybridization (Saarela et

1086 al., 2017). The major conflict in the relative branching order of Phalaridinae + Torreyochloinae

1087 and Aveninae at the base of Poeae chloroplast group 1 in the plastome trees was also found in a

1088 previous plastome study (Saarela et al., 2015), but in that study the different topologies were

1089 inferred in ML and BI vs. MP analyses rather than among plastome partitions, as is the case here.

1090 The phylogenetic signal for Phalaridinae + Torreyochloinae being sister to the rest of the clade is

1091 present in plastome noncoding data, regardless of whether gapped sites are included or excluded,

1092 whereas phylogenetic signal for Aveninae being sister to the rest of the clade is present primarily

1093 in plastome coding data including and excluding gapped sites. The latter topology is also

1094 identified in trees based on complete plastomes, both including and excluding gapped sites. In

1095 complete plastome trees, when gapped sites are excluded and positively selected sides are

1096 included in the analysis, the branching order at the base of the subtree is ambiguous, whereas

1097 when both gapped and positively selected sites are excluded in complete plastome trees,

1098 Phalaridinae + Torreyochloinae are strongly supported as sister to the rest of the clade. These

1099 differences indicate the presence of some conflicting signal in positively selected sites of

1100 plastome coding regions that affect support levels when gapped sites are excluded. The latter is

1101 confirmed by the decrease in support for Aveninae being sister to the rest of the clade in analyses

1102 of plastome coding regions including and excluding positively selected sites ( $\mathrm{E}$ vs. G, BP = 98\%

1103 Vs. $80 \%)$.

1104 Poeae chloroplast group 2 comprises 18 subtribes and numerous genera unplaced to

1105 subtribe (Soreng et al., 2017), and twelve subtribes are represented in the current plastome 
1106 sampling. The major clade comprising Puccinellia nuttalliana + Zingeria

1107 biebersteiniana (Coleanthinae), and Alopecurus arundinaceus (Alopecurinae) + Phleum alpinum

1108 (Phleinae) + Poa palustris (Poinae) has been identified in other plastid studies (e.g., Gillespie et

1109 al., 2007, 2008; Soreng et al., 2007; Schneider et al., 2012; Hochbach et al., 2015), but

1110 relationships among Alopecurinae, Poinae and Phleinae are discordant among the plastome trees.

1111 The conflict is primarily between the noncoding partition, which identifies Phleum alpinum and

1112 Alopecurus arundinaceus as sister taxa (also in one complete plastome analysis including gapped

1113 sites) and all other partitions, which identify Poa palustris and Alopecurus arundinaceus as

1114 strongly supported sister taxa. Although it is unclear which of the two highly supported

1115 topologies is accurate, there is sufficient variation in complete plastomes to robustly resolve

1116 relationships among these closely related genera compared to earlier plastid studies in which

1117 relationships among clades including these three genera were unresolved and/or poorly

1118 supported (Gillespie et al., 2007, 2008; Soreng et al., 2007). Poa L. and Phleum L. were more

1119 closely related to each other than to Alopecurus L. in analyses of combined plastid and nuclear

1120 ribosomal data (Gillespie et al., 2010; Soreng et al., 2015a), a topology probably influenced by

1121 the nuclear ribosomal signal in that dataset. None of the plastome trees identify a Poa + Phleum

1122 clade.

1123 Holcinae (Holcus lanatus) and Airinae (Helictochloa hookeri) are strongly supported

1124 sister taxa in three plastome trees. This topology conflicts with the combined ITS and plastid tree

1125 in Minaya et al. (2015), in which Helictochloa bromoides (Gouan) Romero-Zarco (as Avenula

1126 bromoides (Gouan) H. Scholz) is sister to a Dacytilidinae + Cynosurinae clade, and Holcus L. +

1127 Echinaria Desf. (Sesleriinae) are sister to a clade including taxa of Airinae and Deschampsia P.

1128 Beauv. The plastome topology also conflicts with the $\beta$-amylase tree in Minaya et al. (2015), 
1129 indicative of reticulation. Although Helictochloa Romero-Zarco is currently classified in subtribe

1130 Airinae, few-gene plastid and nuclear analyses indicate the genus is not allied with other taxa of

1131 the subtribe (Quintanar et al., 2007; Saarela et al., 2017). Plastome sampling is needed of the

1132 other genera included in Airinae (Aira L., Antinoria Parl., Avenella Drejer, Corynephorus P.

1133 Beauv., Molineriella Rouy, Periballia Trin.) to clarify circumscription of the subtribe.

1134 In a previous classification (Soreng et al., 2015b), Holcinae comprised Deschampsia,

1135 Holcus and Vahlodea Fr., but in the plastome trees here and in other plastid and nuclear trees,

1136 Deschampsia and Holcus + Vahlodea (not sampled here) do not form a clade (Quintanar et al.,

1137 2007; Saarela et al., 2010, 2017; Grass Phylogeny Working Group II, 2012; Minaya et al., 2015;

1138 Persson \& Rydin, 2016). In the plastome trees, Deschampsia is sister to a clade comprising taxa

1139 of Cynosurinae, Dactylidinae, Parapholiinae and Loliinae. Accordingly, Deschampsia is now

1140 recognized in its own subtribe, Aristaveninae, and Holcinae is circumscribed more narrowly

1141 comprising only Holcus and Vahlodea (Soreng et al., 2017).

1142 Relationships among the remaining six sampled subtribes of Poeae chloroplast group 2

1143 are robustly resolved here. The close relationship between Dactylis glomerata and Lamarckia

1144 aurea, both included in Dacytilidinae, is congruent with other plastid and nuclear analyses (Inda

1145 et al., 2008; Birch et al., 2014; Minaya et al., 2015). The sister group relationship between

1146 Cynosurinae (Cynosurus L., monotypic) and Parapholiinae (eight genera, represented by

1147 Catapodium rigidum) is congruent with earlier plastid and nuclear ribosomal analyses (Inda et

1148 al., 2008; Schaefer et al., 2011; Schneider et al., 2012; Pimentel et al., 2017) with denser

1149 sampling of Parapholiinae. The sister-group relationship between Dactylidinae and Cynosurinae

1150 + Parapholiinae corroborates the findings of earlier studies (Inda et al., 2008; Birch et al., 2014).

1151 The strongly supported Cynosurinae + Dactylidinae + Parapholiinae + Loliinae clade in the 
1152 plastome trees is congruent with a matK tree (Schneider et al., 2012) and is an improvement on

1153 the mostly unresolved and poorly supported relationships among these taxa in other plastid trees

1154 (Quintanar et al., 2007; Soreng et al., 2007; Pimentel et al., 2017). In an earlier plastome study,

1155 Dactylis L. was weakly supported as sister to Loliinae in a ML tree based on plastome coding

1156 regions (Saarela et al., 2015), whereas in the tree based on the parallel plastome coding dataset

1157 here $(\mathrm{F})$, the same branch is strongly supported. This increased support may be a function of the

1158 improved taxon sampling in Dactylidinae, Cynosurinae and Parapholiinae here. Sampling and

1159 relationships within Loliinae here and in an earlier plastome study (Saarela et al., 2015) are

1160 identical, although here we have updated names of some species to reflect their current

1161 classification.

1162 Oryzoideae

1163 Subfamily Oryzoideae is divided into tribes Streptogyneae, Ehrharteae, Phyllorachideae

1164 and Oryzeae (Soreng et al., 2017), which are each represented in our analyses.

\section{Streptogyneae}

1166 Clarification of the evolutionary affinities of the amphi-Atlantic genus Streptogyna P.

1167 Beauv. has been problematic. Streptogyna was traditionally classified as a herbaceous bamboo in

1168 its own tribe, Streptogyneae (Calderón \& Soderstrom, 1980; Soderstrom \& Judziewicz, 1987). It

1169 shares several morphological characters with various distantly related lineages (Kellogg, 2015),

1170 interpretation of which has complicated classification. Molecular studies have helped clarify its

1171 affinities. In studies based primarily on one or a few plastid regions, Streptogyna was sister to

1172 Oryzoideae with varying levels of support (Clark et al., 1995; Zhang, 2000; Duvall et al., 2007;

1173 Davis \& Soreng, 2010; Triplett \& Clark, 2010; Kelchner, 2013). Kelchner (2013) identified a

1174 high level of character conflict in Streptogyna at "key nodes" in a neighbour net analysis of a 
1175 five-region plastid data set, despite strong support for its placement in their tree. In recent

1176 classifications, Streptogyna has been treated as incertae sedis among grasses (Grass Phylogeny

1177 Working Group, 2001), as incertae sedis within the BOP clade (Kellogg, 2015) and as a tribe of

1178 Oryzoideae (Soreng et al., 2015b, 2017). Streptogyna differs from other oryzoids by having

1179 multi-flowered (vs. one-flowered) spikelets. Our results corroborate previous support for the

1180 monophyly of Oryzoideae including Streptogyna, as the subfamily is maximally supported in all

1181 plastome trees except the two based on noncoding regions, in which support for the same

1182 topology is lower $(\mathrm{BP}=87-88 \%)$, indicative of some conflict in the noncoding partition relative

1183 to the rest of the plastome. Nevertheless, there is robust support in the plastome trees for

1184 Streptogyna being sister to the rest of the subfamily.

1185 The affinities of Streptogyna are different, however, in nuclear trees. In a phylogeny

1186 based on phytochrome B, Streptogyna is sister to the BOP clade (Mathews et al., 2000), and in a

1187 phylogeny based on FLOWERING LOCUS T (FT) in which both species of Streptogyna were

1188 sampled, the genus is monophyletic and sister to Bambusoideae with moderately strong support,

1189 and an Oryzoideae + (Streptogyna + Bambusoideae) clade is weakly supported (Hisamoto et al.,

1190 2008); no pooid taxa were included in that study. Given the discordances among nuclear and

1191 plastome phylogenies, it is possible Streptogyna might have arisen as part of an ancient

1192 hybridization event involving a maternal parent ancestral to crown Oryzoideae and a paternal

1193 parent ancestral to crown Bambusoideae. The evolutionary patterns identified in the nuclear trees

1194 might alternatively reflect incomplete lineage sorting. Further sampling of the nuclear genome of

1195 Streptogyna, bamboos and other oryzoids will be required to further characterize the history of

1196 this lineage of grasses. 
1198 Ehrharteae includes four genera: Ehrharta Thunb., Microlaena R. Br., Tetrarrhena R. Br.

1199 and Zotovia Edgar \& Connor (Soreng et al., 2017), all of which are sometimes included in a

1200 single genus, Ehrharta (Kellogg, 2015), a classification congruent with phylogenetic data

1201 (Verboom et al., 2003). As expected, the two species we sampled, Ehrharta bulbosa and

1202 Microlaena stipoides (= Ehrharta stipoides Labill.), form a clade, and this clade is robustly

1203 placed as sister to the rest of the subfamily except Streptogyna. This topology is congruent with

1204 other plastid trees, although not all included Streptogyna (Grass Phylogeny Working Group,

1205 2001; Bouchenak-Khelladi et al., 2008; Grass Phylogeny Working Group II, 2012).

1206 The poorly known tribe Phyllorachideae comprises two genera: Humbertochloa A.

1207 Camus \& Stapf, with two species from Madagascar and Tanzania, and Phyllorachis Trimen, with

1208 one species from equatorial Africa (Kellogg, 2015; Soreng et al., 2017). Humbertochloa has

1209 been included in only two molecular studies (Zhang, 2000; Vorontsova et al., 2016), neither of

1210 which have sufficient taxon sampling from which to draw conclusions about its affinities to other

1211 rice grasses, and Phyllorachis has not been sampled in any molecular studies. In our trees,

1212 Humbertochloa is maximally supported as sister to the Oryzeae clade. This topology is

1213 congruent with recognition of the lineage at either tribal rank within Oryzoideae or subtribal rank

1214 within Oryzeae, with the caveat that the affinities of Phyllorachis sagittata Trimen are unknown.

1215 Oryzeae

1216 Clades corresponding to Oryzeae and the subtribes Oryzinae and Zizaniinae (Ge et al.,

1217 2002; Guo \& Ge, 2005; Tang et al., 2010; Soreng et al., 2017) are maximally supported in all

1218 plastome trees. Oryzinae includes four genera: Oryza, Leersia Sw., Maltebrunia Kunth and

1219 Prosphytochloa Schweick. (Tang et al., 2010; Kellogg, 2015; Soreng et al., 2017). An earlier 
1220 classification (Soreng et al., 2015b) placed Maltebrunia and Prosphytochloa in Zizaniinae, based

1221 on phylogenies in which a sample identified as Prosphytochloa prehensilis was resolved as part

1222 of the Zizaniinae clade (Ge et al., 2002; Guo \& Ge, 2005). However, that Prosphytochloa sample

1223 was later re-determined as a species of Potamophila R. Br. (Tang et al., 2010). Prosphytochloa

1224 and Leersia are maximally supported sister taxa in the plastome trees, and this clade is sister to

1225 Oryza, congruent with a plastid tree in which Maltebrunia and Prosphytochloa are sister taxa

1226 and a Maltebrunia + Prosphytochloa + Leersia clade is sister to Oryza (Tang et al., 2010).

1227 Since rice (Oryza) is the most important food crop worldwide, there has been extensive

1228 phylogenetic research on the ca. 22 wild and two cultivated species of the genus. Although the

122911 plastomes included here have all been published elsewhere, they have not all been combined

1230 in a single phylogenomic analysis. The relationships among the species of Oryza in our plastome

1231 trees are mostly congruent with similar plastome trees (Kim et al., 2015; Liu et al., 2016),

1232 although when multiple individuals of Oryza nivara, Oryza sativa, Oryza rufipogon, Oryza

1233 barthii A. Chev. and Oryza glaberrima Steud. were sampled none of the species was

1234 monophyletic (Kim et al., 2015). Placement of Oryza australiensis Domin sister to the rest of the

1235 genus is congruent with the neighbour joining tree in Liu et al. (2016), in which Oryza

1236 brachyantha A. Chev. \& Roehr.- the most distant congeneric relative of cultivated rice (not

1237 sampled here) — and Oryza australiensis are successive sisters to the rest of the genus, a topology

1238 congruent with studies based on other types of data (Ge et al., 1999). Plastome data are useful for

1239 robustly resolving relationships among closely related species of Oryza with limited conflict

1240 among partitions.

1241 Zizaniinae includes seven genera (Soreng et al., 2017) and our sampling includes four of

1242 these. The sister group relationship between Rhynchoryza subulata and Zizania aquatica in the 
1243 plastome trees is congruent with results of other studies (Tang et al., 2010, 2015), but the varying

1244 branching order of Chikusichloa aquatica and Potamophila parviflora at the base of the clade is

1245 a novel result. Successive branching of Chikusichloa Koidz. and Potamophila, found in six trees,

1246 is congruent with an ML tree based on 20 plastid regions (Tang et al., 2010, 2015). The plastome

1247 partitions that identify Potamophila and Chikusichloa as successively diverging lineages

1248 comprise noncoding regions including gapped sites, either alone or in combination with coding

1249 regions. The dominant signal for this topology (whether accurate or not) is present in the gapped

1250 sites of the noncoding alignment, which when combined with coding region data seemingly

1251 override the conflicting signal in the latter partition. Recent data from the nuclear genome

1252 provides further insight into the Zizaniinae evolutionary tree, even though the nuclear trees are

1253 discordant, in part, with plastome trees. In trees based on 15 individual nuclear genes,

1254 relationships among taxa of Zizaniinae varied considerably and were strongly discordant with

1255 each other and with the plastid topologies here and elsewhere, whereas when the same 15 genes

1256 were analysed together, Chikusichloa and Potamophila formed a clade sister to the rest of the

1257 subtribe (Tang et al., 2015). No plastome trees here identify a Chikusichloa + Potamophila clade.

1258 This discordance between plastid and nuclear trees might be due to incomplete lineage sorting

1259 introgression or both (Tang et al., 2015).

1260 PACMAD clade

1261 Relationships among subfamilies

1262 Although the PACMAD clade has been consistently identified in molecular studies,

1263 relationships among the subfamilies have been generally poorly resolved and weakly supported,

1264 and identifying the root of the PACMAD clade - placement of the branch defining the first or

1265 deepest split in the lineage — has proven particularly challenging (Clark et al., 1995; Mathews et 
1266 al., 2000; Grass Phylogeny Working Group, 2001; Duvall et al., 2007; Bouchenak-Khelladi et

1267 al., 2008; Davis \& Soreng, 2010; Saarela \& Graham, 2010; Grass Phylogeny Working Group II,

1268 2012). Numerous studies, mostly of plastid data, have identified Aristidoideae as the sister group

1269 of the rest of the PACMAD clade, but support for this topology (i.e., for the subclade including

1270 all PACMAD subfamilies except Aristidoideae) has mostly been weak (Clark et al., 1995; Hilu

1271 et al., 1999; Grass Phylogeny Working Group, 2001; Duvall et al., 2007; Sánchez-Ken \& Clark,

1272 2007; Christin et al., 2008a; Grass Phylogeny Working Group II, 2012); for an exception see

1273 Vicentini et al. (2008). Cotton et al. (2015) explored relationships among the PACMAD

1274 subfamilies based on complete plastomes and identified two strongly conflicting topologies at

1275 the base of the clade. In their ML and BI trees, Panicoideae were moderately to strongly

1276 supported as the sister group of the rest of the PACMAD clade (the "panicoid-sister"

1277 hypothesis) - this was an unexpected topology not recovered in previous studies. In their MP

1278 tree, however, Aristidoideae were strongly supported as the sister group to the rest of the

1279 PACMAD clade (the "aristidoid-sister" hypothesis), congruent with most earlier studies of

1280 grasses. In a subsequent plastome study with increased Panicoideae taxon sampling but fewer

1281 representatives of most other PACMAD subfamilies, Burke et al. (2016b) also identified the

1282 panicoid-sister topology. By contrast, in a plastome study focused on Arundinoideae and with

1283 broad sampling across Poaceae, Teisher et al. (2017) recovered all three possible topologies for

1284 the base of PACMAD, of which none was particularly well supported. For example, they

1285 recovered the aristidoid-sister topology when gapped sites were included, with weak support in

$1286 \mathrm{ML}$ and BI trees. Teisher et al. (2017) concluded that plastome data may be insufficient to

1287 resolve this particular set of relationships. The plastome phylogeny of the PACMAD clade 
1288 generated by Piot et al. (2017) cannot be used to address deep relationships in the clade because

1289 they rooted their tree with Aristidoideae.

1290 Relationships at the base of the PACMAD clade in our 14 trees similarly vary in

1291 topology and support. The same two conflicting topologies are identified in seven of our trees,

1292 each with moderate to strong support in at least one of these trees. Three trees excluding gapped

1293 sites identify the panicoid-sister topology (D, R, Z), similar to gap-stripped results in Teisher et

1294 al. (2017), three trees including gapped sites identify the aristidoid-sister topology (Q, W, Y),

1295 and in one tree $(\mathrm{F})$, Aristidoideae + Panicoideae are weakly supported as sister to the rest of the

1296 PACMAD clade, a topology rarely inferred elsewhere. Our three-gene trees parallel the plastid

1297 sampling of Grass Phylogeny Working Group II (2012) (partition A is most similar to their

1298 dataset), who identified the aristidoid-sister topology with weak support in ML trees and

1299 maximum support in BI trees, a topology congruent with the two three-gene trees including

1300 gapped sites reported here. Overall, the aristidoid-sister topology is solely recovered in matrices

1301 in which gapped sites were not stripped, suggesting that the signal for this topology is largely in

1302 the gapped regions.

1303 It is surprising that the two trees of complete plastomes excluding gapped sites provide

1304 no $(\mathrm{BP}<50 \% ; \mathrm{X})$ or only weak $(\mathrm{BP}=58 \% ; \mathrm{Z})$ support for the panicoid-sister topology because

1305 (1) this partition includes noncoding regions excluding gapped sites (dataset R), which, when

1306 analyzed separately, strongly support the panicoid-sister topology; and (2) this partition includes

1307 coding regions that, when analyzed separately, do not provide support greater than 50\% for any

1308 particular topology. Nevertheless, it is possible there is discordant signal in coding regions that

1309 might be contributing to reduced support for the panicoid-sister topology when combined with

1310 noncoding regions excluding gapped sites. Indeed, the alternative topology in tree F, even though 
1311 only weakly supported, supports the idea of discordant signal in coding regions. Furthermore, the

1312 lack of support greater than 50\% for any topology in tree X differs from the ML tree in Cotton et

1313 al. (2015) based on an equivalent dataset, in which the panicoid-sister topology receives

1314 moderate support ( $\mathrm{BP}=77 \%$ ). These differences might be related to the denser taxon sampling

1315 here in Panicoideae and particularly in Aristidoideae, in which we sampled two species each of

1316 Aristida L.), Sartidia De Winter and Stipagrostis Nees, compared to Cotton et al. (2015), as well

1317 as possible alignment differences.

1318 Choice of outgroup in a phylogenetic analysis can affect inferences of the location of the

1319 root of a clade (Graham et al., 2002; de la Torre-Bárcena et al., 2009), especially in clades such

1320 as the PACMAD clade with short deep internodes that are difficult to resolve. Cotton et al.

1321 (2015) tested the effects of including different and varying numbers of non-PACMAD grass

1322 outgroups on the basal topology of the PACMAD clade in ML analyses. Although the panicoid-

1323 sister topology was supported in all but one of their experiments, bootstrap support for this

1324 topology ranged considerably (from 60\% to 91\%) indicating some effect of outgroup on ingroup

1325 branch support. We do not attribute our conflicting topologies to outgroup-effect, since all

1326 analyses include the same broad sampling of taxa of Poaceae, which exceeds the diversity in any

1327 other plastome analysis.

1328 In spite of the uncertain branching order of Aristidoideae and Panicoideae with respect to

1329 the rest of the PACMAD clade, the four remaining PACMAD subfamilies - Arundinoideae,

1330 Micrairoideae, Chloridoideae and Danthonioideae-form a strongly to maximally supported

1331 clade in the plastome trees. This clade has been identified in previous studies (Duvall et al.,

1332 2007, 2010; Grass Phylogeny Working Group II, 2012; Cotton et al., 2015; Burke et al., 2016b;

1333 Piot et al., 2017; Teisher et al., 2017). The strongly supported sister group relationship between 
1334 Chloridoideae and Danthonioideae has similarly been found in other plastid studies, with weak

1335 (Hilu \& Alice, 1999; Duvall et al., 2007; Sánchez-Ken \& Clark, 2007; Christin et al., 2008a) or

1336 moderate to strong support (Grass Phylogeny Working Group, 2001; Bouchenak-Khelladi et al.,

1337 2008; Peterson et al., 2010; Piot et al., 2017; Teisher et al., 2017). These relationship were also

1338 found in a combined ITS and plastid tree with strong support (Minaya et al., 2015), and in a BI

1339 tree based on 122 nuclear loci, but not in MP-EST (Maximum Pseudo-likelihood for Estimating

1340 Species Analyses) analyses of the same nuclear data (Liu et al., 2010). By contrast, a strongly

1341 supported conflicting topology, in which Danthonioideae is sister to Arundinoideae +

1342 Chloridoideae + Panicoideae (Micrairoideae not sampled), was identified in a Bayesian analysis

1343 of combined $n d h F$ and $p h y B$ data (Vicentini et al., 2008), a topology likely influenced by the

1344 nuclear gene included there. Another strongly conflicting topology, in which and the remainder

1345 of the PACMAD subfamilies did not form a clade, was found in a nuclear $\beta$-amylase phylogeny:

1346 Chloridoideae were placed sister to the BOP clade, Danthonioideae were sister to Chloridoideae

1347 + the BOP clade, and Panicoideae was not resolved as monophyletic (Minaya et al., 2015). The

1348 maximally supported clade comprising Arundinoideae and Micrairoideae in the plastome trees

1349 has been recovered in other plastome studies (Duvall et al., 2010; Cotton et al., 2015; Teisher et

1350 al., 2017), whereas in few-gene studies the clade has been recovered with poor (Duvall et al.,

1351 2007; Sánchez-Ken et al., 2007; Christin et al., 2008a) or strong support (Grass Phylogeny

1352 Working Group II, 2012). Given the consistent, non-conflicting support in the plastome trees we

1353 are confident in the accuracy of the relationships among these four subfamilies inferred from

1354 plastome data. 
1355

1356

1357

1358

1359

1360

1361

1362

1363

\section{4}

1365

1366

1367

1368

1369

1370

1371 1372 better sampled.

1373

1374

1375

1376

\section{Danthonioideae}

Danthonioideae includes a single tribe comprising 18 genera, and one genus is incertae sedis in the subfamily (Linder et al., 2010; Soreng et al., 2017). The current analyses include plastomes from seven species and six genera. We find strong support from all plastome partitions for successive divergences of Chionochloa macra Zotov, Chaetobromus involucratus subsp. dregeanus (Nees) Verboom, Danthonia californica Bol., Tribolium hispidum (Thunb.) Desv., Tenaxia guillarmodiae (Conert) N.P. Barker \& H.P. Linder and Rytidosperma Steud. (two species). This topology is congruent with and better supported than the few-gene phylogenetic tree on which the current classification of the subfamily is based (Linder et al., 2010).

\section{Arundinoideae and Micrairoideae}

Arundinoideae includes Arundineae, with four genera and represented here by Monachather paradoxa Steud., and Molinieae, with two subtribes (Crinipinae and Molininae) and three genera incertae sedis (Soreng et al., 2017). Crinipinae includes four genera and is represented here by Elytrophorus spicatus (Willd.) A. Camus, and subtribe Molininae includes four genera and is represented here by Hakonechloa macra (Munro) Honda and Phragmites australis (Cav.) Trin. ex Steud., as in Cotton et al. (2015). Relationships among these taxa are congruent with the plastome trees in Piot et al. (2017) and Teisher et al. (2017), the latter one

Micrairoideae includes three tribes, each represented here: Micraireae (monogeneric), represented here by Micraira F. Muell., Eriachneae (monogeneric) by Eriachne Eck-Boorsb. and Isachneae (six genera) by Isachne R. Br. As in other studies, Micraireae is sister to Eriachneae + Isachneae (Sánchez-Ken et al., 2007; Cotton et al., 2015; Piot et al., 2017; Teisher et al., 2017). 
1377 Of the eight genera of Micrairoideae (Soreng et al., 2017), plastomes have not yet been published

1378 from species of Coelachne R. Br., Heteranthoecia Stapf. and Sphaerocaryum Nees ex Hook. f.

1379 Panicoideae

$1380 \quad$ Panicoideae includes 13 tribes and three genera incertae sedis (Soreng et al., 2017).

1381 Overall support and topology among panicoid lineages here is nearly identical to the earlier

1382 plastome study of Burke et al. (2016b), and the plastome trees are generally better resolved and

1383 supported than in earlier few-gene plastid trees (Sánchez-Ken \& Clark, 2010; Morrone et al.,

1384 2012). However, deep relationships among Zeugiteae, Chasmanthieae, Tristachyideae,

1385 Centotheceae and Thysanolaeneae conflict among plastome partitions: the five taxa form a

1386 weakly to moderately supported clade in some trees $(\mathrm{E}-\mathrm{H}, \mathrm{X}, \mathrm{Z}, \mathrm{BP}=60-87 \%)$, as in Burke et

1387 al. (2016b). In three trees, however, Tristachyideae + Centotheceae + Thysanolaeneae and

1388 Zeugiteae + Chasmanthieae are successively diverging sisters to the rest of the subfamily, with

1389 the large clade including Zeugiteae + Chasmanthieae strongly supported as the sister group of the

1390 rest of Panicoideae excluding Tristachyideae + Centotheceae (Q, W, Y, BP = 90-100\%). These

1391 differing topologies indicate some strong discordance in the plastome datasets. Plastomes

1392 representing Cyperochloeae, Gynerieae and Steyermarkochloeae have not yet been published.

1393 Lecomtella madagascariensis A. Camus is the next to diverge, consistent with recognition of this

1394 taxon in its own tribe, Lecomtelleae (Besnard et al., 2013; Soreng et al., 2017).

1395 The strongly supported relationships among Paniceae, Paspaleae, Andropogoneae and

1396 Arundinelleae in the plastome trees are congruent with other studies: Paniceae is sister to a clade

1397 comprising Paspaleae + (Andropogoneae + Arundinelleae) (Grass Phylogeny Working Group II,

1398 2012; reviewed in Kellogg, 2012). This latter clade was recently recognized as supertribe

1399 Andropogonodae (Soreng et al., 2017), a clade mainly of species with $\mathrm{x}=10$ that is robustly 
1400 supported in the plastome trees. Paspaleae genera, recently reconstituted a tribe (Morrone et al.

1401 2012), were historically included in supertribe Panicodae (Soreng et al. 2015b).

\section{Andropogoneae}

1403 Nine subtribes and six genera incertae sedis are recognized in tribe Andropogoneae

1404 (Soreng et al., 2017), a large lineage in which multiple allopolyploidization events have been

1405 documented (Estep et al., 2014). The two subtribes of Andropogoneae for which plastomes are

1406 not sampled here are Chionachninae (five genera) and Germainiinae (four genera) (Soreng et al.,

1407 2017). Relationships among the seven subtribes sampled in the plastome trees here and in Burke

1408 et al. (2016b) are much better resolved and supported than in studies based on a few plastid

1409 genes and ITS (Mathews et al., 2002; Skendzic et al., 2007; Teerawatananon et al., 2011), and

1410 are mostly congruent with recent studies of low-copy nuclear loci in the tribe (Estep et al., 2014;

1411 Hawkins et al., 2015) and with another plastome tree with somewhat different sampling (Piot et

1412 al., 2017). Andropogoninae and Saccharinae are sister taxa, and within Andropogoninae, the

1413 sister group relationship between Diheteropogon amplectens var. catangensis and Hyparrhenia

1414 subplumosa, and the successive branching of Themeda sp., Iseleima macratherum and

1415 Bothriochloa alta + Capillipedium venustum, are congruent with other plastid and nuclear trees

1416 (Kellogg, 2012; Estep et al., 2014; Hawkins et al., 2015).

1417 Saccharinae includes 26 genera, of which we sampled Eulalia Kunth, Saccharum L.,

1418 Sorghum, Sorghastrum Nash and Imperata Cirillo. In all but one plastome tree, Eulalia and

1419 Sorghastrum are sister taxa, with varying levels of support; this topology is congruent with the

1420 plastome tree in Burke et al. (2016b). Most earlier studies did not identify a close relationship

1421 between these genera (Skendzic et al., 2007; Grass Phylogeny Working Group II, 2012),

1422 although they were included in the same clade (with other genera) in trees based on low-copy 
1423 nuclear loci (Estep et al., 2014; Hawkins et al., 2015). In all but one plastome tree, Saccharum

1424 and Sorghum form a strongly supported clade, and Imperata is sister to this clade. The affinities

1425 of the Eulalia + Sorghastrum and Imperata + Saccharum + Sorghum clades, however, vary

1426 among trees; in other words, Saccharinae is not consistently resolved as monophyletic. Burke et

1427 al. (2016b) found Eulalia + Sorghastrum to be sister to Andropogoninae, with weak to strong

1428 support, and we find this same topology with weak to moderate support in five plastome trees, of

1429 which all but one are based on partitions excluding gapped sites. In four analyses including

1430 gapped sites, however, Saccharinae is monophyletic, and Eulalia + Sorghastrum and Imperata +

1431 Saccharum + Sorghum are sister clades.

1432 The strongly supported clade comprising Ischaemum afrum (Ischaeminae; six genera)

1433 and Coix lacryma-jobi (Coicinae; one genus) + Rottboellia cochinchinensis (Rottboelliinae; 16

1434 genera) that is sister to Andropogoninae + Saccharinae in the plastome trees has also been found

1435 in other plastid studies (Grass Phylogeny Working Group II, 2012), but was not recovered in

1436 nuclear analyses, in which most deep branches within the tribe were poorly supported (Estep et

1437 al., 2014). At the base of the Andropogoneae clade in the plastome trees, subtribes Arthraxoninae

1438 (one genus) and Tripsacinae (seven genera, represented by Zea) diverge successively as sisters to

1439 the rest of the tribe, consistent with the better-sampled nuclear tree in Estep et al. (2014).

1440 Paspaleae

1441 Paspaleae includes subtribes Paspalinae, Otachyriinae and Arthropogoninae and the

1442 incertae sedis genus Reynaudia Kunth. Our sampling includes two genera of Paspalinae

1443 (Axonopus P. Beauv. and Paspalum), three of Otachyriinae (Otachyrium Nees, Plagiantha

1444 Renvoize and Steinchisma Raf.) and two of Arthropogoninae (Coleataenia Griseb. and

1445 Oncorachis Morrone \& Zuloaga). Monophyly of each subtribe is robustly supported in the 
1446 plastome trees, and despite our limited taxon sampling, the strong support for a sister group

1447 relationship between Arthropogoninae and Otachyriinae is an improvement on earlier studies

1448 with greater taxon sampling but less sequence data per taxon, in which relationships among the

1449 three subtribes were unresolved (Acosta et al., 2014) or only weakly supported (Grass Phylogeny

1450 Working Group II, 2012). Relationships among the subtribes are similarly resolved in the

1451 plastome tree of Piot et al. (2017). Relationships among the three sampled genera of

1452 Otachyriinae in our plastome trees are congruent with earlier plastid trees (Grass Phylogeny

1453 Working Group II, 2012; Acosta et al., 2014).

1454 Paniceae

1455 Paniceae includes seven subtribes and eight genera incertae sedis (Soreng et al., 2017).

1456 There has been considerable phylogenetic investigation of the tribe, mostly based on one or a

1457 few gene regions (reviewed in Washburn et al., 2015). Numerous clades now recognized as

1458 tribes and subtribes were identified in a single-plastid-gene study with dense taxon sampling, in

1459 which most aspects of backbone relationships were unresolved (Morrone et al., 2012).

1460 Phylogenomic studies are providing new insights into relationships in this tribe. Washburn et al.

1461 (2015) analyzed 78 chloroplast, 22 mitochondrial and 2 nrDNA loci from 45 taxa of Paniceae,

1462 Burke et al. (2016b) analyzed complete plastomes from 16 taxa of Paniceae, and our sampling of

1463 the tribe builds slightly on the latter study by adding three additional plastomes. Plastid-based

1464 topologies in the two earlier studies and the current one are similar, with the following lineages

1465 diverging successively: Anthephorinae, Boivinellinae, Dichantheliinae + Neurachninae,

1466 Panicinae, Melinidinae and Cenchrinae. The strong support along the backbone of the Paniceae

1467 tree in the current and earlier plastome studies (Washburn et al., 2015; Burke et al., 2016b) is a

1468 substantial improvement on studies with considerably less genomic sampling (Grass Phylogeny 
1469 Working Group II, 2012; Morrone et al., 2012; Zuloaga et al., 2014). The moderately to

1470 maximally supported clade comprising Dichantheliinae + Neurachninae and Cenchrinae +

1471 Melinidinae + Panicinae is congruent with the plastome and combined plastome, mitochondrial

1472 and nuclear trees in Washburn et al. (2015). They also found Sacciolepis Nash (incertae sedis

1473 within Paniceae and not sampled here) to be part of this clade and moderately to strongly

1474 supported as sister to Dichantheliinae + Neurachninae. In a combined nuclear $(p h y B)$ and plastid

$1475(n d h F)$ tree, however, Sacciolepis is embedded in Panicinae (Vicentini et al., 2008), possibly

1476 reflecting discordance between plastid and nuclear data due to hybridization. Relationships

1477 inferred among taxa of Melinidinae in Washburn et al. (2015), Burke et al. (2016b) and the

1478 current trees are also congruent. In this study, Whiteochloa capillipes is united with species of

1479 Panicinae in all trees from the 14 partitions (mean $\mathrm{BP}=92 \%)$ as was inferred earlier (Burke et

1480 al., 2016a). However, this result conflicts with those of two previous studies using incompletely

1481 sequenced plastid loci. The previous studies placed Whiteochloa capillipes among Cenchrinae,

1482 but with marginal jackknife or bootstrap support (both $\leq 50 \%$; GPWG II, 2012; Morrone et al.

1483 2012). The two earlier studies obtained DNA from the same plant (voucher: J. Risler 1804, MO)

1484 and the loci sequenced are among those with the greatest number of positively selected sites

1485 (ndhF, matK, and $r b c L)$; the plastome data were obtained from a different accession. The

1486 inflorescence and spikelet morphologies of Whiteochloa are more similar to those of Panicinae

1487 than Cenchrinae. Setae, which are synapomorphic for Cenchrinae (hence the common name

1488 "Bristle clade”), are notably absent from Whiteochloa (Morrone et al. 2012).

1489 Four possible explanations for this discrepancy are: 1) The use of plastid loci, which have

1490 high numbers of positively selected sites, skewed previous phylogenetic analyses. Such

1491 phylogenies, especially when based on a single gene, are susceptible to selection artifacts (see 
1492 above). 2) One of the two plants was misidentified, although it is not clear which other

1493 Australian grasses might be mistaken for Whiteochloa capillipes. When homologous regions

1494 from our complete plastome are aligned with the previously sequenced markers, nucleotide

1495 identities range only from 95-97\%, which suggests that the two sources of DNA are not

1496 conspecific. The plant used to produce the complete plastome (Duvall s.n., DEK) shows

1497 characters that are diagnostic for Whiteochloa. However, two duplicates of the voucher J. Risler

14981804 (DNA, MO) are also consistent with the current concept of Whiteochloa capillipes. 3)

1499 Whiteochloa capillipes is actually a complex of hybrids between species of Panicinae and

1500 Cenchrinae. The direction of the cross would determine which of two possible plastome

1501 haplotypes (Panicinae or Cenchrinae) was captured, depending on the female parent, whereas the

1502 morphological phenotypes of the reciprocal hybrids might be similar. Nuclear sequences of

1503 Panicinae and Cenchrinae, which have not been obtained to date, would be needed to test this

1504 third point and determine the identities of parent species. 4) There was a labeling mix-up or

1505 contamination somewhere in the extraction or sequencing process. This could be clarified by re-

1506 extracting and sequencing both specimens.

1507 Subtribe Cenchrinae includes some 24 genera (Soreng et al., 2017) and most aspects of

1508 its phylogeny are poorly resolved (Kellogg et al., 2009; Chemisquy et al., 2010; Morrone et al.,

1509 2012). The two genera included here, Cenchrus L. and Setaria, of which we sampled three

1510 species, form a clade, as in Burke et al. (2016b), but relationships among them conflict strongly.

1511 In eight trees, Cenchrus and Setaria italica + Setaria viridis form a maximally supported clade,

1512 whereas in two trees Setaria is strongly supported as monophyletic and sister to Cenchrus.

1513 Although the species treated here as Setaria geminata has been recognized in the genus

1514 Paspalidium Stapf, many authors have included it in Setaria (Webster, 1993, 1995; Veldkamp, 
1515 1994; Morrone et al., 2014; Soreng et al., 2017). In our trees, inclusion of Paspalidium in Setaria

1516 is supported only by plastome coding data. In other studies, relationships among Setaria and

1517 related genera are unclear. For example, in a broadly sampled $n d h F$ tree of Setaria and related

1518 genera, species of Paspalidium formed a clade that was part of a broader clade including a subset

1519 of Setaria species (including the type species) from China and South America, Ixophorus

1520 unisetus (J. Presl) Schltdl., Zuloagaea bulbosa (Kunth) E. Bess, Stenotaphrum secundatum

1521 (Walter) Kuntze and Uranthoecium truncatum (Maiden \& Betche) Stapf (Kellogg et al., 2009).

1522 Sampling of a much broader selection of genera and species in Cenchrinae will be needed to

1523 clarify the plastome phylogeny in this group.

1524 Subtribe Boivinellinae includes 18 to 19 genera (Silva et al., 2017; Soreng et al., 2017).

1525 Burke et al. (2016b) sampled three of these and found them to form a maximally supported

1526 clade, but relationships among the genera differed among their MP (Amphicarpum sister to

1527 Oplismenus + Echinochloa), and ML and BI analyses (Oplismenus sister to Amphicarpum +

1528 Echinochloa). Relationships among these genera similarly differ among our plastome trees. In

1529 nuclear phylogenies, Echinochloa is not part of the Boivinellinae clade (Christin et al., 2007;

1530 Vicentini et al., 2008). In a better-sampled plastome tree, a maximally supported clade of six

1531 species of Echinochloa is weakly supported as sister to a maximally supported clade comprising

1532 Brachiaria fragrans A. Camus, Panicum locopodioides Bory ex Nees, Chasechloa A. Camus,

1533 Lasiacis nigra Davidse, Oplismenus burmannii (Retz.) P. Beauv. and Pseudolasiacis

1534 leptolomoides (A. Camus) A. Camus (Piot et al., 2017). Washburn et al. (2015) sampled

1535 Alloteropsis, Echinochloa (two species) and Oplismenus, and relationships among these taxa

1536 were weakly supported in their plastid tree. Our trees include Amphicarpum, Oplismenus, two

1537 species of Echinochloa and three species of Alloteropsis. The latter genus is of particular interest 
1538 to evolutionary biologists (Lundgren et al., 2015) because one species, Alloteropsis semialata,

1539 has two subspecies differing in photosynthetic pathway: one is $C_{3}$ and one is $\mathrm{C}_{4}$ (Gibbs Russell,

1540 1983; Lundgren et al., 2016). Monophyly of Boivinellinae is strongly supported in all but tree Y,

1541 in which Amphicarpum is strongly supported as sister to Thyridolepis xerophila and the lineage

1542 is placed outside the main Boivinellinae clade; reasons for this alternative topology are unclear.

1543 Relationships among the three species of Alloteropsis are congruent with the tree in Ibrahim et

1544 al. (2009), which identifies two major lineages in the genus: one comprising Alloteropsis

1545 cimicina (L.) Stapf sister to Alloteropsis paniculata (Benth.) Stapf + Alloteropsis papillosa

1546 Clayton; the other comprising Alloteropsis angusta and Alloteropsis semialata. Relationships

1547 among the four genera, however, vary among the plastome trees. Similar uncertainty at the base

1548 of the Boivinellinae tree is present in other studies based on fewer gene regions but greater taxon

1549 sampling (Grass Phylogeny Working Group II, 2012; Morrone et al., 2012; Silva et al., 2017).

\section{Chloridoideae}

1551 Chloridoideae includes five tribes (Centropodieae, Triraphideae, Eragrostideae,

1552 Cynodonteae and Zoysieae) and seven genera incertae sedis at tribal rank (Soreng et al., 2017).

1553 The successive branching order of Centropodieae, Triraphideae, Eragrostideae, Zoysieae and

1554 Cynodonteae is congruent with other studies of plastid data (Columbus et al., 2007; Peterson et

1555 al., 2010; 2011; 2014a; 2016; Duvall et al., 2016; Piot et al., 2017). However, the relationship of

1556 Centropodieae to the rest of Chloridoideae is unclear in nuclear trees, which did not resolve

1557 relationships among Chloridoideae, Arundinoideae, Danthonioideae and Centropodieae

1558 (including Centropodia Rchb. and Ellisochloa P.M. Peterson \& N.P. Barker) (Fisher et al.,

1559 2016). Relationships among the other four tribes of Chloridoideae in nuclear trees, however, are

1560 congruent with the plastome trees (Fisher et al., 2016). Our sampling of Chloridoideae includes 
1561 one of the three genera of Triraphideae (Triraphis $\mathrm{R}$. Br.), two of the three subtribes of

1562 Eragrostideae (Eragrostidinae, Unioliinae) and both subtribes of Zoysieae (Sporobolinae,

1563 Zoysiinae). The relationships we find among the three sampled species of Sporobolus

1564 (Sporobolinae), of which two were previously recognized in the genus Spartina Schreb., are

1565 congruent with previous studies (Peterson et al., 2014b, c).

1566 Cynodonteae is a large and variable tribe consisting of 94 genera (Peterson et al., 2016;

1567 Soreng et al., 2017) for which there are no known morphological synapomorphies. Twenty-five

1568 subtribes of Cynodonteae are currently recognized (Peterson et al., 2014a, 2016, 2017a; Soreng

1569 et al., 2017), some of which are combined in Kellogg (2015), and eight of these are represented

1570 here. Sampling in Boutelouinae, Monanthochloinae and Hilariinae is identical to that in Duvall et

1571 al. (2016), and relationships among these subtribes (Hilariinae sister to Boutelouinae +

1572 Monanthochloinae) are congruent with other plastid analyses (Peterson et al., 2010, 2014a,

1573 2015). They are also congruent with the 56 nuclear gene MP-EST tree in Fisher et al. (2016), but

1574 not their 122 locus BI tree, in which Distichlis and Hilaria are sister taxa. Based on a phylogeny

1575 using seven plastid and ITS regions, these three subtribes are part of a larger clade recognized as

1576 supersubtribe Boutelouodinae, also including subtribes Allolepiinae, Jouveinae, Kaliniinae,

1577 Muhlenbergiinae, Scleropogoninae, Sohnsiinae and Traginae (Peterson et al., 2017a). In Peterson

1578 et al. (2017a), Boutelouinae + Monanthochloinae are moderately supported as sister to Kaliniinae

1579 and Hilariinae are unsupported as sister to Allolepiinae.

1580 Compared to a previous plastome study of Chloridoideae (Duvall et al., 2016), we

1581 include new plastomes from Trichoneurinae (Trichoneura grandiglumis), Tripogoninae

1582 (Halopyrum mucronatum and Melanocenchris abyssinica), Triodiinae (Triodia stipoides (S.W.L.

1583 Jacobs) Crisp \& Mant and Triodia wiseana C.A. Gardner), Eleusininae (Astrebla pectinata, 
1584 Chloris barbata, Eustachys glauca, Leptochloa pluriflora, Oxychloris scariosa) and

1585 Dactylocteniinae (Dactyloctenium aegyptium). The sister group relationship between

1586 Trichoneurinae and Dactylocteniinae is congruent with and better supported than recent plastid

1587 trees in which Neobouteloua Gould + Dactyloctenium (L.) Willd. (Dactylocteniinae) are sister to

1588 a large but weakly supported clade including Orcuttiinae and a clade recognized as supersubtribe

1589 Gouiniodinae comprising subtribes Cteniinae, Farragininae, Gouiniinae, Hubbardochloinae,

1590 Perotidinae, Trichoneurinae and Zaqiqahinae, of which only Trichoneurinae is sampled here

1591 (Peterson et al., 2015, 2016; Soreng et al., 2017). In a combined plastid and ITS tree, however,

1592 Dactylocteniinae and Eleusininae are sister taxa, albeit with weak support (Peterson et al., 2016).

1593 The close relationship between the two species of Triodia (Triodiinae), one of which ( $T$.

1594 stipoides) was previously recognized in Monodia S.W.L. Jacobs, is congruent with other studies

1595 (Hilu \& Alice, 2001; Grass Phylogeny Working Group II, 2012). Monodia is nested within

1596 Triodia (Toon et al., 2015), and this and the related genus Symplectrodia Lazarides have been

1597 synonymized under Triodia (Crisp et al., 2015; Soreng et al., 2017).

1598 The branching order of the five sampled taxa of Eleusininae is congruent with the plastid

1599 tree that included 28 genera of the subtribe in Peterson et al. (2015), but clear resolution of

1600 relationships awaits the inclusion of the remaining 143 species in 23 genera of Eleusininae not

1601 sampled in our study. Strong support in six trees for Astrebla pectinata and Leptochloa pluriflora

1602 being successive sisters to the Oxychloris scariosa + Eustachys glauca + Chloris barbata clade

1603 is congruent with other plastid trees (Peterson et al., 2016). However, the strongly supported but

1604 discordant (reversed) branching order of Astrebla pectinata and Leptochloa pluriflora in one

1605 plastome tree (noncoding regions including gapped sites) is congruent with the combined plastid

1606 + ITS tree in Peterson et al. (2016), although the relevant deep branches in their tree only 
1607 moderately supported. Relationships among Eleusininae, Triodiinae and Dactylocteniinae are

1608 poorly supported in the plastid trees in Peterson et al. (2016), whereas we find these three

1609 lineages plus Trichoneurinae to be a clade with moderate to strong support in analyses of

1610 noncoding regions and complete plastomes. Peterson et al. (2016) found this same unsupported

1611 clade to include nine additional subtribes (Aeluropodinae, Cteniinae, Farragininae, Gouiniinae,

1612 Hubbardochloinae, Orcuttiinae, Orininae, Perotidinae, Zaqiqahinae). Nevertheless,

1613 interrelationships among these subtribes vary. The topology in two trees, in which

1614 Dactylocteniinae + Trichoneurinae and Eleusininae are sister groups, is congruent with the 56

1615 nuclear gene MP-EST tree in Fisher et al. (2016), who did not sample Trichoneurinae. However,

1616 topology of the nuclear tree in Fisher et al. (2016) was mostly incongruent with better sampled

1617 plastid trees (Peterson et al., 2010, 2014a), and they attributed these nuclear and plastid

1618 incongruences to incomplete lineage sorting and gene flow. We also find one moderately

1619 supported alternative topology in one plastome tree, in which Triodiinae and Dactylocteniinae +

1620 Trichoneurinae are sister groups. The deep branches in this part of the Cynodonteae clade are

1621 consistently short in all trees, which is likely contributing to the topological uncertainty. Lack of

1622 representative sampling of related subtribes in the plastome tree is also likely contributing to the

1623 problematic reconstruction of deep relationships among these lineages.

1624 Peterson et al. (2016) were the first to sample the monotypic Halopyrum Stapf in a

1625 molecular study and found it to be nested within Tripogoninae, where it is now classified. Our

1626 results are consistent with this, as we find Halopyrum mucronatum and Melanocenchris

1627 abyssinica to be sister taxa, although we lack samples of five additional genera that have been

1628 placed in the subtribe (Peterson et al., 2017b; Soreng et al. 2017). The differing deep placements

1629 for Tripogoninae in the plastid trees, either in a robust clade with Eleusininae + Triodiinae + 
1630 Dactylocteniinae + Trichoneurinae (the dominant topology) or sister to the remainder of the

1631 Cynodonteae (only in tree R), are likely the result of either conflicting signal or lack of signal in

1632 the noncoding partition excluding gapped sites. Moreover, in the single best ML tree from this

1633 analysis (Supplemental Figure 1), relationships among these lineages are unresolved and it is

1634 therefore surprising there is such high bootstrap support for this alternative topology. Overall, the

1635 strong support from plastome data for the mostly non-conflicting relationships inferred among

1636 subtribal taxa of Cynodonteae is a considerable improvement on earlier plastid trees, in which

1637 relationships among these subtribal lineages were mostly poorly supported (Grass Phylogeny

1638 Working Group II, 2012; Peterson et al., 2014a, 2015), and denser plastome sampling across the

1639 tribe may lead to improved understanding of relationships, particularly of deep branches.

1640 However, studies of nuclear loci that have identified topologies that conflict with those from

1641 plastid data indicate that plastome analyses likely do not accurately reflect evolutionary history

1642 in this large clade (Fisher et al., 2016).

1643

1644 Future Directions

1645 Taxon density is key for resolving contradictory branching patterns. A robust plastome

1646 phylogeny of Poaceae with complete genus-level sampling is likely attainable within five years,

1647 dependent on the availability of rare species or those restricted to remote areas. Such a

1648 phylogenetic tree would contribute to further improvement, refinement and confidence in

1649 classification of grasses, and would facilitate broad characterization of the molecular

1650 evolutionary histories of plastomes in grasses, allow more precise divergence estimations, and

1651 produce complete descriptions of microstructural events and rare genomic changes in the

1652 plastome. We suggest that future work on plastome phylogeny of Poaceae should aim to (1) 
1653 sample representatives from the few tribes (Guaduelleae, Duthieae, Brylkinieae, Cyperochloeae,

1654 Steyermarkochloeae, Gynerieae) and many subtribes for which plastomes have not yet been

1655 published, as well as the few genera that remain unplaced to a tribe or a subtribe, most of which

1656 have no sequence data available; (2) complete genus-level sampling of plastomes in all tribes and

1657 subtribes, focusing first on genera whose affinities within tribes, subtribes and subfamilies are

1658 unclear in existing phylogenies (e.g., Milium, Beckmannia, Cinna) in Poeae group 2; Avenella in

1659 Airinae; Gynerium (Gynerieae) in Panicoideae) and genera that have not been included in any

1660 phylogenetic study, such as Phyllorachis (Phyllorachideae); (3) sample plastomes representing

1661 all lineages of genera known to be para- or polyphyletic and which have not yet undergone

1662 taxonomic revision; (4) sample taxa of particular evolutionary interest, such

1663 as Aristida longifolia, the $\mathrm{C}_{3}$ sister to all other species of Aristida, which are $\mathrm{C}_{4}$. Attention should

1664 also be paid to stems and loop micro inversions and data bias from complementary base pair

1665 mutations in stems, in mechanical alignments. Attention to nuclear genomes is needed beyond all

1666 this, to clarify reticulation events, as those are not evident in plastid trees.

1667

\section{Conclusions}

High throughput sequencing, high speed computation, and big data science software tools

1670 together facilitate genome-scale systematic studies of plants. Here, we present the most

1671 comprehensive plastome phylogenomic study of Poaceae to date with specific emphasis on the

1672 effects of data partitioning. The plastome phylogeny is highly congruent with the latest

1673 classifications of Poaceae, with most branches that define tribes and subtribes strongly, and

1674 usually maximally supported, even though we have not sampled plastomes from all of the tribes. 
1675 One interesting exception is the subtribal placement of Whiteochloa in Panicoideae, a result that

1676 should be confirmed through further study.

1677 We demonstrate strong improvements in resolution and support in our plastome

1678 phylogenomic analyses of Poaceae, particularly when compared to single and few-gene plastid

1679 phylogenies. We recommend analyses of both coding and noncoding plastome regions while

1680 excluding regions that may be aligned ambiguously by removing all sites with gaps introduced

1681 by the alignment. Such ambiguous regions sometimes showed spurious "signal."

1682 Although the plastid coding loci uniformly show a dominant signal of purifying selection,

1683 positively selected codons were also identified in most loci. We show that widely used loci in

1684 grass systematics, such as $n d h F$, matK, $r p o C 2$, and $r b c L$, are particularly subject to selective

1685 effects and have the highest numbers of positively selected codons among plastid loci. Use of

1686 noncoding intergenic spacers, introns, and protein coding loci such as certain photosystem genes

1687 e.g., psaA and $p s a B$, which have few positively selected codons, can reduce phylogenomic

1688 artifacts due to selection.

1689 Relationships among PACMAD subfamilies were previously reported and widely cited in

1690 a benchmark paper of grass systematics (Grass Phylogeny Working Group II, 2012). That study

1691 was taxonomically denser than this study, but relied on considerably less molecular data,

1692 coincidentally analyzed the loci with the most positively selected codons, and, in the interest of

1693 retaining the most sequence data, included alignment gaps. Here we show that the positions of

1694 Panicoideae and Aristidoideae relative to the remaining PACMAD subfamilies is dependent on

1695 the data partition that is analyzed, and that earlier results should be viewed in the context of that

1696 information. This is a pivotal node in grass systematics that has broad historical significance for

1697 the adaptive changes that occurred during transitions from forests/forest margin habitats to open 
1698 grasslands. Additional taxonomic sampling of plastomes and parallel nuclear studies obtained

1699 from transcriptomes or libraries enriched with specific targets will be needed to fully address

1700 these issues.

1701

1702 Acknowledgements

1703 We thank Dr. George Rogers, West Palm Beach State University, for help obtaining materials,

1704 Olivia East, Northern Illinois University, for technical assistance, and Marcial Escudero,

1705 Elizabeth Kellogg and an anonymous reviewer for constructive feedback on earlier versions of

1706 the manuscript.

1707

1708 
1710

1711

1712

1713

1714

1715

1716

1717

1718

1719

1720

1721

1722

1723

1724

1725

1726

1727

1728

1729

1730

1731

1732

1733

1734

1735

1736

1737

1738

1739

1740

1741

1742

1743

1744

1745

1746

1747

1748

1749

1750

1751

1752

1753

1754

Acosta JM, Scataglini MA, Reinheimer R, and Zuloaga FO. 2014. A phylogenetic study of subtribe Otachyriinae (Poaceae, Panicoideae, Paspaleae). Plant Systematics and Evolution 300:21552166. $10.1007 / \mathrm{s} 00606-014-1034-8$

Akaike H. 1974. A new look at the statistical model identification. IEEE Transactions on Automatic Control 19:716-723. 10.1109/TAC.1974.1100705

Asano T, Tsudzuki T, Takahashi S, Shimada H, and Kadowaki K-i. 2004. Complete nucleotide sequence of the sugarcane (Saccharum officinarum) chloroplast genome: A comparative analysis of four monocot chloroplast genomes. DNA Research 11:93-99. 10.1093/dnares/11.2.93

Attigala L, Triplett JK, Kathriarachchi H-S, and Clark LG. 2014. A new genus and a major temperate bamboo lineage of the Arundinarieae (Poaceae: Bambusoideae) from Sri Lanka based on a multilocus plastid phylogeny. Phytotaxa 174:187-205. 10.11646/phytotaxa.174.4.1

Attigala L, Wysocki WP, Duvall MR, and Clark LG. 2016. Phylogenetic estimation and morphological evolution of Arundinarieae (Bambusoideae: Poaceae) based on plastome phylogenomic analysis. Molecular Phylogenetics and Evolution 101:111-121. 10.1016/j.ympev.2016.05.008

Bamboo Phylogeny Group. 2012. An updated tribal and subtribal classification of the bamboos (Poaceae: Bambusoideae). Bamboo Science \& Culture: The Journal of the American Bamboo Society 24:110.

Bankevich A, Nurk S, Antipov D, Gurevich AA, Dvorkin M, Kulikov AS, Lesin VM, Nikolenko SI, Pham S, Prjibelski AD, Pyshkin AV, Sirotkin AV, Vyahhi N, Tesler G, Alekseyev MA, and Pevzner PA. 2012. SPAdes: A new genome assembly algorithm and its applications to single-cell sequencing. Journal of Computational Biology 19:455-477. 10.1089/cmb.2012.0021

Barkworth ME, Jacobs S, and Zhang H-Q. 2009. Connorochloa: a new genus in Triticeae. Breeding Science 59:685-686. 10.1270/jsbbs.59.685

Barrett CF, Baker WJ, Comer JR, Conran JG, Lahmeyer SC, Leebens-Mack JH, Li J, Lim GS, MayfieldJones DR, Perez L, Medina J, Pires JC, Santos C, Wm Stevenson D, Zomlefer WB, and Davis JI. 2016. Plastid genomes reveal support for deep phylogenetic relationships and extensive rate variation among palms and other commelinid monocots. New Phytologist 209:855-870. $10.1111 / \mathrm{nph} .13617$

Bernhardt N, Brassac J, Kilian B, and Blattner FR. 2017. Dated tribe-wide whole chloroplast genome phylogeny indicates recurrent hybridizations within Triticeae. BMC Evolutionary Biology 17:141. 10.1186/s12862-017-0989-9

Besnard G, Christin P-A, Malé P-JG, Coissac E, Ralimanana H, and Vorontsova MS. 2013. Phylogenomics and taxonomy of Lecomtelleae (Poaceae), an isolated panicoid lineage from Madagascar. Annals of Botany 112:1057-1066. 10.1093/aob/mct174

Birch JL, Cantrill DJ, Walsh NG, and Murphy DJ. 2014. Phylogenetic investigation and divergence dating of Poa (Poaceae, tribe Poeae) in the Australasian region. Botanical Journal of the Linnean Society 175:523-552. 10.1111/boj.12185

Blaner A, Schneider J, and Röser M. 2014. Phylogenetic relationships in the grass family (Poaceae) based on the nuclear single copy locus topoisomerase 6 compared with chloroplast DNA. Systematics and Biodiversity 12:111-124. 10.1080/14772000.2014.890137

Bortiri E, Coleman-Derr D, Lazo G, Anderson O, and Gu Y. 2008. The complete chloroplast genome sequence of Brachypodium distachyon: sequence comparison and phylogenetic analysis of eight grass plastomes. BMC Research Notes 1:61. 10.1186/1756-0500-1-61

Bouchenak-Khelladi Y, Salamin N, Savolainen V, Forest F, van der Bank M, Chase MW, and Hodkinson TR. 2008. Large multi-gene phylogenetic trees of the grasses (Poaceae): Progress towards

PeerJ reviewing PDF | (2017:08:19682:2:0:NEW 4 Jan 2018) 
1755

1756

1757

1758

1759

1760

1761

1762

1763

1764

1765

1766

1767

1768

1769

1770

1771

1772

1773

1774

1775

1776

1777

1778

1779

1780

1781

1782

1783

1784

1785

1786

1787

1788

1789

1790

1791

1792

1793

1794

1795

1796

1797

1798

1799

1800

1801

1802

1803 complete tribal and generic level sampling. Molecular Phylogenetics and Evolution 47:488-505. 10.1016/j.ympev.2008.01.035

Bremer K. 2002. Gondwanan evolution of the grass alliance of families (Poales). Evolution 56:13741387. 10.1111/j.0014-3820.2002.tb01451.x

Brown R. 1814. Gramineae. In: Finders M, ed. A voyage to Terra Australis. W. Bulmer \& Company: London, 5803-5583.

Burke SV, Clark LG, Triplett JK, Grennan CP, and Duvall MR. 2014. Biogeography and phylogenomics of New World Bambusoideae (Poaceae), revisited. American Journal of Botany 101:886-891. 10.3732/ajb.1400063

Burke SV, Grennan CP, and Duvall MR. 2012. Plastome sequences of two New World bamboosArundinaria gigantea and Cryptochloa strictiflora (Poaceae) - extend phylogenomic understanding of Bambusoideae. American Journal of Botany 99:1951-1961. 10.3732/ajb.1200365

Burke SV, Lin C-S, Wysocki WP, Clark LG, and Duvall MR. 2016a. Phylogenomics and plastome evolution of tropical forest grasses (Leptaspis, Streptochaeta: Poaceae). Frontiers in Plant Science 7:1993 10.3389/fpls.2016.01993

Burke SV, Wysocki WP, Zuloaga FO, Craine JM, Pires JC, Edger PP, Mayfield-Jones D, Clark LG, Kelchner SA, and Duvall MR. 2016b. Evolutionary relationships in Panicoid grasses based on plastome phylogenomics (Panicoideae; Poaceae). BMC Plant Biology 16:1-11. 10.1186/s12870016-0823-3

Calderón CE, and Soderstrom TR. 1980. The genera of Bambusoideae (Poaceae) of the American continent: keys and comments. Smithsonian Contributions to Botany 44:1-27. $10.5479 /$ si.0081024X.44

Catalán P, Kellogg EA, and Olmstead RG. 1997. Phylogeny of Poaceae subfamily Pooideae based on chloroplast $n d h f$ gene sequences. Molecular Phylogenetics and Evolution 8:150-166. 10.1006/mpev.1997.0416

Catalán P, López-Álvarez D, Díaz-Pérez A, Sancho R, and López-Herránz ML. 2016b. Phylogeny and evolution of the genus Brachypodium. In: Vogel J, ed. Genetics and genomics of Brachypodium. Plant Genetics and Genomics: Crops and Models 18. New York: Springer, 9-38.

Catalán P, Müller J, Hasterok R, Jenkins G, Mur LAJ, Langdon T, Betekhtin A, Siwinska D, Pimentel M, and López-Alvarez D. 2012. Evolution and taxonomic split of the model grass Brachypodium distachyon. Annals of Botany 109:385-405. 10.1093/aob/mcr294

Chase MW, Fay MF, Devey DS, Maurin O, Rønsted N, Davies TJ, Pillon Y, Petersen G, Seberg O, and Tamura MN. 2006. Multigene analyses of monocot relationships: a summary. Aliso 22:63-75.

Chemisquy MA, Giussani LM, Scataglini MA, Kellogg EA, and Morrone O. 2010. Phylogenetic studies favour the unification of Pennisetum, Cenchrus and Odontelytrum (Poaceae): a combined nuclear, plastid and morphological analysis, and nomenclatural combinations in Cenchrus. Annals of Botany 106:107-130. 10.1093/aob/mcq090

Chokthaweepanich H. 2014. Phylogenetics and evolution of the paleotropical woody bamboos (Poaceae: Bambusoideae: Bambuseae). Ph.D. dissertation. Iowa State Univeristy.

Christin P-A, Besnard G, Edwards EJ, and Salamin N. 2012. Effect of genetic convergence on phylogenetic inference. Molecular Phylogenetics and Evolution 62:921-927. 10.1016/j.ympev.2011.12.002

Christin P-A, Besnard G, Samaritani E, Duvall MR, Hodkinson TR, Savolainen V, and Salamin N. 2008 a. Oligocene CO2 decline promoted C-4 photosynthesis in grasses. Current Biology 18:37-43. 10.1016/j.cub.2007.11.058

Christin P-A, Salamin N, Muasya AM, Roalson EH, Russier F, and Besnard G. 2008b. Evolutionary switch and genetic convergence on $r b c L$ following the evolution of $\mathrm{C} 4$ photosynthesis. Molecular Biology and Evolution 25:2361-2368. 10.1093/molbev/msn178 
1804

1805

1806

1807

1808

1809

1810

1811

1812

1813

1814

1815

1816

1817

1818

1819

1820

1821

1822

1823

1824

1825

1826

1827

1828

1829

1830

1831

1832

1833

1834

1835

1836

1837

1838

1839

1840

1841

1842

1843

1844

1845

1846

1847

1848

1849

1850

1851

1852

1853

Christin P-A, Salamin N, Savolainen V, Duvall MR, and Besnard G. 2007. C-4 photosynthesis evolved in grasses via parallel adaptive genetic changes. Current Biology 17:1241-1247. 10.1016/j.cub.2007.06.036

Clark L, Dransfield S, Triplett J, and Sánchez-Ken G. 2007. Phylogenetic relationships among the oneflowered, determinate genera of Bambuseae (Poaceae: Bambusoideae). Aliso 23:315-332. 10.5642/aliso.20072301.26

Clark LG, Zhang W, and Wendel JF. 1995. A phylogeny of the grass family (Poaceae) based on $n d h F$ sequence data. Systematic Botany 20:436-460.

Columbus JT, Cerros-Tlatilpa R, Kinney MS, Siqueiros-Delgado ME, Bell HL, Griffith MP, and Refulio Rodriguez NF. 2007. Phylogenetics of Chloridoideae (Gramineae): a preliminary study based on nuclear ribosomal internal transcribed spacer and chloroplast trnL-F sequences. Aliso 23:565579.

Cotton JL, Wysocki WP, Clark LG, Kelchner SA, Pires JC, Edger PP, Mayfield-Jones D, and Duvall MR. 2015. Resolving deep relationships of PACMAD grasses: a phylogenomic approach. BMC Plant Biology 15:178. 10.1186/s12870-015-0563-9

Crisp MD, Mant J, Toon A, and Cook LG. 2015. Australian spinifex grasses: new names in Triodia for Monodia and Symplectrodia. Phytotaxa 230:293-296. 10.11646/phytotaxa.230.3.9

Darriba D, Taboada GL, Doallo R, and Posada D. 2012. jModelTest 2: more models, new heuristics and parallel computing. Nature Methods 9:772. 10.1038/nmeth.2109

Davis JI, McNeal JR, Barrett CF, Chase MW, Cohen JI, Duvall MR, Givnish TJ, Graham SW, Petersen G, and Pires JC. 2013. Contrasting patterns of support among plastid genes and genomes for major clades of the monocotyledons. In: Wilkin P, and Mayo SJ, eds. Early events in monocot evolution. Systematics Association Special Volume Series. New York: Cambridge University Press, 315-349.

Davis JI, and Soreng RJ. 2007. A preliminary phylogenetic analysis of the grass subfamily Pooideae (Poaceae), with attention to structural features of the plastid and nuclear genomes, including an intron loss in GBSSI. Aliso 23:335-348. 10.5642/aliso.20072301.27

Davis JI, and Soreng RJ. 2010. Migration of endpoints of two genes relative to boundaries between regions of the plastid genome in the grass family (Poaceae). American Journal of Botany 97:874892. 10.3732/ajb.0900228

de la Torre-Bárcena JE, Kolokotronis S-O, Lee EK, Stevenson DW, Brenner ED, Katari MS, Coruzzi GM, and DeSalle R. 2009. The impact of outgroup choice and missing data on major seed plant phylogenetics using genome-wide est data. PLOS ONE 4:e5764. 10.1371/journal.pone.0005764

Diekmann K, Hodkinson TR, Wolfe KH, Bekerom, R van den, Dix PJ, and Barth S. 2009. Complete chloroplast genome sequence of a major allogamous forage species, Perennial Ryegrass (Lolium perenne L.). DNA Research 16:165-176. 10.1093/dnares/dsp008

Döring E, Schneider J, Hilu KW, and Röser M. 2007. Phylogenetic relationships in the Aveneae/Poeae complex (Pooideae, Poaceae). Kew Bulletin 62:407-424.

Doyle JJ, Davis JI, Soreng RJ, Garvin D, and Anderson MJ. 1992. Chloroplast DNA inversions and the origin of the grass family (Poaceae). Proceedings of the National Academy of Sciences of the United States of America 89:7722-7726.

Duvall ML, Fisher AE, Columbus JT, Ingram AL, Wysocki WP, Burke SV, Clark LG, and Kelchner SA. 2016. Phylogenomics and plastome evolution of the Chloridoid grasses (Chloridoideae: Poaceae). International Journal of Plant Sciences 177:235-246. 10.1086/684526

Duvall ML, Leseberg CH, Grennan CP, and Morris LM. 2010. Molecular evolution and phylogenetics of complete chloroplast genomes in Poaceae. In: Seberg O, Petersen G, Barfod AS, and Davis JI, eds. Diversity, phylogeny, and evolution in the monocotyledons. Aarhus: Aarhus University Press, $437-450$.

Duvall MR, Davis JI, Clark LG, Noll JD, Goldman DH, and Sanchez-Ken JG. 2007. Phylogeny of the grasses (Poaceae) revisited. Aliso 23:237-247. 10.5642/aliso.20072301.18 
1854

1855

1856

1857

1858

1859

1860

1861

1862

1863

1864

1865

1866

1867

1868

1869

1870

1871

1872

1873

1874

1875

1876

1877

1878

1879

1880

1881

1882

1883

1884

1885

1886

1887

1888

1889

1890

1891

1892

1893

1894

1895

1896

1897

1898

1899

1900

1901

1902

1903

1904
Duvall MR, Saar DE, Grayburn WS, and Holbrook GP. 2003. Complex transitions between C3 and C4 photosynthesis during the evolution of Paniceae: A phylogenetic case study emphasizing the position of Steinchisma hians (Poaceae), a C3-C4 intermediate. International Journal of Plant Sciences 164:949-958. 10.1086/378657

Duvall MR, Yadav SR, Burke SV, and Wysocki WP. 2017. Grass plastomes reveal unexpected paraphyly with endemic species of Micrairoideae from India and new haplotype markers in Arundinoideae. American Journal of Botany. 10.3732/ajb.1600285

Edgar R. 2004. MUSCLE: multiple sequence alignment with high accuracy and high throughput. Nucleic Acids Research 32:1792-1797. 10.1093/nar/gkh340

Escobar J, Scornavacca C, Cenci A, Guilhaumon C, Santoni S, Douzery E, Ranwez V, Glemin S, and David J. 2011. Multigenic phylogeny and analysis of tree incongruences in Triticeae (Poaceae). BMC Evolutionary Biology 11:181. 10.1186/1471-2148-11-181

Estep MC, McKain MR, Vela Diaz D, Zhong J, Hodge JG, Hodkinson TR, Layton DJ, Malcomber ST, Pasquet R, and Kellogg EA. 2014. Allopolyploidy, diversification, and the Miocene grassland expansion. Proceedings of the National Academy of Sciences 111:15149-15154. 10.1073/pnas.1404177111

Ferreira FM, Van Den Berg C, Hollowell VC, and Oliveira RP. 2013. Parianella (Poaceae, Bambusoideae): morphological and biogeographical information reveals a new genus of herbaceous bamboos from Brazil. Phytotaxa 77:27-32. 10.11646/phytotaxa.77.2.2

Fisher AE, Clark LG, and Kelchner SA. 2014. Molecular phylogeny estimation of the bamboo genus Chusquea (Poaceae: Bambusoideae: Bambuseae) and description of two new subgenera. Systematic Botany 39:829-844. 10.1600/036364414x681554

Fisher AE, Hasenstab KM, Bell HL, Blaine E, Ingram AL, and Columbus JT. 2016. Evolutionary history of chloridoid grasses estimated from 122 nuclear loci. Molecular Phylogenetics and Evolution 105:1-14. 10.1016/j.ympev.2016.08.011

Fisher AE, Triplett JK, Ho C-S, Schiller AD, Oltrogge KA, Schroder ES, Kelchner SA, and Clark LG. 2009. Paraphyly in the Bamboo Subtribe Chusqueinae (Poaceae: Bambusoideae) and a Revised Infrageneric Classification for Chusquea. Systematic Botany 34:673-683. 10.1600/036364409790139790

Gao J, and Gao L-Z. 2016. The complete chloroplast genome sequence of the Phyllostachys sulphurea (Poaceae: Bambusoideae). Mitochondrial DNA Part A: DNA Mapping, Sequencing, and Analysis 27:983-985. 10.3109/19401736.2014.926516

Gao J, Li K, and Gao L-Z. 2016. The complete chloroplast genome sequence of the Bambusa multiplex (Poaceae: Bambusoideae). Mitochondrial DNA Part A: DNA Mapping, Sequencing, and Analysis 27:980-982. 10.3109/19401736.2014.926515

Ge S, Li A, Lu B-R, Zhang S-Z, and Hong D-Y. 2002. A phylogeny of the rice tribe Oryzeae (Poaceae) based on matK sequence data. American Journal of Botany 89:1967-1972. 10.3732/ajb.89.12.1967

Ge S, Sang T, Lu B-R, and Hong D-Y. 1999. Phylogeny of rice genomes with emphasis on origins of allotetraploid species. Proceedings of the National Academy of Sciences 96:14400-14405. 10.1073/pnas.96.25.14400

Gibbs Russell GE. 1983. The taxonomic position of C3 and C4 Alloteropsis semialata (Poaceae) in southern Africa. Bothalia 14:205-213.

Gillespie LJ, Archambault A, and Soreng RJ. 2007. Phylogeny of Poa (Poaceae) based on trnT-trnF sequence data: major clades and basal relationships. Aliso 23:420-434. 10.5642/aliso.20072301.33

Gillespie LJ, Soreng RJ, Bull RD, Jacobs SWL, and Refulio-Rodriguez NF. 2008. Phylogenetic relationships in subtribe Poinae (Poaceae, Poeae) based on nuclear ITS and plastid trnT-trnL-trnF sequences. Botany 86:938-967. 10.1139/b08-076

Gillespie LM, Soreng RJ, Paradis LM, and Bull RD. 2010. Phylogeny and reticulation in Poinae subtribal complex based on nrITS, ETS and trnTLF data. In: Seberg O, Petersen G, Barfod A, and Davis 
1905

1906

1907

1908

1909

1910

1911

1912

1913

1914

1915

1916

1917

1918

1919

1920

1921

1922

1923

1924

1925

1926

1927

1928

1929

1930

1931

1932

1933

1934

1935

1936

1937

1938

1939

1940

1941

1942

1943

1944

1945

1946

1947

1948

1949

1950

1951

1952

1953

1954

1955
JI, eds. Diversity, phylogeny, and evolution in the monocotyledons. Denmark: Aarhus University Press, 589-617.

Givnish TJ, Ames M, McNeal JR, McKain MR, Steele PR, dePamphilis CW, Graham SW, Pires JC, Stevenson DW, Zomlefer WB, Briggs BG, Duvall MR, Moore MJ, Heaney JM, Soltis DE, Soltis PS, Thiele K, and Leebens-Mack JH. 2010. Assembling the tree of the monocotyledons: Plastome sequence phylogeny and evolution of Poales. Annals of the Missouri Botanical Garden 97:584616. $10.3417 / 2010023$

Gogniashvili M, Naskidashvili P, Bedoshvili D, Kotorashvili A, Kotaria N, and Beridze T. 2015. Complete chloroplast DNA sequences of Zanduri wheat (Triticum spp.). Genetic Resources and Crop Evolution 62:1269-1277. 10.1007/s10722-015-0230-x

Goh WL, Chandran S, Lin RS, Xia NH, and Wong KM. 2010. Phylogenetic relationships among Southeast Asian climbing bamboos (Poaceae: Bambusoideae) and the Bambusa complex. Biochemical Systematics and Ecology 38:764-773. 10.1016/j.bse.2010.07.006

Golovnina KA, Glushkov SA, Blinov AG, Mayorov VI, Adkison LR, and Goncharov NP. 2007. Molecular phylogeny of the genus Triticum L. Plant Systematics and Evolution 264:195-216. 10.1007/s00606-006-0478-x

Gornicki P, Zhu H, Wang J, Challa GS, Zhang Z, Gill BS, and Li W. 2014. The chloroplast view of the evolution of polyploid wheat. New Phytologist 204:704-714. 10.1111/nph.12931

Graham SW, Olmstead RG, and Barrett SC. 2002. Rooting phylogenetic trees with distant outgroups: a case study from the commelinoid monocots. Molecular Biology and Evolution 19:1769-1781. 10.1093/oxfordjournals.molbev.a003999

Graham SW, Zgurski JM, McPherson MA, Cherniawsky DM, Saarela JM, Horne EFC, Smith SY, Wong WA, O'Brien HE, Biron VL, Pires JC, Olmstead RG, Chase MW, and Rai HS. 2006. Robust inference of monocot deep phylogeny using an expanded multigene plastid data set. Aliso 22:321.

Grass Phylogeny Working Group. 2001. Phylogeny and subfamilial classification of the grasses (Poaceae). Annals of the Missouri Botanical Garden 88:373-457.

Grass Phylogeny Working Group II. 2012. New grass phylogeny resolves deep evolutionary relationships and discovers C4 origins. New Phytologist 193:304-312. 10.1111/j.1469-8137.2011.03972.x

Guindon S, and Gascuel O. 2003. A simple, fast, and accurate algorithm to estimate large phylogenies by maximum likelihood. Systematic Biology 52:696-704. 10.1080/10635150390235520

Guo Y-L, and Ge S. 2005. Molecular phylogeny of Oryzeae (Poaceae) based on DNA sequences from chloroplast, mitochondrial, and nuclear genomes. American Journal of Botany 92:1548-1558. 10.3732/ajb.92.9.1548

Hand ML, Spangenberg GC, Forster JW, and Cogan NOI. 2013. Plastome sequence determination and comparative analysis for members of the Lolium-Festuca grass species complex. G3: Genes|Genomes|Genetics 3:607-616. 10.1534/g3.112.005264

Hawkins JS, Ramachandran D, Henderson A, Freeman J, Carlise M, Harris A, and Willison-Headley Z. 2015. Phylogenetic reconstruction using four low-copy nuclear loci strongly supports a polyphyletic origin of the genus Sorghum. Annals of Botany. 10.1093/aob/mcv097

Hilu KW, and Alice LA. 1999. Evolutionary implications of matK indels in Poaceae. American Journal of Botany 86:1735-1741. 10.2307/2656671

Hilu KW, and Alice LA. 2001. A phylogeny of Chloridoideae (Poaceae) based on matK Sequences. Systematic Botany 26:386-405. 10.1043/0363-6445-26.2.386

Hilu KW, Alice LA, and Liang H. 1999. Phylogeny of Poaceae inferred from matK sequences. Annals of the Missouri Botanical Garden 86:835-851. 10.2307/2666171

Hisamoto Y, Kashiwagi H, and Kobayashi M. 2008. Use of flowering gene FLOWERING LOCUS T (FT) homologs in the phylogenetic analysis of bambusoid and early diverging grasses. Journal of Plant Research 121:451. 10.1007/s10265-008-0181-9

Hochbach A, Schneider J, and Röser M. 2015. A multi-locus analysis of phylogenetic relationships within grass subfamily Pooideae (Poaceae) inferred from sequences of nuclear single copy gene regions 
1956

1957

1958

1959

1960

1961

1962

1963

1964

1965

1966

1967

1968

1969

1970

1971

1972

1973

1974

1975

1976

1977

1978

1979

1980

1981

1982

1983

1984

1985

1986

1987

1988

1989

1990

1991

1992

1993

1994

1995

1996

1997

1998

1999

2000

2001

2002

2003

2004

2005

compared with plastid DNA. Molecular Phylogenetics and Evolution 87:14-27.

10.1016/j.ympev.2015.03.010

Ibrahim DG, Burke T, Ripley BS, and Osborne CP. 2009. A molecular phylogeny of the genus Alloteropsis (Panicoideae, Poaceae) suggests an evolutionary reversion from $\mathrm{C} 4$ to $\mathrm{C} 3$ photosynthesis. Annals of Botany 103:127-136. 10.1093/aob/mcn204

Inda LA, Segarra-Moragues JG, Mueller J, Peterson PM, and Catalán P. 2008. Dated historical biogeography of the temperate Loliinae (Poaceae, Pooideae) grasses in the northern and southern hemispheres. Molecular Phylogenetics and Evolution 46:932-957. 10.1016/j.ympev.2007.11.022

International Brachypodium Initiative. 2010. Genome sequencing and analysis of the model grass Brachypodium distachyon. Nature 463:763-768. 10.1038/nature08747

Jones SS, Burke SV, and Duvall MR. 2014. Phylogenomics, molecular evolution, and estimated ages of lineages from the deep phylogeny of Poaceae. Plant Systematics and Evolution 300:1421-1436. 10.1007/s00606-013-0971-y

Katayama H, and Ogihara Y. 1996. Phylogenetic affinities of the grasses to other monocots as revealed by molecular analysis of chloroplast DNA. Current Genetics 29:572-581. 10.1007/BF02426962

Katoh K, and Standley DM. 2013. MAFFT multiple sequence alignment software version 7: improvements in performance and usability. Molecular Biology and Evolution 30:772-780. $10.1093 / \mathrm{molbev} / \mathrm{mst} 010$

Kearse M, Moir R, Wilson A, Stones-Havas S, Cheung M, Sturrock S, Buxton S, Cooper A, Markowitz S, Duran C, Thierer T, Ashton B, Meintjes P, and Drummond A. 2012. Geneious Basic: An integrated and extendable desktop software platform for the organization and analysis of sequence data. Bioinformatics 28:1647-1649. 10.1093/bioinformatics/bts199

Kelchner SA. 2013. Higher level phylogenetic relationships within the bamboos (Poaceae: Bambusoideae) based on five plastid markers. Molecular Phylogenetics and Evolution 67:404413. 10.1016/j.ympev.2013.02.005

Kellogg EA. 2012. Phylogenetic relationships of Saccharinae and Sorghinae. In: Paterson AH, ed. Genomics of the Saccharinae. Plant Genetics and Genomics: Crops and Models 11. Springer New York, 3-21.

Kellogg EA. 2015. Flowering Plants. Monocots: Poaceae. In: Kubitzki K, ed. The Families and Genera of Vascular Plants 13. Springer International Publishing.

Kellogg EA, Aliscioni SS, Morrone O, Pensiero J, and Zuloaga F. 2009. A phylogeny of Setaria (Poaceae, Panicoideae, Paniceae) and related genera based on the chloroplast gene $n d h F$. International Journal of Plant Sciences 170:117-131. doi:10.1086/593043

Kellogg EA, Camara PE, Rudall PJ, Ladd P, Malcomber ST, Whipple CJ, and Doust AN. 2013. Early inflorescence development in the grasses (Poaceae). Frontiers in Plant Science 4:250. 10.3389/fpls.2013.00250

Kim K, Lee SC, Lee J, Yu Y, Yang K, Choi BS, Koh HJ, Waminal NE, Choi HI, Kim NH, Jang W, Park HS, Lee J, Lee HO, Joh HJ, Lee HJ, Park JY, Perumal S, Jayakodi M, Lee YS, Kim B, Copetti D, Kim S, Kim S, Lim KB, Kim YD, Lee J, Cho KS, Park BS, Wing RA, and Yang TJ. 2015. Complete chloroplast and ribosomal sequences for 30 accessions elucidate evolution of Oryza AA genome species. Scientific Reports 5:15655. 10.1038/srep15655

Lee J, Kang Y, Shin SC, Park H, and Lee H. 2014. Combined analysis of the chloroplast genome and transcriptome of the Antarctic vascular plant Deschampsia antarctica Desv. PLOS ONE 9:e92501. 10.1371/journal.pone.0092501

Leseberg CH, and Duvall MR. 2009. The complete chloroplast genome of Coix lacryma-jobi and a comparative molecular evolutionary analysis of plastomes in cereals. Journal of Molecular Evolution 69:311-318. 10.1007/s00239-009-9275-9

Linder HP, Baeza M, Barker NP, Galley C, Humphreys AM, Lloyd KM, Orlovich DA, Pirie MD, Simon BK, Walsh N, and Verboom GA. 2010. A generic classification of the Danthonioideae (Poaceae). Annals of the Missouri Botanical Garden 97:306-364. 10.3417/2009006

PeerJ reviewing PDF | (2017:08:19682:2:0:NEW 4 Jan 2018) 
2006

2007

2008

2009

2010

2011

2012

2013

2014

2015

2016

2017

2018

2019

2020

2021

2022

2023

2024

2025

2026

2027

2028

2029

2030

2031

2032

2033

2034

2035

2036

2037

2038

2039

2040

2041

2042

2043

2044

2045

2046

2047

2048

2049

2050

2051

2052

2053

2054

2055

2056

Liu F, Tembrock LR, Sun C, Han G, Guo C, and Wu Z. 2016. The complete plastid genome of the wild rice species Oryza brachyantha (Poaceae). Mitochondrial DNA Part B: Resources 1:218-219. 10.1080/23802359.2016.1155093

Liu L, Yu L, and Edwards SV. 2010. A maximum pseudo-likelihood approach for estimating species trees under the coalescent model. BMC Evolutionary Biology 10:302. 10.1186/1471-2148-10-302

Liu Q, Liu H, Wen J, and Peterson PM. 2014. Infrageneric phylogeny and temporal divergence of Sorghum (Andropogoneae, Poaceae) based on low-copy nuclear and plastid sequences. PLOS ONE 9:e104933. 10.1371/journal.pone.0104933

Liu Y, Su X, Lv T, Liu T, and Chen K. 2017. Characterization of the complete chloroplast genome sequence of Littledalea racemosa Keng (Poaceae: Bromeae). Conservation Genetics Resources. 10.1007/s12686-017-0820-3

Lu D, Zhao Y, Han R, Wang L, and Qin P. 2016. The complete chloroplast genome sequence of the Purple Feathergrass Stipa purpurea (Poales: Poaceae). Conservation Genetics Resources 8:101104. 10.1007/s12686-016-0519-x

Lundgren MR, Besnard G, Ripley BS, Lehmann CE, Chatelet DS, Kynast RG, Namaganda M, Vorontsova MS, Hall RC, Elia J, Osborne CP, and Christin P-A. 2015. Photosynthetic innovation broadens the niche within a single species. Ecology Letters 18:1021-1029. 10.1111/ele.12484

Lundgren MR, Christin P-A, Escobar EG, Ripley BS, Besnard G, Long CM, Hattersley PW, Ellis RP, Leegood RC, and Osborne CP. 2016. Evolutionary implications of C3-C4 intermediates in the grass Alloteropsis semialata. Plant, Cell \& Environment 39:1874-1885.

Ma P-F, Zhang Y-X, Guo Z-H, and Li D-Z. 2015. Evidence for horizontal transfer of mitochondrial DNA to the plastid genome in a bamboo genus. Scientific Reports 5:11608. 10.1038/srep11608

Ma P-F, Zhang Y-X, Zeng C-X, Guo Z-H, and Li D-Z. 2014. Chloroplast phylogenomic analyses resolve deep-level relationships of an intractable bamboo tribe Arundinarieae (Poaceae). Systematic Biology 63:933-950. 10.1093/sysbio/syu054

Marchant AD, and Briggs BG. 2007. Ecdeiocoleaceae and Joinvilleaceae, sisters of Poaceae (Poales): evidence from matK data. Telopea 11:437-450. 10.7751/telopea20075743

Mariac C, Scarcelli N, Pouzadou J, Barnaud A, Billot C, Faye A, Kougbeadjo A, Maillol V, Martin G, Sabot F, Santoni S, Vigouroux Y, and Couvreur TLP. 2014. Cost-effective enrichment hybridization capture of chloroplast genomes at deep multiplexing levels for population genetics and phylogeography studies. Molecular Ecology Resources 14:1103-1113. 10.1111/17550998.12258

Mason-Gamer RJ. 2001. Origin of North American Elymus (Poaceae: Triticeae) allotetraploids based on granule-bound starch synthase gene sequences. Systematic Botany 26:757-768. 10.1043/03636445-26.4.757

Mason-Gamer RJ. 2005. The $\beta$-amylase genes of grasses and a phylogenetic analysis of the Triticeae (Poaceae). American Journal of Botany 92:1045-1058. 10.3732/ajb.92.6.1045

Mason-Gamer RJ, Orme NL, and Anderson CM. 2002. Phylogenetic analysis of North American Elymus and the monogenomic Triticeae (Poaceae) using three chloroplast DNA data sets. Genome 45:991-1002.

Mathews S, Spangler RE, Mason-Gamer RJ, and Kellogg EA. 2002. Phylogeny of Andropogoneae inferred from phytochrome B, GBSSI, and NDHF. International Journal of Plant Sciences 163:441-450.

Mathews S, Tsai RC, and Kellogg EA. 2000. Phylogenetic structure in the grass family (Poaceae): evidence from the nuclear gene phytochrome B. American Journal of Botany 87:96-107. $10.2307 / 2656688$

McTavish EJ, Steel M, and Holder MT. 2015. Twisted trees and inconsistency of tree estimation when gaps are treated as missing data - The impact of model mis-specification in distance corrections. Molecular Phylogenetics and Evolution 93:289-295. 10.1016/j.ympev.2015.07.027

Michelangeli FA, Davis JI, and Stevenson DW. 2003. Phylogenetic relationships among Poaceae and related families as inferred from morphology, inversions in the plastid genome, and sequence data

Peer] reviewing PDF | (2017:08:19682:2:0:NEW 4 Jan 2018) 
2057

2058

2059

2060

2061

2062

2063

2064

2065

2066

2067

2068

2069

2070

2071

2072

2073

2074

2075

2076

2077

2078

2079

2080

2081

2082

2083

2084

2085

2086

2087

2088

2089

2090

2091

2092

2093

2094

2095

2096

2097

2098

2099

2100

2101

2102

2103

2104

2105

2106

2107

from the mitochondrial and plastid genomes. American Journal of Botany 90:93-106. 10.3732/ajb.90.1.93

Middleton CP, Senerchia N, Stein N, Akhunov ED, Keller B, Wicker T, and Kilian B. 2014. Sequencing of chloroplast genomes from wheat, barley, rye and their relatives provides a detailed insight into the evolution of the Triticeae tribe. PLOS ONE 9:e85761. 10.1371/journal.pone.0085761

Miller MA, Pfeiffer W, and Schwartz T. 2010. Creating the CIPRES Science Gateway for inference of large phylogenetic trees. Proceedings of the Gateway Computing Environments Workshop (GCE), 14 Nov 2010, New Orleans, Louisiana. Washington, DC: IEEE, 1-8.

Minaya M, Díaz-Pérez A, Mason-Gamer R, Pimentel M, and Catalán P. 2015. Evolution of the betaamylase gene in the temperate grasses: Non-purifying selection, recombination, semiparalogy, homeology and phylogenetic signal. Molecular Phylogenetics and Evolution 91:68-85. 10.1016/j.ympev.2015.05.014

Morris LM, and Duvall MR. 2010. The chloroplast genome of Anomochloa marantoidea (Anomochlooideae; Poaceae) comprises a mixture of grass-like and unique features. American Journal of Botany 97:620-627. 10.3732/ajb.0900226

Morrone O, Aagesen L, Scataglini MA, Salariato DL, Denham SS, Chemisquy MA, Sede SM, Giussani LM, Kellogg EA, and Zuloaga FO. 2012. Phylogeny of the Paniceae (Poaceae: Panicoideae): integrating plastid DNA sequences and morphology into a new classification. Cladistics 28:333356. 10.1111/j.1096-0031.2011.00384.x

Morrone O, Aliscioni SS, Veldkamp JF, Pensiero JF, Zuloaga FO, and Kellogg EA. 2014. Revision of Old World species of Setaria (Poaceae: Panicoideae: Paniceae). Systematic Botany Monographs 96:1-161.

Murrell B, Wertheim JO, Moola S, Weighill T, Scheffler K, and Pond SLK. 2012. Detecting individual sites subject to episodic diversifying selection. PLoS Genetics 8(7):e1002764.

Myszczyński K, Nobis M, Szczecinska M, Sawicki J, and Nowak A. 2015. The complete plastid genome of the middle Asian endemic of Stipa lipskyi (Poaceae). Mitochondrial DNA Part A: DNA Mapping, Sequencing, and Analysis:1-2. 10.3109/19401736.2015.1106491

Nah G, Im J-H, Kim J-W, Kim K, Lim J, Choi AY, Choi I-Y, Yang T-J, Park T-S, Lee D, and Kim D-S. 2016. The complete chloroplast genomes of three Korean Echinochloa crus-galli accessions. Mitochondrial DNA Part A: DNA Mapping, Sequencing, and Analysis 27:4357-4358. 10.3109/19401736.2015.1089499

Nasernakhaei F, Rahiminejad MR, Saeidi H, and Tavassoli M. 2015. Phylogenetic relationships among the Iranian Triticum diploid gene pool as inferred from the loci Acc1 and Pgk1. Phytotaxa 201:111-121. 10.11646/phytotaxa.201.2.1

Nei M, and Kumar S. 2000. Molecular evolution and phylogenetics. New York: Oxford University Press.

Nock CJ, Waters DLE, Edwards MA, Bowen SG, Rice N, Cordeiro GM, and Henry RJ. 2011. Chloroplast genome sequences from total DNA for plant identification. Plant Biotechnology Journal 9:328-333. 10.1111/j.1467-7652.2010.00558.x

Oliveira RP, Clark LG, Schnadelbach AS, Monteiro SHN, Borba EL, Longhi-Wagner HM, and van den Berg C. 2014. A molecular phylogeny of Raddia and its allies within the tribe Olyreae (Poaceae, Bambusoideae) based on noncoding plastid and nuclear spacers. Molecular Phylogenetics and Evolution 78:105-117. 10.1016/j.ympev.2014.04.012

Orton LM, Burke SV, Wysocki WP, and Duvall MR. 2016. Plastid phylogenomic study of species within the genus Zea: rates and patterns of three classes of microstructural changes. Current Genetics:113. 10.1007/s00294-016-0637-8

Peng Z, Zhang C, Zhang Y, Hu T, and Mu S. 2013. Transcriptome sequencing and analysis of the fast growing shoots of Moso bamboo (Phyllostachys edulis). PLOS ONE 8. 10.1371/journal.pone.0078944

Persson NL, and Rydin C. 2016. Phylogenetic relationships of the 'Briza complex' to other members of the subfamily Pooideae (Poaceae). Plant Ecology and Evolution 149:216-227.

10.5091/plecevo.2016.1194

Peer) reviewing PDF | (2017:08:19682:2:0:NEW 4 Jan 2018) 
2108

2109

2110

2111

2112

2113

2114

2115

2116

2117

2118

2119

2120

2121

2122

2123

2124

2125

2126

2127

2128

2129

2130

2131

2132

2133

2134

2135

2136

2137

2138

2139

2140

2141

2142

2143

2144

2145

2146

2147

2148

2149

2150

2151

2152

2153

2154

2155

2156

2157
Perumal S, Jayakodi M, Kim D-S, Yang T-j, and Natesan S. 2016. The complete chloroplast genome sequence of Indian barnyard millet, Echinochloa frumentacea (Poaceae). Mitochondrial DNA Part B: Resources 1:79-80. 10.1080/23802359.2015.1137832

Petersen G, and Seberg O. 1997. Phylogenetic analysis of the Triticeae (Poaceae) based on rpoA sequence data. Molecular Phylogenetics and Evolution 7:217-230. 10.1006/mpev.1996.0389

Petersen G, and Seberg O. 2002. Molecular evolution and phylogenetic application of DMC1. Molecular Phylogenetics and Evolution 22:43-50. 10.1006/mpev.2001.1011

Petersen G, Seberg O, Yde M, and Berthelsen K. 2006. Phylogenetic relationships of Triticum and Aegilops and evidence for the origin of the A, B, and D genomes of common wheat (Triticum aestivum). Molecular Phylogenetics and Evolution 39:70-82. 10.1016/j.ympev.2006.01.023

Peterson PM, Romaschenko K, and Arrieta YH. 2014a. A molecular phylogeny and classification of the Cteniinae, Farragininae, Gouiniinae, Gymnopogoninae, Perotidinae, and Trichoneurinae (Poaceae: Chloridoideae: Cynodonteae). Taxon 63:275-286. 10.12705/632.35

Peterson PM, Romaschenko K, and Arrieta YH. 2015. A molecular phylogeny and classification of the Eleusininae with a new genus, Micrachne (Poaceae: Chloridoideae: Cynodonteae). Taxon 64:445-467. 10.12705/643.5

Peterson PM, Romaschenko K, Arrieta YH, and Saarela JM. 2014b. (2332) Proposal to conserve the name Sporobolus against Spartina, Crypsis, Ponceletia, and Heleochloa (Poaceae: Chloridoideae: Sporobolinae). Taxon 63:1373-1374. 10.12705/636.23

Peterson PM, Romaschenko K, Arrieta YH, and Saarela JM. 2014c. A molecular phylogeny and new subgeneric classification of Sporobolus (Poaceae: Chloridoideae: Sporobolinae). Taxon 63:12121243. $10.12705 / 636.19$

Peterson PM, Romaschenko K, Barker NP, and Linder HP. 2011. Centropodieae and Ellisochloa, a new tribe and genus in Chloridoideae (Poaceae). Taxon 60:1113-1122.

Peterson PM, Romaschenko K, and Herrera Arrieta Y. 2016. A molecular phylogeny and classification of the Cynodonteae (Poaceae: Chloridoideae) with four new genera: Orthacanthus, Triplasiella, Tripogonella, and Zaqiqah; three new subtribes: Dactylocteniinae, Orininae, and Zaqiqahinae; and a subgeneric classification of Distichlis. Taxon 65:1263-1287. 10.12705/656.4

Peterson PM, Romaschenko K, and Herrera Arrieta Y. 2017a. Four new subtribes: Allolepiinae, Jouveinae, Kaliniinae, and Sohnsiinae in the Cynodonteae (Poaceae: Chloridoideae). Phytoneuron 2017-44:1-9.

Peterson PM, Romaschenko K, Herrera Arrieta Y, and Saarela JM. 2017b. Molecular phylogeny of the subtribe Sporobolinae and a classification of the subfamily Chloridoideae (Poaceae). Memoirs of the New York Botanical Garden 118:127-151. 10.21135/893275341.003

Peterson PM, Romaschenko K, and Johnson G. 2010. A classification of the Chloridoideae (Poaceae) based on multi-gene phylogenetic trees. Molecular Phylogenetics and Evolution 55:580-598. 10.1016/j.ympev.2010.01.018

Pimentel M, Escudero M, Sahuquillo E, Minaya MÁ, and Catalán P. 2017. Are diversification rates and chromosome evolution in the temperate grasses (Pooideae) associated with major environmental changes in the Oligocene-Miocene? PeerJ 5:e3815. 10.7717/peerj.3815

Piot A, Hackel J, Christin P-A, and Besnard G. 2017. One-third of the plastid genes evolved under positive selection in PACMAD grasses. Planta. 10.1007/s00425-017-2781-x

Pond SLK, and Frost SDW. 2005. Datamonkey: rapid detection of selective pressure on individual sites of codon alignments. Bioinformatics 21:2531-2533. 10.1093/bioinformatics/bti320

Quintanar A, Castroviejo S, and Catalán P. 2007. Phylogeny of the tribe Aveneae (Pooideae, Poaceae) inferred from plastid trnT-F and nuclear ITS sequences. American Journal of Botany 94:1554 1569. 10.3732/ajb.94.9.1554

Rodríguez-Ezpeleta N, Brinkmann H, Roure B, Lartillot N, Lang BF, and Philippe H. 2007. Detecting and overcoming systematic errors in genome-scale phylogenies. Systematic Biology 56:389-399. $10.1080 / 10635150701397643$ 
2158

2159

2160

2161

2162

2163

2164

2165

2166

2167

2168

2169

2170

2171

2172

2173

2174

2175

2176

2177

2178

2179

2180

2181

2182

2183

2184

2185

2186

2187

2188

2189

2190

2191

2192

2193

2194

2195

2196

2197

2198

2199

2200

2201

2202

2203

2204

2205

2206

2207

2208

Romaschenko K, Garcia-Jacas N, Peterson PM, Soreng RJ, Vilatersana R, and Susanna A. 2014. Miocene-Pliocene speciation, introgression, and migration of Patis and Ptilagrostis (Poaceae: Stipeae). Molecular Phylogenetics and Evolution 70:244-259. 10.1016/j.ympev.2013.09.018

Romaschenko K, Peterson PM, Soreng RJ, Garcia-Jacas N, Futorna O, and Susanna A. 2012. Systematics and evolution of the needle grasses (Poaceae: Pooideae: Stipeae) based on analysis of multiple chloroplast loci, ITS, and lemma micromorphology. Taxon 61:18-44.

Roure B, Baurain D, and Philippe H. 2013. Impact of missing data on phylogenies inferred from empirical phylogenomic data sets. Molecular Biology and Evolution 30:197-214. $10.1093 / \mathrm{molbev} / \mathrm{mss} 208$

Rousseau-Gueutin M, Bellot S, Martin GE, Boutte J, Chelaifa H, Lima O, Michon-Coudouel S, Naquin D, Salmon A, Ainouche K, and Ainouche M. 2015. The chloroplast genome of the hexaploid Spartina maritima (Poaceae, Chloridoideae): Comparative analyses and molecular dating. Molecular Phylogenetics and Evolution 93:5-16. 10.1016/j.ympev.2015.06.013

Ruiz-Sanchez E, Sosa V, and Mejia-Saules MT. 2011. Molecular phylogenetics of the Mesoamerican bamboo Olmeca (Poaceae, Bambuseae): Implications for taxonomy. Taxon 60:89-98.

Saarela JM, Bull RD, Paradis MJ, Ebata SN, Peterson PM, Soreng RJ, and Paszko B. 2017. Molecular phylogenetics of cool-season grasses in the subtribes Agrostidinae, Anthoxanthinae, Aveninae, Brizinae, Calothecinae, Koeleriinae and Phalaridinae (Poaceae: Pooideae: Poeae: Poeae chloroplast group 1). Phytokeys 87:1-139. 10.3897/phytokeys.87.12774.

Saarela JM, and Graham SW. 2010. Inference of phylogenetic relationships among the subfamilies of grasses (Poaceae: Poales) using meso-scale exemplar-based sampling of the plastid genome. Botany 88:65-84. 10.1139/B09-093

Saarela JM, Liu Q, Peterson PM, Soreng RJ, and Paszko B. 2010. Phylogenetics of the grass 'Aveneaetype plastid DNA clade' (Poaceae: Pooideae, Poeae) based on plastid and nuclear ribosomal DNA sequence data. In: Seberg O, Petersen G, Barfod A, and Davis JI, eds. Diversity, phylogeny, and evolution in the monocotyledons. Aarhus: Aarhus University Press, 557-587.

Saarela JM, Wysocki WP, Barrett CF, Soreng RJ, Davis JI, Clark LG, Kelchner SA, Pires JC, Edger PP, Mayfield DR, and Duvall MR. 2015. Plastid phylogenomics of the cool-season grass subfamily: clarification of relationships among early-diverging tribes. AoB Plants 7:plv046. 10.1093/aobpla/plv046

Sánchez-Ken G, and Clark LG. 2007. Phylogenetic relationships within the Centothecoideae + Panicoideae clade (Poaceae) based on $n d h F$ intron sequences and structural data. Aliso 23:487502. 10.5642/aliso.20072301.38

Sánchez-Ken JG, and Clark LG. 2010. Phylogeny and a new tribal classification of the Panicoideae s.1. (Poaceae) based on plastid and nuclear sequence data and structural data. American Journal of Botany 97:1732-1748. 10.3732/ajb.1000024

Sánchez-Ken JG, Clark LG, Kellogg EA, and Kay EE. 2007. Reinstatement and emendation of subfamily Micrairoideae (Poaceae). Systematic Botany 32:71-80.

Sancho R, Cantalapiedra CP, Lopez-Alvarez D, Gordon SP, Vogel JP, Catalan P, and Contreras-Moreira B. 2017. Comparative plastome genomics and phylogenomics of Brachypodium: flowering time signatures, introgression and recombination in recently diverged ecotypes. New Phytologist. $10.1111 /$ nph.14926

Saski C, Lee S-B, Fjellheim S, Guda C, Jansen R, Luo H, Tomkins J, Rognli O, Daniell H, and Clarke J. 2007. Complete chloroplast genome sequences of Hordeum vulgare, Sorghum bicolor and Agrostis stolonifera, and comparative analyses with other grass genomes. TAG Theoretical and Applied Genetics 115:571-590. 10.1007/s00122-007-0595-0

Schaefer H, Hardy OJ, Silva L, Barraclough TG, and Savolainen V. 2011. Testing Darwin's naturalization hypothesis in the Azores. Ecology Letters 14:389-396. 10.1111/j.14610248.2011.01600.x

Schneider J, Winterfeld G, Hoffmann MH, and Röser M. 2011. Duthieeae, a new tribe of grasses (Poaceae) identified among the early diverging lineages of subfamily Pooideae: molecular

PeerJ reviewing PDF | (2017:08:19682:2:0:NEW 4 Jan 2018) 
2209

2210

2211

2212

2213

2214

2215

2216

2217

2218

2219

2220

2221

2222

2223

2224

2225

2226

2227

2228

2229

2230

2231

2232

2233

2234

2235

2236

2237

2238

2239

2240

2241

2242

2243

2244

2245

2246

2247

2248

2249

2250

2251

2252

2253

2254

2255

2256

2257

phylogenetics, morphological delineation, cytogenetics and biogeography. Systematics and Biodiversity 9:27-44. 10.1080/14772000.2010.544339

Schneider J, Winterfeld G, and Röser M. 2012. Polyphyly of the grass tribe Hainardieae (Poaceae: Pooideae): identification of its different lineages based on molecular phylogenetics, including morphological and cytogenetic characteristics. Organisms Diversity \& Evolution 12:113-132. $10.1007 / \mathrm{s} 13127-012-0077-3$

Seberg O, and Petersen G. 2007. Phylogeny of Triticeae (Poaceae) based on three organelle genes, two single-copy nuclear genes, and morphology. Aliso: A Journal of Systematic and Evolutionary Botany 23:362-371. 10.5642/aliso.20072301.29

Shavit Grievink L, Penny D, and Holland BR. 2013. Missing data and influential sites: Choice of sites for phylogenetic analysis can be as important as taxon sampling and model choice. Genome Biology and Evolution 5:681-687. 10.1093/gbe/evt032

Silva C, Besnard G, Piot A, Razanatsoa J, Oliveira RP, and Vorontsova MS. 2017. Museomics resolve the systematics of an endangered grass lineage endemic to north-western Madagascar. Annals of Botany 119:339-351. 10.1093/aob/mcw208

Skendzic EM, Columbus JT, and Cerros-Tlatilpa R. 2007. Phylogenetics of Andropogoneae (Poaceae: Panicoideae) based on nuclear ribosomal internal transcribed spacer and chloroplast $\operatorname{trn} L-F$ sequences. Aliso 23:530-544.

Soderstrom TR, and Judziewicz EJ. 1987. Systematics of the Amphi-Atlantic bambusoid genus Streptogyna (Poaceae). Annals of the Missouri Botanical Garden 74:871-888. 10.2307/2399454

Soreng RJ, and Davis JI. 1998. Phylogenetics and character evolution in the grass family: Simultaneous analysis of morphological and chloroplast DNA restriction site character sets. The Botanical Review 64:1-85. 10.1007/BF02868851

Soreng RJ, and Davis JI. 2000. Phylogenetic structure in Poaceae subfamily Pooideae as inferred from molecular and morphological characters: misclassification versus reticulation. In: Jacobs SWL, and Everett J, eds. Grasses: Systematics and Evolution. Collingwood, Victoria, Australia: CSIRO, 61-74.

Soreng RJ, Davis JI, and Voionmaa MA. 2007. A phylogenetic analysis of Poeae sensu lato based on morphological characters and sequence data from three plastid-encoded genes: evidence for reticulation, and a new classification for the tribe. Kew Bulletin 62:425-454.

Soreng RJ, Gillespie LJ, Koba H, Boudko E, and Bull RD. 2015a. Molecular and morphological evidence for a new grass genus, Dupontiopsis (Poaceae tribe Poeae subtribe Poinae s.1.), endemic to alpine Japan, and implications for the reticulate origin of Dupontia and Arctophila within Poinae s.1. Journal of Systematics and Evolution 53:138-162. 10.1111/jse.12146

Soreng RJ, Peterson PM, Romaschenko K, Davidse G, Teisher JK, Clark LG, Barberá P, Gillespie LJ, and Zuloaga FO. 2017. A worldwide phylogenetic classification of the Poaceae (Gramineae) II. An update and comparison of two 2015 classifications. Journal of Systematics and Evolution 55:259-290. 10.1111/jse.12262

Soreng RJ, Peterson PM, Romaschenko K, Davidse G, Zuloaga FO, Judziewicz EJ, Filgueiras TS, Davis J, and Morrone O. 2015b. A worldwide phylogenetic classification of the Poaceae (Gramineae). Journal of Systematics and Evolution 53:117-137. 10.1111/jse.12150

Stamatakis A. 2014. RAxML Version 8: A tool for phylogenetic analysis and post-analysis of large phylogenies. Bioinformatics 30:1312-1313. 10.1093/bioinformatics/btu033

Sungkaew S, Stapleton CMA, Salamin N, and Hodkinson TR. 2008. Non-monophyly of the woody bamboos (Bambuseae; Poaceae): a multi-gene region phylogenetic analysis of Bambusoideae s.s. Journal of Plant Research 122:95-108. 10.1007/s10265-008-0192-6

Sungkaew S, Stapleton CMA, Salamin N, and Hodkinson TR. 2009. Non-monophyly of the woody bamboos (Bambuseae; Poaceae): a multi-gene region phylogenetic analysis of Bambusoideae s.s. Journal of Plant Research 122:95-108. 10.1007/s10265-008-0192-6

PeerJ reviewing PDF | (2017:08:19682:2:0:NEW 4 Jan 2018) 
2258

2259

2260

2261

2262

2263

2264

2265

2266

2267

2268

2269

2270

2271

2272

2273

2274

2275

2276

2277

2278

2279

2280

2281

2282

2283

2284

2285

2286

2287

2288

2289

2290

2291

2292

2293

2294

2295

2296

2297

2298

2299

2300

2301

2302

2303

2304

2305

2306

2307

Tamura K, Stecher G, Peterson D, Filipski A, and Kumar S. 2013. MEGA6: Molecular Evolutionary Genetics Analysis Version 6.0. Molecular Biology and Evolution 30:2725-2729. 10.1093/molbev/mst197

Tang L, Zou X-H, Achoundong G, Potgieter C, Second G, Zhang D-Y, and Ge S. 2010. Phylogeny and biogeography of the rice tribe (Oryzeae): Evidence from combined analysis of 20 chloroplast fragments. Molecular Phylogenetics and Evolution 54:266-277. 10.1016/j.ympev.2009.08.007

Tang L, Zou X-H, Zhang L-B, and Ge S. 2015. Multilocus species tree analyses resolve the ancient radiation of the subtribe Zizaniinae (Poaceae). Molecular Phylogenetics and Evolution 84:232239. 10.1016/j.ympev.2015.01.011

Teerawatananon A, Jacobs SWL, and Hodkinson TR. 2011. Phylogenetics of Panicoideae (Poaceae) based on chloroplast and nuclear DNA sequences. Telopea 13:115-142. 10.7751/telopea20116009

Teisher JK, McKain MR, Schaal BA, and Kellogg EA. 2017. Polyphyly of Arundinoideae (Poaceae) and evolution of the twisted geniculate lemma awn. Annals of Botany. 10.1093/aob/mcx058

Tonti-Filippini J, Nevill PG, Dixon K, and Small I. 2017. What can we do with 1000 plastid genomes? The Plant Journal. 10.1111/tpj.13491

Toon A, Crisp MD, Gamage H, Mant J, Morris DC, Schmidt S, and Cook LG. 2015. Key innovation or adaptive change? A test of leaf traits using Triodiinae in Australia. Scientific Reports 5:12398. $10.1038 /$ srep 12398

Triplett JK, and Clark LG. 2010. Phylogeny of the temperate bamboos (Poaceae: Bambusoideae: Bambuseae) with an emphasis on Arundinaria and allies. Systematic Botany 35:102-120. 10.1600/036364410790862678

Triplett JK, Clark LG, Fisher AE, and Wen J. 2014. Independent allopolyploidization events preceded speciation in the temperate and tropical woody bamboos. New Phytologist 204:66-73. $10.1111 / \mathrm{nph} .12988$

Truszkowski J, and Goldman N. 2016. Maximum likelihood phylogenetic inference is consistent on multiple sequence alignments, with or without gaps. Systematic Biology 65:328-333. 10.1093/sysbio/syv089

Veldkamp JF. 1994. Miscellaneous notes on southeast Asian Gramineae. IX Setaria and Paspalidium. Blumea 39:373-384.

Verboom GA, Linder HP, Stock WD, and Baum D. 2003. Phylogenetics of the grass genus Ehrharta: Evidence for radiation in the summer-arid zone of the South African cape. Evolution 57:10081021. 10.1554/0014-3820(2003)057[1008:POTGGE]2.0.CO;2

Vicentini A, Barber JC, Aliscioni SS, Giussani LM, and Kellogg EA. 2008. The age of the grasses and clusters of origins of C-4 photosynthesis. Global Change Biology 14:2963-2977. 10.1111/j.13652486.2008.01688.x

Vieira LdN, dos Anjos KG, Faoro H, Fraga HPdF, Greco TM, Pedrosa FdO, de Souza EM, Rogalski M, de Souza RF, and Guerra MP. 2016. Phylogenetic inference and SSR characterization of tropical woody bamboos tribe Bambuseae (Poaceae: Bambusoideae) based on complete plastid genome sequences. Current Genetics 62:443-453. 10.1007/s00294-015-0549-z

Vorontsova MS, Besnard G, Forest F, Malakasi P, Moat J, Clayton WD, Ficinski P, Savva GM, Nanjarisoa OP, Razanatsoa J, Randriatsara FO, Kimeu JM, Luke WRQ, Kayombo C, and Linder HP. 2016. Madagascar's grasses and grasslands: anthropogenic or natural? Proceedings of the Royal Society of London B: Biological Sciences 283. 10.1098/rspb.2015.2262

Wambugu PW, Brozynska M, Furtado A, Waters DL, and Henry RJ. 2015. Relationships of wild and domesticated rices (Oryza AA genome species) based upon whole chloroplast genome sequences. Scientific Reports 5:13957. 10.1038/srep13957

Wang S, and Gao L-Z. 2015. The complete chloroplast genome of an irreplaceable dietary and model crop, foxtail millet (Setaria italica). Mitochondrial DNA Part A: DNA Mapping, Sequencing, and Analysis:1-2. 10.3109/19401736.2015.1089562

PeerJ reviewing PDF | (2017:08:19682:2:0:NEW 4 Jan 2018) 
2308

2309

2310

2311

2312

2313

2314

2315

2316

2317

2318

2319

2320

2321

2322

2323

2324

2325

2326

2327

2328

2329

2330

2331

2332

2333

2334

2335

2336

2337

2338

2339

2340

2341

2342

2343

2344

2345

2346

2347

2348

2349

2350

2351

2352

2353

2354

2355

2356

2357

2358

Wang S, and Gao L-Z. 2016. Complete chloroplast genome sequence of green foxtail (Setaria viridis), a promising model system for C4 photosynthesis. Mitochondrial DNA Part A: DNA Mapping, Sequencing, and Analysis 27:3707-3708. 10.3109/19401736.2015.1079867

Warnow T. 2012. Standard maximum likelihood analyses of alignments with gaps can be statistically inconsistent. PLoS Currents: Tree of Life 4:RRN1308. 10.1371/currents.RRN1308

Washburn JD, Schnable JC, Davidse G, and Pires JC. 2015. Phylogeny and photosynthesis of the grass tribe Paniceae. American Journal of Botany 102:1493-1505. 10.3732/ajb.1500222

Waters DLE, Nock CJ, Ishikawa R, Rice N, and Henry RJ. 2012. Chloroplast genome sequence confirms distinctness of Australian and Asian wild rice. Ecology and Evolution 2:211-217. 10.1002/ece3.66

Webster RD. 1993. Nomenclature of Setaria (Poaceae: Paniceae). Sida 15:447-489.

Webster RD. 1995. Nomenclatural changes in Setaria and Paspalidium (poaceae: Paniceae). Sida 16:439-446.

Wu F-H, Kan D-P, Lee S-B, Daniell H, Lee Y-W, Lin C-C, Lin N-S, and Lin C-S. 2009. Complete nucleotide sequence of Dendrocalamus latiflorus and Bambusa oldhamii chloroplast genomes. Tree Physiology 29:847-856. 10.1093/treephys/tpp015

Wu M, Lan S, Cai B, Chen S, Chen H, and Zhou S. 2015. The complete chloroplast genome of Guadua angustifolia and comparative analyses of neotropical-paleotropical bamboos. PLOS ONE 10:e0143792. 10.1371/journal.pone.0143792

Wu Z-Q, and Ge S. 2012. The phylogeny of the BEP clade in grasses revisited: Evidence from the wholegenome sequences of chloroplasts. Molecular Phylogenetics and Evolution 62:573-578. 10.1016/j.ympev.2011.10.019

$\mathrm{Wu} \mathrm{Z}$, and Ge S. 2016. The whole chloroplast genome of wild rice (Oryza australiensis). Mitochondrial DNA Part A: DNA Mapping, Sequencing, and Analysis 27:1062-1063. 10.3109/19401736.2014.928868

Wysocki WP, Burke SV, Swingley WD, and Duvall MR. 2016a. The first complete plastid genome from Joinvilleaceae (J. ascendens; Poales) shows unique and unpredicted rearrangements. PLOS ONE 11:e0163218. 10.1371/journal.pone.0163218

Wysocki WP, Clark LG, Attigala L, Ruiz-Sanchez E, and Duvall MR. 2015. Evolution of the bamboos (Bambusoideae; Poaceae): a full plastome phylogenomic analysis. BMC Evolutionary Biology 15:50. 10.1186/s12862-015-0321-5

Wysocki WP, Clark LG, Kelchner SA, Burke SV, Pires JC, Edger PP, Mayfield DR, Triplett JK, Columbus JT, Ingram AL, and Duvall MR. 2014. A multi-step comparison of short-read full plastome sequence assembly methods in grasses. Taxon 63:899-910. 10.12705/634.5

Wysocki WP, Ruiz-Sanchez E, Yin Y, and Duvall MR. 2016b. The floral transcriptomes of four bamboo species (Bambusoideae; Poaceae): support for common ancestry among woody bamboos. BMC Genomics 17:384. 10.1186/s12864-016-2707-1

Yang HM, Zhang YX, Yang JB, and Li DZ. 2013. The monophyly of Chimonocalamus and conflicting gene trees in Arundinarieae (Poaceae: Bambusoideae) inferred from four plastid and two nuclear markers. Molecular Phylogenetics and Evolution 68:340-356. 10.1016/j.ympev.2013.04.002

Yang HQ, Yang JB, Peng ZH, Gao J, Yang YM, Peng S, and Li DZ. 2008. A molecular phylogenetic and fruit evolutionary analysis of the major groups of the paleotropical woody bamboos (Gramineae: Bambusoideae) based on nuclear ITS, GBSSI gene and plastid trnL-F DNA sequences. Molecular Phylogenetics and Evolution 48:809-824. 10.1016/j.ympev.2008.06.001

Ye C-Y, Lin Z, Li G, Wang Y-Y, Qiu J, Fu F, Zhang H, Chen L, Ye S, Song W, Jin G, Zhu J, Lu Y, Guo L, and Fan L. 2014. Echinochloa chloroplast genomes: Insights into the evolution and taxonomic identification of two weedy species. PLOS ONE 9:e113657. 10.1371/journal.pone.0113657

Young HA, Lanzatella CL, Sarath G, and Tobias CM. 2011. Chloroplast genome variation in upland and lowland switchgrass. PLOS ONE 6:e23980. 10.1371/journal.pone.0023980

Zeng C-X, Zhang Y-X, Triplett JK, Yang J-B, and Li D-Z. 2010. Large multi-locus plastid phylogeny of the tribe Arundinarieae (Poaceae: Bambusoideae) reveals ten major lineages and low rate of

PeerJ reviewing PDF | (2017:08:19682:2:0:NEW 4 Jan 2018) 
2359

2360

2361

2362

2363

2364

2365

2366

2367

2368

2369

2370

2371

2372

2373

2374

2375

2376

2377

2378

2379

2380

2381

2382

2383

2384

2385

2386

2387

2388

2389

2390

2391

2392

2393

2394

2395

2396

2397

2398

2399

molecular divergence. Molecular Phylogenetics and Evolution 56:821-839.

10.1016/j.ympev.2010.03.041

Zerbino DR, and Birney E. 2008. Velvet: Algorithms for de novo short read assembly using de Bruijn graphs. Genome Research 18:821-829. 10.1101/gr.074492.107

Zhang D, Li K, Gao J, Liu Y, and Gao L-Z. 2016a. The complete plastid genome sequence of the wild rice Zizania latifolia and comparative chloroplast genomics of the rice tribe Oryzeae, Poaceae. Frontiers in Ecology and Evolution 4:88. 10.3389/fevo.2016.00088

Zhang J, Zhang D, Shi C, Gao J, and Gao L-z. 2016b. The complete chloroplast genome sequence of Chikusichloa aquatica (Poaceae: Oryzeae). Mitochondrial DNA Part A: DNA Mapping, Sequencing, and Analysis 27:2771-2772. 10.3109/19401736.2015.1053058

Zhang W. 2000. Phylogeny of the grass family (Poaceae) from rpll6 intron sequence data. Molecular Phylogenetics and Evolution 15:135-146. 10.1006/mpev.1999.0729

Zhang X-Z, and Chen S-Y. 2016. Genome skimming reveals the complete chloroplast genome of Ampelocalamus naibunensis (Poaceae: Bambusoideae: Arundinarieae) with phylogenomic implication. Mitochondrial DNA Part B: Resources 1:635-637. 10.1080/23802359.2016.1214550

Zhang X-Z, Zeng C-X, Ma P-F, Haevermans T, Zhang Y-X, Zhang L-N, Guo Z-H, and Li D-Z. 2016c. Multi-locus plastid phylogenetic biogeography supports the Asian hypothesis of the temperate woody bamboos (Poaceae: Bambusoideae). Molecular Phylogenetics and Evolution 96:118-129. 10.1016/j.ympev.2015.11.025

Zhang Y-J, Ma P-F, and Li D-Z. 2011. High-throughput sequencing of six bamboo chloroplast genomes: Phylogenetic implications for temperate woody bamboos (Poaceae: Bambusoideae). PLOS ONE 6:e20596.

Zhang Y-X, Zeng C-X, and Li D-Z. 2012. Complex evolution in Arundinarieae (Poaceae: Bambusoideae): Incongruence between plastid and nuclear GBSSI gene phylogenies. Molecular Phylogenetics and Evolution 63:777-797. 10.1016/j.ympev.2012.02.023

Zhao L, Zhang N, Ma P-F, Liu Q, Li D-Z, and Guo Z-H. 2013. Phylogenomic analyses of nuclear genes reveal the evolutionary relationships within the BEP clade and the evidence of positive selection in Poaceae. PLOS ONE 8:e64642. 10.1371/journal.pone.0064642

Zhou M-Y, Zhang Y-X, Haevermans T, and Li D-Z. 2017. Towards a complete generic-level plastid phylogeny of the paleotropical woody bamboos (Poaceae: Bambusoideae). Taxon 66:539-553. $10.12705 / 663.2$

Zhou M, An M, Xia X, Yang H, Cheng M, Wang K, and Fang W. 2016. Sequencing and phylogenetic analysis of the chloroplast genome of Pseudosasa japonica f. Akebonosuji. Biochemical Systematics and Ecology 69:41-50. 10.1016/j.bse.2016.08.002

Zuloaga FO, Salomón L, and Scataglini MA. 2014. Phylogeny of sections Clavelligerae and Pectinatae of Panicum (Poaceae, Panicoideae, Paniceae): establishment of the new subtribe Dichantheliinae and the genus Adenochloa. Plant Systematics and Evolution 301:1693-1711. 10.1007/s00606014-1186-6 


\section{Table $\mathbf{1}$ (on next page)}

Vouchers (standard herbarium codes are used) or seed sources of plant material for 15 new plastomes, GenBank accession numbers, and other sequencing and assembly details.

$\mathrm{PI}=$ Plant Introduction number and W6 = West Regional PI group, U.S. National Plant Germplasm System (https://npgsweb.ars-grin.gov/); MSB = Millenium Seed Bank, Kew (apps.kew.org/seedlist/SeedlistServlet). 


\begin{tabular}{|c|c|c|c|c|c|c|}
\hline Species & $\begin{array}{l}\text { GenBank accession } \\
\text { number }\end{array}$ & $\begin{array}{l}\text { Voucher/seed } \\
\text { source }\end{array}$ & $\begin{array}{l}\text { Single end } \\
\text { library prep. } \\
\text { method }\end{array}$ & Mode & Assembler & $\begin{array}{l}\text { Annotation } \\
\text { Reference }\end{array}$ \\
\hline Agrostis gigantea Roth & MF460976 & PI 619538 & Nextera & $\begin{array}{l}\text { High } \\
\text { Output }\end{array}$ & $\begin{array}{l}\text { Iterative } \\
\text { Velvet }\end{array}$ & NC_027468 \\
\hline $\begin{array}{l}\text { Alopecurus arundinaceus } \\
\text { Poir. }\end{array}$ & MF460977 & PI 380664 & Nextera & $\begin{array}{l}\text { High } \\
\text { Output }\end{array}$ & $\begin{array}{l}\text { Iterative } \\
\text { Velvet }\end{array}$ & NC_027468 \\
\hline Aristida ternipes Cav. & MF460978 & MSB 98474 & Nextera XT & $\begin{array}{l}\text { Rapid } \\
\text { Mode }\end{array}$ & SPAdes & NC_025228 \\
\hline $\begin{array}{l}\text { Connorochloa tenuis } \\
\text { (Buchanan) Barkworth, } \\
\text { S.W.L. Jacobs \& H.Q. } \\
\text { Zhang }\end{array}$ & MF460979 & PI 531685 & Nextera XT & $\begin{array}{l}\text { Rapid } \\
\text { Mode }\end{array}$ & SPAdes & NC_021761 \\
\hline $\begin{array}{l}\text { Drepanostachyum } \\
\text { falcatum (Nees) Keng f. }\end{array}$ & MF460981 & L. Clark 1756 (ISC) & Nextera & $\begin{array}{l}\text { High } \\
\text { Output }\end{array}$ & $\begin{array}{l}\text { Iterative } \\
\text { Velvet }\end{array}$ & NC_024725 \\
\hline Lamarckia aurea (L.) & MF460982 & PI 378959 & Nextera XT & Rapid & SPAdes & NC_027437 \\
\hline
\end{tabular}




\begin{tabular}{|c|c|c|c|c|c|c|}
\hline Moench & & & & Mode & & 3 \\
\hline $\begin{array}{l}\text { Leptochloa pluriflora (E. } \\
\text { Fourn.) P.M. Peterson \& } \\
\text { N. Snow }\end{array}$ & MF460983 & PI 337598 & Nextera XT & $\begin{array}{l}\text { Rapid } \\
\text { Mode }\end{array}$ & SPAdes & NC_027650 \\
\hline $\begin{array}{l}\text { Oxychloris scariosa (F. } \\
\text { Muell.) Lazarides }\end{array}$ & MF460971 & PI 238262 & Nextera XT & $\begin{array}{l}\text { Rapid } \\
\text { Mode }\end{array}$ & SPAdes & NC_024262 \\
\hline $\begin{array}{l}\text { Prosphytochloa } \\
\text { prehensilis (Nees) } \\
\text { Schweick. }\end{array}$ & MF460972 & $\begin{array}{l}\text { G. Guala } 1689 \\
\text { (ISC) }\end{array}$ & Nextera & $\begin{array}{l}\text { High } \\
\text { Output }\end{array}$ & $\begin{array}{l}\text { Iterative } \\
\text { Velvet }\end{array}$ & NC_026967 \\
\hline $\begin{array}{l}\text { Rytidosperma pallidum } \\
\text { (R. Br.) A.M. Humphreys } \\
\text { \& H.P. Linder }\end{array}$ & MF460980 & $\begin{array}{l}\text { P. Linder } 5664 \\
(\mathrm{BOL})\end{array}$ & Nextera & $\begin{array}{l}\text { High } \\
\text { Output }\end{array}$ & $\begin{array}{l}\text { Iterative } \\
\text { Velvet }\end{array}$ & NC_025232 \\
\hline $\begin{array}{l}\text { Stipagrostis uniplumis } \\
\text { (Licht. ex Roem. \& } \\
\text { Schult.) De Winter var. } \\
\text { uniplumis }\end{array}$ & MF460973 & $\begin{array}{l}\text { N. Snow \& M. } \\
\text { Chatukuta } 6853 \\
\text { (MO) }\end{array}$ & Nextera & $\begin{array}{l}\text { High } \\
\text { Output }\end{array}$ & $\begin{array}{l}\text { Iterative } \\
\text { Velvet }\end{array}$ & NC_025228 \\
\hline
\end{tabular}




\begin{tabular}{|c|c|c|c|c|c|c|}
\hline $\begin{array}{l}\text { Taeniatherum caput- } \\
\text { medusae (L.) Nevski }\end{array}$ & MF460974 & PI 561092 & Nextera XT & $\begin{array}{l}\text { Rapid } \\
\text { Mode }\end{array}$ & SPAdes & NC_009950 \\
\hline $\begin{array}{l}\text { Triodia stipoides (S.W.L. } \\
\text { Jacobs ) Crisp \& Mant }\end{array}$ & MF460970 & $\begin{array}{l}\text { Barrett } 3523 \\
\text { (PERTH) }\end{array}$ & Nextera & $\begin{array}{l}\text { High } \\
\text { Output }\end{array}$ & $\begin{array}{l}\text { Iterative } \\
\text { Velvet }\end{array}$ & NC_024262 \\
\hline $\begin{array}{l}\text { Triodia wiseana C.A. } \\
\text { Gardner }\end{array}$ & MF460975 & $\begin{array}{l}\text { Peterson et al } \\
14384 \text { (US) }\end{array}$ & Nextera & $\begin{array}{l}\text { High } \\
\text { Output }\end{array}$ & $\begin{array}{l}\text { Iterative } \\
\text { Velvet }\end{array}$ & NC_024262 \\
\hline $\begin{array}{l}\text { Zingeria biebersteiniana } \\
\text { (Claus) P.A. Smirn. }\end{array}$ & MF460984 & W6 19209 & Nextera XT & $\begin{array}{l}\text { Rapid } \\
\text { Mode }\end{array}$ & SPAdes & NC_009950 \\
\hline
\end{tabular}




\section{Table 2 (on next page)}

Descriptions of the plastome partitions analyzed. Partitions variously included a subset of coding regions, all coding regions, noncoding regions and the complete plastome, including coding and noncoding partitions.

In the alignments of each of these four core partitions we variously included or excluded gapped sites and positively selected sites in partitions including coding regions. 


\begin{tabular}{|c|c|c|c|c|}
\hline Code & Data partition & $\begin{array}{c}\text { Gapped sites } \\
\text { stripped }\end{array}$ & $\begin{array}{l}\text { Positively } \\
\text { selected } \\
\text { sites } \\
\text { removed }\end{array}$ & $\begin{array}{l}\text { Matrix } \\
\text { length }\end{array}$ \\
\hline A & $r b c L, n d h F$, matK & - & - & 7195 \\
\hline B & $r b c L, n d h F$, matK & + & - & 3476 \\
\hline $\mathrm{C}$ & $r b c L, n d h F$, matK & - & + & 6722 \\
\hline $\mathrm{D}$ & $r b c L, n d h F$, matK & + & + & 5077 \\
\hline $\mathrm{E}$ & Plastome coding & - & - & 59299 \\
\hline $\mathrm{F}$ & Plastome coding & + & - & 46707 \\
\hline G & Plastome coding & - & + & 55851 \\
\hline $\mathrm{H}$ & Plastome coding & + & + & 44975 \\
\hline Q & Plastome noncoding & - & $\mathrm{n} / \mathrm{a}$ & 143401 \\
\hline $\mathrm{R}$ & Plastome noncoding & + & $\mathrm{n} / \mathrm{a}$ & 26307 \\
\hline $\mathrm{W}$ & Complete plastome & - & - & 197529 \\
\hline $\mathrm{X}$ & Complete plastome & + & - & 78714 \\
\hline $\mathrm{Y}$ & Complete plastome & - & + & 197332 \\
\hline Z & Complete plastome & + & + & 71140 \\
\hline
\end{tabular}




\section{Table 3 (on next page)}

Pairwise comparisons of trees inferred from plastome partitions differing by the inclusion or exclusion of positively selected sites and gapped sites.

For each comparison the table records the number of shared (identical) clades with bootstrap support (BP) $\geq 50 \%$, maximum $B P$, identical $B P$, and $B P \geq 50 \%$ and $\geq 70 \%$ in one tree but $<$ $50 \%$ in the other; the range of BP difference and mean difference in BP for shared clades when positively selected and gapped sites are excluded; and the numbers of shared clades for which BP increases and decreases when positively selected and gapped sites are excluded. 
Positively selected sites included or excluded

Gapped sites included or excluded

\begin{tabular}{|c|c|c|c|c|c|c|c|c|c|c|c|c|c|c|c|}
\hline & \multicolumn{7}{|c|}{ Positively selected sites included or excluded } & \multicolumn{8}{|c|}{ Gapped sites included or excluded } \\
\hline & A vs. C & B vs. D & E vs. G & $\begin{array}{c}\text { F vs. } \\
\text { H }\end{array}$ & W vs. Y & $\begin{array}{c}\text { X vs. } \\
\text { Z }\end{array}$ & $\overline{\mathrm{x}}$ & A vs. B & D & vs. & G vs. & Q vs. R & $\begin{array}{c}\text { W vs. } \\
\text { X }\end{array}$ & Y vs. $\mathrm{Z}$ & $\overline{\mathrm{x}}$ \\
\hline $\begin{array}{l}\text { No. of shared clades with } \\
\mathrm{BP} \geq 50 \%\end{array}$ & 201 & 192 & 227 & 229 & 233 & 238 & $\begin{array}{l}220 \\
\pm \\
17\end{array}$ & 200 & 197 & 230 & 228 & 211 & 227 & 224 & $\begin{array}{l}215 \\
\pm \\
14\end{array}$ \\
\hline $\begin{array}{l}\text { No. }(\%) \text { of shared clades } \\
\text { with BP }=100 \%\end{array}$ & $\begin{array}{l}106 \\
(53)\end{array}$ & $90(47)$ & $\begin{array}{l}185 \\
(81)\end{array}$ & $\begin{array}{l}185 \\
(81)\end{array}$ & $203(87)$ & $\begin{array}{l}198 \\
(83)\end{array}$ & $\begin{array}{l}160 \\
\pm \\
45\end{array}$ & $\begin{array}{l}104 \\
(52)\end{array}$ & $\begin{array}{l}95 \\
(48)\end{array}$ & $\begin{array}{l}184 \\
(80)\end{array}$ & $\begin{array}{l}185 \\
(81)\end{array}$ & $158(75)$ & $\begin{array}{l}200 \\
(88)\end{array}$ & $189(84)$ & $\begin{array}{l}159 \\
\pm \\
40\end{array}$ \\
\hline $\begin{array}{l}\text { No. of clades with BP } \geq \\
50 \%(\geq 70 \%) \text { in one tree } \\
\text { and }<50 \% \text { in the other }\end{array}$ & $\begin{array}{l}\text { 13(4) } \\
\text { in } A \text {, } \\
14(2) \\
\text { in } C\end{array}$ & $\begin{array}{l}19(5) \\
\text { in } B \text {, } \\
14(6) \\
\text { in D }\end{array}$ & $\begin{array}{l}\text { 12(4) } \\
\text { in } \mathrm{E}, \\
10(3) \\
\text { in } \mathrm{G}\end{array}$ & $\begin{array}{l}9(5) \\
\text { in } \mathrm{F}, \\
8(2) \\
\text { in } \mathrm{H}\end{array}$ & $\begin{array}{l}11(10) \text { in } \\
W, \\
15(11) \text { in } \\
Y\end{array}$ & $\begin{array}{l}4(0) \\
\text { in } X, \\
2(1) \\
\text { in } Z\end{array}$ & & $\begin{array}{l}\text { 14(7) } \\
\text { in A, } \\
11(3) \\
\text { in B }\end{array}$ & $\begin{array}{l}18(7) \\
\text { in } C \text {, } \\
9(2) \\
\text { in D }\end{array}$ & $\begin{array}{l}9(1) \\
\text { in } \\
\text { E, } \\
8(4)\end{array}$ & $\begin{array}{l}10(3) \\
\text { in } G, \\
8(2) \text { in } \\
H\end{array}$ & $\begin{array}{l}31(20) \\
\text { in } \mathrm{Q}, \\
14(9) \text { in } \\
\mathrm{R}\end{array}$ & $\begin{array}{l}11(3) \\
\text { in } W, \\
15(8) \\
\text { in } X\end{array}$ & $\begin{array}{l}22(16) \\
\text { in } Y \text {, } \\
22(11) \\
\text { in } \mathrm{Z}\end{array}$ & \\
\hline $\begin{array}{l}\text { Range of support } \\
\text { difference }\end{array}$ & $-39-41$ & $-29-40$ & $-27-26$ & $\begin{array}{l}-30- \\
22\end{array}$ & $-20-30$ & $\begin{array}{l}-48- \\
40\end{array}$ & & $-16-33$ & $\begin{array}{l}-44- \\
33\end{array}$ & $\begin{array}{l}- \\
28-\end{array}$ & $-27-30$ & $-30-43$ & $-22-31$ & $-23-40$ & \\
\hline
\end{tabular}




\begin{tabular}{|c|c|c|c|c|c|c|c|c|c|c|c|c|c|c|c|}
\hline $\begin{array}{l}\text { Mean support difference } \pm \\
\text { s.d. [Absolute mean } \\
\text { support difference } \pm \text { s.d.] }\end{array}$ & $\begin{array}{l}2 \pm 9 \\
{[4 \pm 9]}\end{array}$ & $\begin{array}{l}1 \pm 9 \\
{[4 \pm 8]}\end{array}$ & $\begin{array}{l}1 \pm 5 \\
{[2 \pm 5]}\end{array}$ & $\begin{array}{l}0 \pm 4 \\
{[1 \pm} \\
4]\end{array}$ & $\begin{array}{l}0 \pm 4[1 \\
\pm 4]\end{array}$ & $\begin{array}{l}0 \pm 7 \\
{[2 \pm} \\
7]\end{array}$ & & $\begin{array}{l}2 \pm 5 \\
{[3 \pm 5]}\end{array}$ & $\begin{array}{l}0 \pm 9 \\
{[4 \pm} \\
8]\end{array}$ & $\begin{array}{l}0 \pm \\
4[2 \\
\pm 4]\end{array}$ & $\begin{array}{l}0 \pm 5 \\
{[2 \pm 5]}\end{array}$ & $\begin{array}{l}3 \pm 8[3 \\
\pm 8]\end{array}$ & $\begin{array}{l}1 \pm 5[1 \\
\pm 5]\end{array}$ & $\begin{array}{l}1 \pm 6[2 \\
\pm 6]\end{array}$ & \\
\hline $\begin{array}{l}\text { No. of shared clades with } \\
\text { identical support }\end{array}$ & 114 & 100 & 188 & 189 & 205 & 201 & $\begin{array}{l}166 \\
\pm \\
42\end{array}$ & 112 & 103 & 187 & 191 & 159 & 201 & 193 & $\begin{array}{l}164 \\
\pm \\
38\end{array}$ \\
\hline $\begin{array}{l}\text { No. of shared clades with } \\
\text { increased support when } \\
\text { positively selected/gapped } \\
\text { sites removed }\end{array}$ & 29 & 46 & 15 & 16 & 16 & 11 & $\begin{array}{l}22 \\
\pm \\
12\end{array}$ & 20 & 32 & 15 & 19 & 3 & 5 & 9 & $\begin{array}{l}15 \\
\pm 9\end{array}$ \\
\hline $\begin{array}{l}\text { No. of shared clades with } \\
\text { decreased support when } \\
\text { positively selected/gapped } \\
\text { sites removed }\end{array}$ & 58 & 46 & 24 & 24 & 12 & 26 & $\begin{array}{l}32 \\
\pm \\
15\end{array}$ & 68 & 62 & 28 & 19 & 49 & 21 & 22 & $\begin{array}{l}38 \\
\pm \\
13\end{array}$ \\
\hline
\end{tabular}

1 


\section{Table 4 (on next page)}

Pairwise comparison of bootstrap support (BP) for clades identified in three-gene (A, B, $C, D)$ and complete plastome coding trees $(E, F, G, H)$. 


\begin{tabular}{|l|l|l|l|l|}
\hline & A vs. E & B. vs. F & C vs. G & D vs. H \\
\hline $\begin{array}{l}\text { No. of shared clades with } \\
\text { maximum BP }\end{array}$ & 119 & 103 & 116 & 103 \\
\hline $\begin{array}{l}\text { No. of shared clades with BP }> \\
50 \% \text { ( } \geq 10 \% \text { higher) in the first of } \\
\text { the two compared trees, and the } \\
\text { range of the differences in BP for } \\
\text { shared clades }\end{array}$ & $6(4), 2-29 \%$ & $6(2), 2-28 \%$ & $6(1), 1-14 \%$ & $3(0), 1-$ \\
\hline $\begin{array}{l}\text { No. of shared clades with BP }> \\
50 \% \text { and higher } \geq 10 \% \text { higher) in } \\
\text { the second of the two compared } \\
\text { trees, and the range of the } \\
\text { differences in BP for shared clades }\end{array}$ & $44 \%$ & & & \\
\hline $\begin{array}{l}\text { No. of clades with BP } \geq 70 \% \text { in the } \\
\text { first of the compared trees and }< \\
50 \% \text { in the second of the compared } \\
\text { trees }\end{array}$ & 8 & $47 \%$ & $49 \%$ & $1-49 \%$ \\
\hline $\begin{array}{l}\text { No. of clades with BP support }< \\
50 \% \text { in the first of the compared } \\
\text { trees and } \geq 70 \% \text { in the second of } \\
\text { the compared trees }\end{array}$ & 34 & 2 & 5 & \\
\hline
\end{tabular}




\section{Table 5 (on next page)}

Summary of moderately to strongly supported conflicting clades among trees inferred from different plastome partitions.

The table identifies clade compositions, the trees in which the clades are present with bootstrap support $\geq 70 \%$, and bootstrap support for the clades. Shared taxa in conflicting clades are boldfaced. 


\begin{tabular}{|c|c|c|}
\hline Conflicting clades & Trees & $\begin{array}{l}\text { Support } \\
(\%)\end{array}$ \\
\hline $\begin{array}{l}\text { Panicoideae + Chloridoideae + Micrairoideae + Arundinoideae + } \\
\text { Danthonioideae ("aristidoid sister" hypothesis) // Aristidoideae + } \\
\text { Chloridoideae + Micrairoideae + Arundinoideae + Danthonioideae } \\
\text { ("panicoid sister" hypothesis) }\end{array}$ & $\mathrm{A}, \mathrm{Q}, \mathrm{W}, \mathrm{Y} / / \mathrm{R}$ & $\begin{array}{l}87-100 / / \\
93\end{array}$ \\
\hline $\begin{array}{l}\text { Arundinoideae }[\text { Phragmites }+ \text { Hakonechloa }+ \text { Elytrophorus }+ \text { Monachather }] \\
\text { // Monachather }+ \text { Micrairoideae }\end{array}$ & $\begin{array}{l}\text { E-H, Q, R, W- } \\
\mathrm{Z} / / \mathrm{D}\end{array}$ & $\begin{array}{l}93-100 / / \\
72\end{array}$ \\
\hline $\begin{array}{l}\text { Tripogoninae + Dactylocteniinae + Trichoneurinae + Triodiinae + } \\
\text { Eleusininae // Boutelouinae + Hilariinae + Monanthochloinae }+ \\
\text { Dactylocteniinae + Trichoneurinae + Triodiinae + Eleusininae }\end{array}$ & $\begin{array}{l}\mathrm{A}-\mathrm{C}, \mathrm{E}-\mathrm{H}, \mathrm{Q} \\
\mathrm{W}-\mathrm{Z} / / \mathrm{R}\end{array}$ & $\begin{array}{l}83-100 / / \\
95\end{array}$ \\
\hline $\begin{array}{l}\text { Dactylocteniinae + Trichoneurinae + Triodiinae // Dactylocteniinae + } \\
\text { Trichoneurinae + Eleusininae }\end{array}$ & $\mathrm{X} / / \mathrm{Q}, \mathrm{Y}$ & $\begin{array}{l}72 / / 77- \\
92\end{array}$ \\
\hline $\begin{array}{l}\text { Leptochloa }+ \text { Chloris }+ \text { Eustachys }+ \text { Oxychloris } / / \text { Astrebla }+ \text { Chloris }+ \\
\text { Eustachys }+ \text { Oxychloris }\end{array}$ & $\begin{array}{l}\text { A-H, W, X, Z // } \\
\text { Q }\end{array}$ & $\begin{array}{l}93-100 / / \\
100\end{array}$ \\
\hline $\begin{array}{l}\text { Dactylocteniinae + Trichoneurinae // Eleusininae + Trichoneurinae // } \\
\text { Dactylocteniinae + Tripogoninae }\end{array}$ & $\begin{array}{l}\mathrm{E}-\mathrm{G}, \mathrm{Q}, \mathrm{R}, \mathrm{W} \\
\mathrm{X}, \mathrm{Z} / / \mathrm{D} / / \mathrm{A}\end{array}$ & $\begin{array}{l}73-100 / / \\
80 / / 72 \\
\end{array}$ \\
\hline $\begin{array}{l}\text { Centotheceae }+ \text { Thysanolaeneae + Tristachyideae }+ \text { Zeugiteae }+ \\
\text { Chasmanthieae } / / \text { Chasmanthieae }+ \text { Zeugiteae }+ \text { the rest of Panicoideae } \\
\text { except Centotheceae }+ \text { Thysanolaeneae }+ \text { Tristachyideae }\end{array}$ & $\begin{array}{l}\text { E, F, G, X // Q, } \\
W, Y\end{array}$ & $\begin{array}{l}70-87 / / \\
90-100\end{array}$ \\
\hline Paniceae + Paspaleae // Lecomtelleae + Paspaleae & $\begin{array}{l}\text { A, E-H, Q, X-Z } \\
/ / \mathrm{R}\end{array}$ & $\begin{array}{l}89-100 / / \\
72\end{array}$ \\
\hline $\begin{array}{l}\text { Echinochloa }+ \text { Amphicarpum }+ \text { Alloteropsis } / / \text { Oplismenus }+ \text { Amphicarpum }+ \\
\text { Alloteropsis } / / \text { Echinochloa }+ \text { Oplismenus }+ \text { Alloteropsis }\end{array}$ & $\begin{array}{l}\mathrm{A}, \mathrm{B}, \mathrm{F} / / \mathrm{W} / / \\
\mathrm{Y}\end{array}$ & $\begin{array}{l}70-84 / / \\
75 / / 97\end{array}$ \\
\hline $\begin{array}{l}\text { Amphicarpum + Alloteropsis // Amphicarpum + Thyridolepis // Oplismenus + } \\
\text { Alloteropsis }\end{array}$ & $\begin{array}{l}\mathrm{B}, \mathrm{E}-\mathrm{H}, \mathrm{Q}, \mathrm{R}, \\
\mathrm{X}, \mathrm{Z} / / \mathrm{C}, \mathrm{D}, \mathrm{Y}\end{array}$ & $\begin{array}{l}71-100 / / \\
72-97 / / \\
73\end{array}$ \\
\hline $\begin{array}{l}\text { Cenchrus }+ \text { Setaria italica }+ \text { Setaria viridis } / / \text { Setaria italica }+ \text { Setaria viridis }+ \\
\text { Setaria geminata }\end{array}$ & $\begin{array}{l}\mathrm{G}, \mathrm{H}, \mathrm{Q}, \mathrm{R}, \mathrm{W} \\
\mathrm{X}-\mathrm{Z} / / \mathrm{B}, \mathrm{D}, \mathrm{E}\end{array}$ & $\begin{array}{l}100 / / \\
77-100\end{array}$ \\
\hline Arthropogoninae + Otachyriinae // Otachyriinae + Paspalinae & $\begin{array}{l}\text { E-H, Q, R, W- } \\
\mathrm{Z} / / \mathrm{C}, \mathrm{D}\end{array}$ & $\begin{array}{l}98-100 / / \\
74-95\end{array}$ \\
\hline Thyridolepis + Dichanthelium // Thyridolepis + Amphicarpum & $\begin{array}{l}\mathrm{E}-\mathrm{H}, \mathrm{Q}, \mathrm{R}, \mathrm{W} \\
\mathrm{X}, \mathrm{Z} / / \mathrm{C}, \mathrm{D}, \mathrm{Y}\end{array}$ & $\begin{array}{l}98-100 / / \\
72-97\end{array}$ \\
\hline $\begin{array}{l}\text { Eulalia }+ \text { Sorghastrum }+ \text { Andropogoninae } / / \text { Eulalia }+ \text { Sorghastrum }+ \\
\text { Imperata }+ \text { Saccharum }+ \text { Sorghum }\end{array}$ & $\begin{array}{l}\mathrm{E}, \mathrm{F}, \mathrm{X}, \mathrm{Z} / / \mathrm{G} \\
\mathrm{Q}, \mathrm{W}, \mathrm{Y}\end{array}$ & $\begin{array}{l}70-82 / / \\
75-93\end{array}$ \\
\hline $\begin{array}{l}\text { Potamophila + Zizania + Rhynchoryza // Chikusichloa +Zizania }+ \\
\text { Rhynchoryza }\end{array}$ & $\begin{array}{l}\mathrm{E}-\mathrm{H}, \mathrm{X}, \mathrm{Z} / / \mathrm{Q} \\
\mathrm{W}, \mathrm{Y}\end{array}$ & $\begin{array}{l}100 / / \\
100\end{array}$ \\
\hline Oryza sativa + Oryza nivara // Oryza sativa + Oryza rufipogon & $\begin{array}{l}\mathrm{G}, \mathrm{Q}, \mathrm{R}, \mathrm{W}-\mathrm{Z} / / \\
\mathrm{F}\end{array}$ & $\begin{array}{l}95-100 / / \\
87\end{array}$ \\
\hline $\begin{array}{l}\text { Bambusa multiplex }+ \text { Bambusa oldhamii }+ \text { Bambusa emeiensis }+ \text { Bambusa } \\
\text { bambos // Bambusa multiplex }+ \text { Bambusa oldhamii }+ \text { Bambusa emeiensis }+B \\
\text { Bambusa arnhemica // Bambusa multiplex }+ \text { Bambusa oldhamii }+ \text { Bambusa } \\
\text { emeiensis }+ \text { Dendrocalamus }\end{array}$ & $\begin{array}{l}\mathrm{R}, \mathrm{W}, \mathrm{X}, \mathrm{Z} / / \mathrm{Q} \\
/ / \mathrm{G}\end{array}$ & $\begin{array}{l}83-97 / / \\
84 / / 75\end{array}$ \\
\hline Olmeca + Otatea // Olmeca + Guadua & $\begin{array}{l}\mathrm{A}-\mathrm{H}, \mathrm{Q}, \mathrm{W}-\mathrm{Z} / / \\
\mathrm{R}\end{array}$ & $\begin{array}{l}97-100 / / \\
87\end{array}$ \\
\hline Indosasa + Oligostachyum // Indosasa + Pleioblastus & $\begin{array}{l}\text { Q, W-Z // E, F, } \\
\mathrm{H}\end{array}$ & $\begin{array}{l}70-93 / / \\
70-78 \\
\end{array}$ \\
\hline $\begin{array}{l}\text { Oligostachyum }+ \text { Indosasa }+ \text { Pleioblastus // Oligostachyum }+ \text { Indosasa }+ \\
\text { Acidosasa }\end{array}$ & $\begin{array}{l}\text { E-H, Y, Z // R, } \\
\text { W }\end{array}$ & $\begin{array}{l}72-93 / / \\
83-93\end{array}$ \\
\hline $\begin{array}{l}\text { Brachypodieae + Poeae + Bromeae + Triticeae // Diarrheneae + Brachypodieae } \\
\text { // Diarrheneae + Poeae + Bromeae + Triticeae }\end{array}$ & $\begin{array}{l}\text { A-C, E, G, Q, } \\
\mathrm{W}, \mathrm{Y} / / \mathrm{Z} / / \mathrm{D}\end{array}$ & $\begin{array}{l}80-100 / / \\
72 / / 78\end{array}$ \\
\hline $\begin{array}{l}\text { Triticum macha + Triticum turgidum // Triticum turgidum + Triticum aestivum } \\
\text { // Triticum macha }+ \text { Triticum aestivum }\end{array}$ & $\begin{array}{l}\text { A, C, F, H, R, } \\
\text { X, Z//E, G, W } \\
\text { //Y }\end{array}$ & $\begin{array}{l}80-100 / / \\
75-90 / / \\
88\end{array}$ \\
\hline $\begin{array}{l}\text { Aegilops kotschyi + Aegilops sharonensis // Aegilops longissima + Aegilops } \\
\text { sharonensis }\end{array}$ & $\mathrm{Q}, \mathrm{W}, \mathrm{Y} / / \mathrm{A}$ & $78 / / 74$ \\
\hline Poa + Alopecurus $/ /$ Phleum + Alopecurus & $\begin{array}{l}\mathrm{D}-\mathrm{H}, \mathrm{X}-\mathrm{Z} / / \mathrm{Q} \\
\mathrm{W}\end{array}$ & $\begin{array}{l}85-100 / / \\
100\end{array}$ \\
\hline $\begin{array}{l}\text { Helictochloa }+ \text { Holcus } / / \text { Helictochloa }+ \text { Deschampsia }+ \text { Dactylidinae }+ \\
\text { Loliinae }\end{array}$ & $\mathrm{W}-\mathrm{Y} / / \mathrm{F}$ & $\begin{array}{l}92-100 / / \\
70\end{array}$ \\
\hline $\begin{array}{l}\text { Phalaridinae + Torreyochloinae + Anthoxanthinae }+ \text { Brizinae + Agrostidinae } \\
\text { // Aveninae + Anthoxanthinae + Brizinae + Agrostidinae }\end{array}$ & $\begin{array}{l}\text { Q, R, Z // A-D, } \\
\text { H, W, Y }\end{array}$ & $\begin{array}{l}98-100 / / \\
64-100\end{array}$ \\
\hline $\begin{array}{l}\text { Hickeliinae + Dinochloinae + Greslaninae // Bambusinae + Dinochloinae + } \\
\text { Greslaninae }\end{array}$ & $\begin{array}{l}\text { E-H, Q, W, Y // } \\
\text { A, C, D, R, X, Z }\end{array}$ & $\begin{array}{l}92-100 / / \\
70-100\end{array}$ \\
\hline
\end{tabular}


Figure 1 (on next page)

Proportion and raw numbers of positively selected codons for each plastome protein coding sequence (CDS).

Red represents positive selection in CDS that are commonly used in phylogenetic studies, while blue represents positive selection in other CDS. Proportionate data are only represented up to 0.15 selected codons for clarity of illustration. 
Figure 2 (on next page)

Comparison of bootstrap support across trees.

(A) Support values and trend lines for all clades identified in at least one tree with support $\geq$ $50 \%$. Trend lines were plotted in $\mathrm{R}$, using the command geom_smooth in ggplot2 with the method "LOESS". Clade no. corresponds to numerical clade identifiers as noted in Supplemental Dataset 16. (B) Mean support values with standard error bars for each tree. Trees were grouped by a Least Significant Difference test with a Bonferonni correction. Groups are identified by the analysis and labeled with one or two letter designators showing overlap in some cases. 


\section{Figure $\mathbf{3}$ (on next page)}

Maximum likelihood phylogram from analysis of complete plastomes excluding gapped sites and including positively selected sites (tree $\mathrm{X}$ ) showing relationships among major lineages of Poaceae.

Subfamilies are collapsed and only the branch subtending each subfamilial clade is shown. Bootstrap support is indicated along branches, according to the legend on the upper left. Two alternative topologies within the PACMAD clade, not shown in the figure, are identified in our trees: (1) Aristidoideae are sister to the rest of the PACMAD clade, with BP $=69-100 \%$, in trees A, C, Q, W and Y; and (2) Aristidoideae and Panicoideae form a weakly supported clade $(B P=52 \%)$ in tree $F$ that is sister to the rest of the PACMAD clade. 
PeerJ

ㅁ $\mathrm{BP}=100 \%$ in all three-gene and complete plastome trees

口 $\mathrm{BP}=100 \%$ in all complete plastome trees

$\square \mathrm{BP}=90-100 \%$ in all complete plastome trees

ㅁ $\mathrm{BP}=80-100 \%$ in all complete plastome trees

$\square \mathrm{BP}=70-100 \%$ in all complete plastome trees

$\mathrm{BP}=53 \%$ (tree D), 93\% (R)

and $58 \%(\mathrm{Z})$

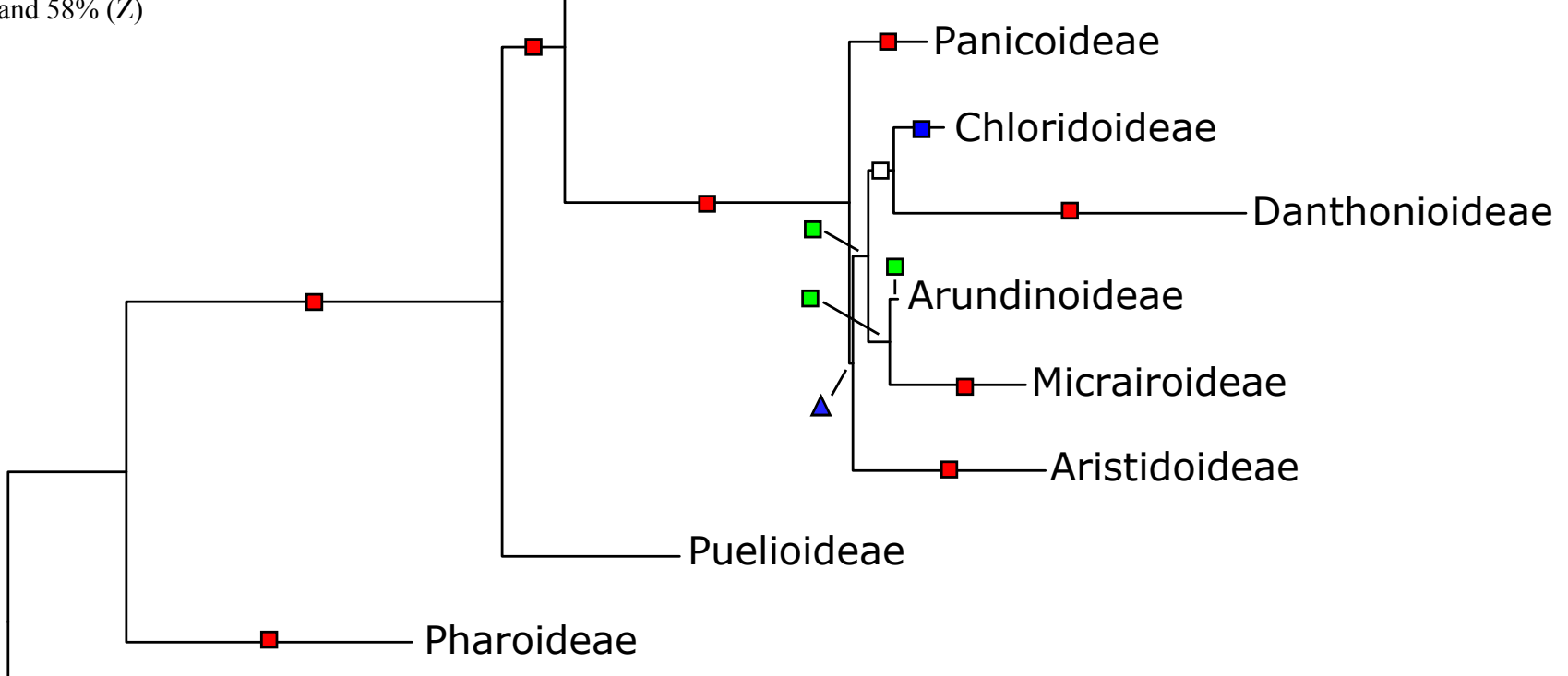




\section{Figure 4(on next page)}

Pooideae portion of the maximum likelihood tree inferred from complete plastomes excluding gapped sites and including positively selected sites (tree $\mathrm{X}$ ).

Bootstrap support, when $\geq 50 \%$, for clades in this tree and clades shared among this and other trees, is summarized along branches, according to the legend. Numbers along branches are bootstrap support values in tree $X$. 
$\mathrm{BP}=$ 00 fm tur tree $(\mathrm{X})$

(not shown if $\mathrm{BP}=100 \%$ in all trees)

BP $=100 \%$ in all three-gene and complete plastome trees

- $\mathrm{BP}=100 \%$ in all complete plastome trees

$\square \mathrm{BP}=90-100 \%$ in all complete plastome trees

$\square \mathrm{BP}=80-100 \%$ in all complete plastome trees

$\square \mathrm{BP}=70-100 \%$ in all complete plastome trees

Clade recovered with $\mathrm{BP} \geq \mathbf{5 0 \%}$ in:

all 14 trees

$\Delta$ (not shown if $\mathrm{BP}=100 \%$ in all trees)

$\triangle 12-13$ trees

$\triangle 10-11$ trees

$\triangle 8-9$ trees

$\triangle$ 6-7 trees

$\triangle 4-5$ trees

$\Delta 1-3$ trees
Lolium pratense

Lolium arundinaceum

Drymochloa sylvatica

- Festuca ovina

$\Delta$

Catapodium rigidum

$\Delta \frac{\Delta}{\Delta} \square\left[\begin{array}{l}\text { Dactylis glomerata } \\ \text { Lamarckia aurea }\end{array}\right.$

$\Delta \Delta \square\left[\begin{array}{l}\Delta \\ \Delta\end{array}\right.$

- Deschampsia antarctica

CHolcus lanatus

Helictochloa hookeri

Alopecurus arundinaceus

$\square-$ Poa palustris

- Phleum alpinum

Zingeria biebersteiniana

- Puccinellia nuttalliana

- Agrostis stolonifera

$\Delta \longrightarrow$ Agrostis gigantea

$\Delta \longrightarrow$ Gastridium ventricosum

- Calamagrostis breviligulata

- Briza maxima

${ }_{50}^{\Delta} \underbrace{}_{\Delta} C_{\text {Anthoxanthum nitens }}{ }_{\text {Anthoxanthum odoratum }}$

- Avena sativa

Trisetum cernuum

Torreyochloa pallida

- Phalaris arundinacea

53 - Aegilops searsii

$\triangle \leftarrow$ Aegilops kotschyi

- Aegilops bicornis

$52-$ Aegilops sharonensis

$\Delta \leftarrow$ Aegilops longissima

- Aegilops geniculata

- Aegilops cylindrica

- Aegilops tauschi

- Triticum urartu

Triticum monococcum

- Triticum macha

$\Delta-$ Triticum turgidum

$\Delta \longleftarrow$ Triticum aestivum

- Triticum timopheevii

- Aegilops speltoides var. speltoides Taeniatherum caput-medusae

Secale cereale

Connorochloa tenuis

- Hordeum vulgare subsp. vulgare

- Hordeum jubatum

- Bromus vulgaris

[ Brachypodium distachyon

55

- Diarrhena obovata

- Nassella hyalina

Eriocoma hymenoides

$\Delta$ - Piptatherum songaricum

Oryzopsis asperifolia

$\Delta^{-}$Ampelodesmos mauritanicus

- Piptochaetium avenaceum

- Melica mutica

- Melica subulata

$\Delta$ Phaenosperma globosum

- Nardus stricta

Lygeum spartum

- Brachyelytrum aristosum
Loliinae

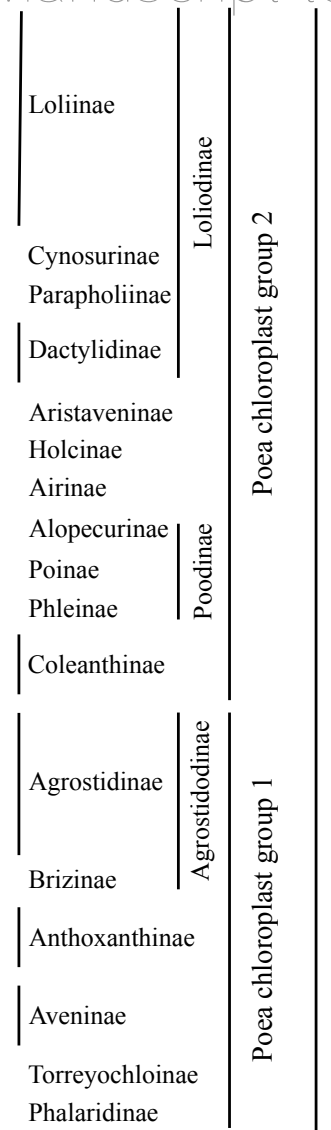

Poeae

Triticeae

Triticinae

Bromeae

Brachypodieae

Diarrheneae

Stipeae

Ampelodesmeae

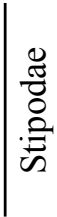

Meliceae

Phaenospermateae

Nardeae

Lygeae

Brachyelytreae 
Figure $\mathbf{5}$ (on next page)

Bambusoideae portion of the maximum likelihood tree inferred from complete plastomes excluding gapped sites and including positively selected sites (tree $\mathrm{X}$ ).

Bootstrap support, when $\geq 50 \%$, for clades in this tree and clades shared among this and other trees, is summarized along branches, according to the legend. Numbers along branches are bootstrap support values in tree $X$. 
92 - Phyllostachys aurea $60 \triangle \leftarrow$ Phyllostachys propinqua

${ }_{97}{ }_{1}$ C Phyllostachys nigra var. henonis

68

$\Delta \backslash$ Phyllostachys sulphurea

$\triangle$

- Phyllostachys edulis

$75-$ Fargesia nitida

Bashania fargesii

(4) $95-$ Yushania levigata

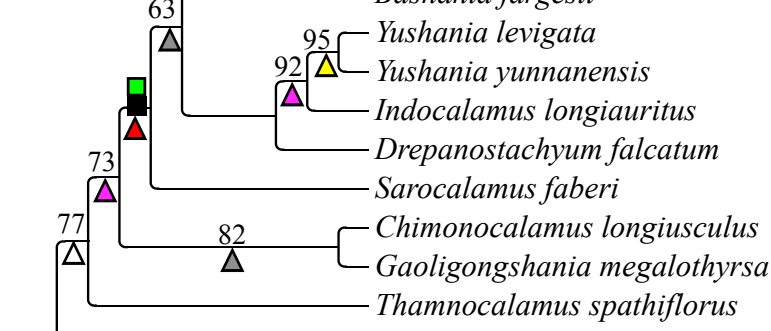

70 - Indosasa sinica

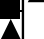

$5 3 \longdiv { \Delta }$ Oligostachyum shiuyingianum

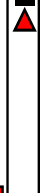

$\mathbf{\lambda}$

- Acidosasa purpurea

Pleioblastus maculatus

- Pseudosasa japonica

$\square[$ Arundinaria appalachiana

$\Delta \quad 93 \square$ Arundinaria tecta

$\Delta$

- Arundinaria gigantea

-Sasa veitchii

72 Gelidocalamus tessellatus

$\Delta-$ Shibataea kumasaca

$\Delta-$ Ferrocalamus rimosivaginus

Indocalamus wilsonii

- Ampelocalamus calcareus

- Bambusa oldhamii

$\triangle-$ Bambusa multiplex
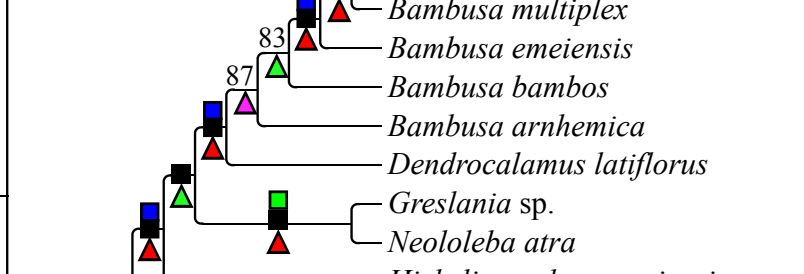

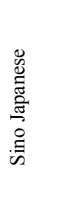

clade IX

clade VII

Arundinariinae

Arundinarieae

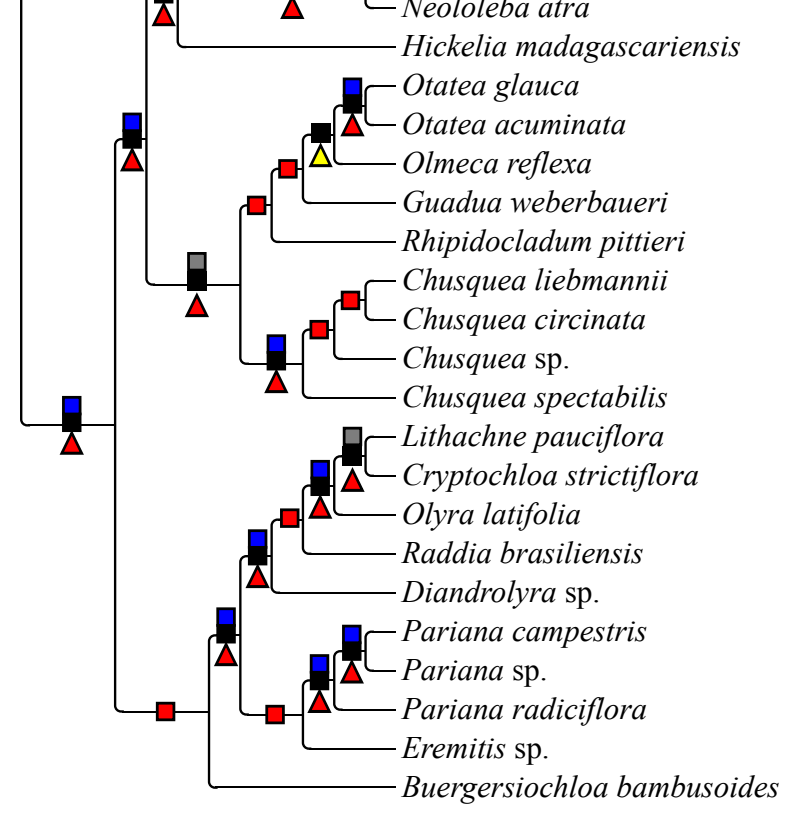

Bambusinae

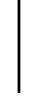

Greslaninae

Dinochloinae

Hickeliinae

Bambuseae

$\mid$

Arthrostylidiinae

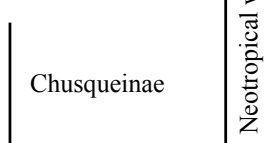

Olyrinae

Olyreae

to Figure 6

$\checkmark$

to Figure 8
$\mathrm{BP}=100 \%$ in this tree $(\mathrm{X})$

(not shown if $\mathrm{BP}=100 \%$ in all trees)

$\square \mathrm{BP}=100 \%$ in all three-gene and complete plastome trees

$\mathrm{BP}=100 \%$ in all complete plastome trees

$\mathrm{BP}=90-100 \%$ in all complete plastome trees
Clade recovered with $\mathrm{BP} \geq \mathbf{5 0 \%}$ in:

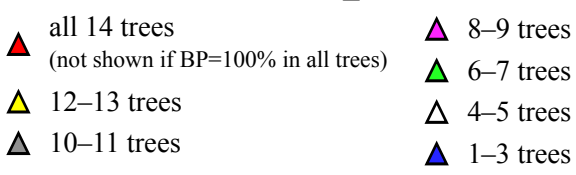




\section{Figure 6 (on next page)}

Oryzoideae portion of the maximum likelihood tree inferred from complete plastomes excluding gapped sites and including positively selected sites (tree X).

Bootstrap support, when $\geq 50 \%$, for clades in this tree and clades shared among this and other trees, is summarized along branches, according to the legend. Numbers along branches are bootstrap support values in tree $\mathrm{X}$. 


\section{to Figure 5}

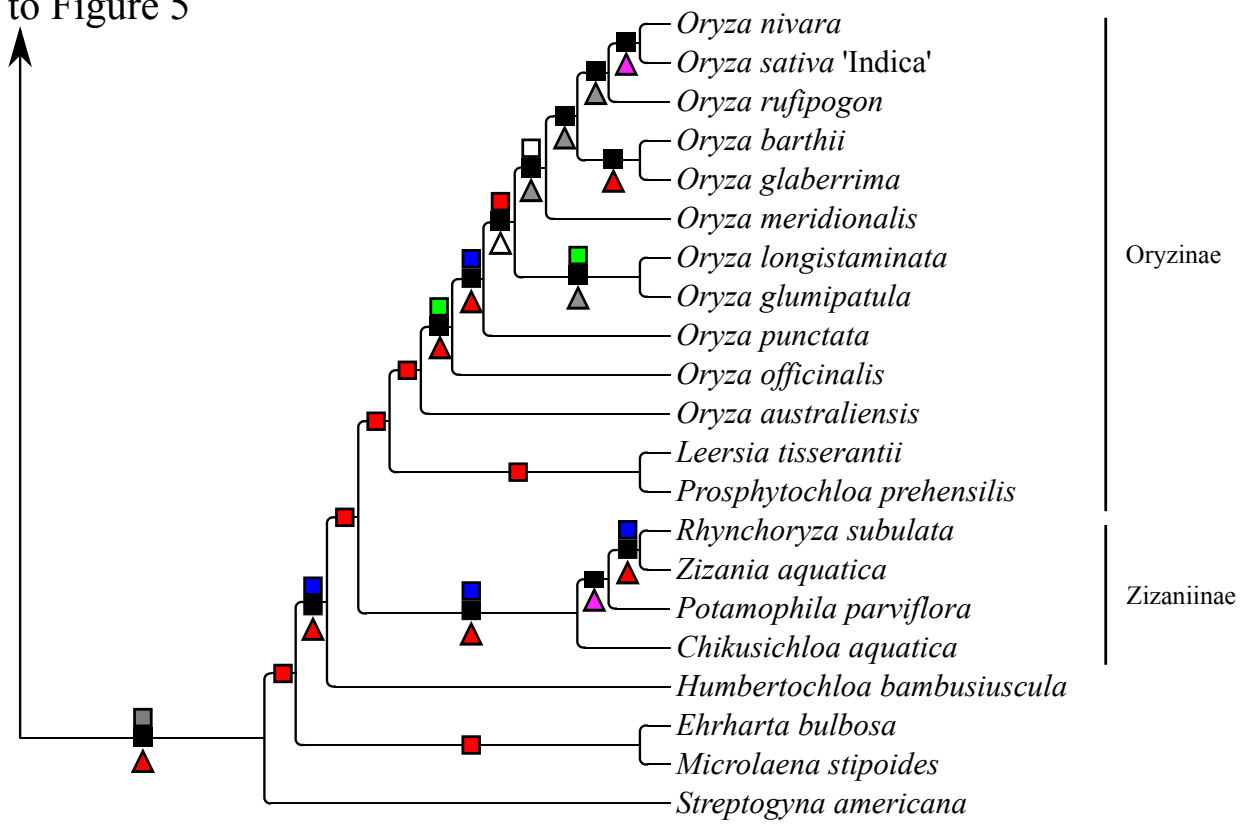

$\mathrm{BP}=100 \%$ in this tree $(\mathrm{X})$

(not shown if $\mathrm{BP}=100 \%$ in all trees)

$\square \mathrm{BP}=100 \%$ in all three-gene and complete plastome trees

口 $\mathrm{BP}=100 \%$ in all complete plastome trees

$\square \mathrm{BP}=90-100 \%$ in all complete plastome trees

$\square \mathrm{BP}=80-100 \%$ in all complete plastome trees

$\square \mathrm{BP}=70-100 \%$ in all complete plastome trees
Clade recovered with $\mathrm{BP} \geq \mathbf{5 0 \%}$ in:
all 14 trees
$\triangle 8-9$ trees
$\triangle$ (not shown if $\mathrm{BP}=100 \%$ in all trees)
$\triangle 6-7$ trees
$\triangle 12-13$ trees
$\Delta 4-5$ trees
$\triangle 10-11$ trees
$\Delta 1-3$ trees

Oryzeae

Phyllorachideae

Ehrharteae

Streptogyneae 
Figure 7 (on next page)

Panicoideae portion of the maximum likelihood tree inferred from complete plastomes excluding gapped sites and including positively selected sites (tree $\mathrm{X}$ ).

Bootstrap support, when $\geq 50 \%$, for clades in this tree and clades shared among this and other trees, is summarized along branches, according to the legend. Numbers along branches are bootstrap support values in tree $X$. 
$\mathrm{BP}=100 \%$ in this $\mathrm{ne}(\mathrm{X})$
$($ not shown if $\mathrm{BP}=100 \%$ in ares

$\mathrm{BP}=100 \%$ in all three-gene and complete

plastome trees

$\mathrm{BP}=100 \%$ in all complete

plastome trees

$\mathrm{BP}=90-100 \%$ in all complete

plastome trees

$\square \mathrm{BP}=80-100 \%$ in all complete plastome trees

$\square \mathrm{BP}=70-100 \%$ in all complete plastome trees

Clade recovered with $\mathrm{BP} \geq \mathbf{5 0 \%}$ in:

all 14 trees

$\Delta$ (not shown if $\mathrm{BP}=100 \%$ in all trees)

$\triangle 12-13$ trees

$\triangle 10-11$ trees

$\triangle 8-9$ trees

$\triangle 6-7$ trees

$\triangle 4-5$ trees

$\Delta$ 1-3 trees

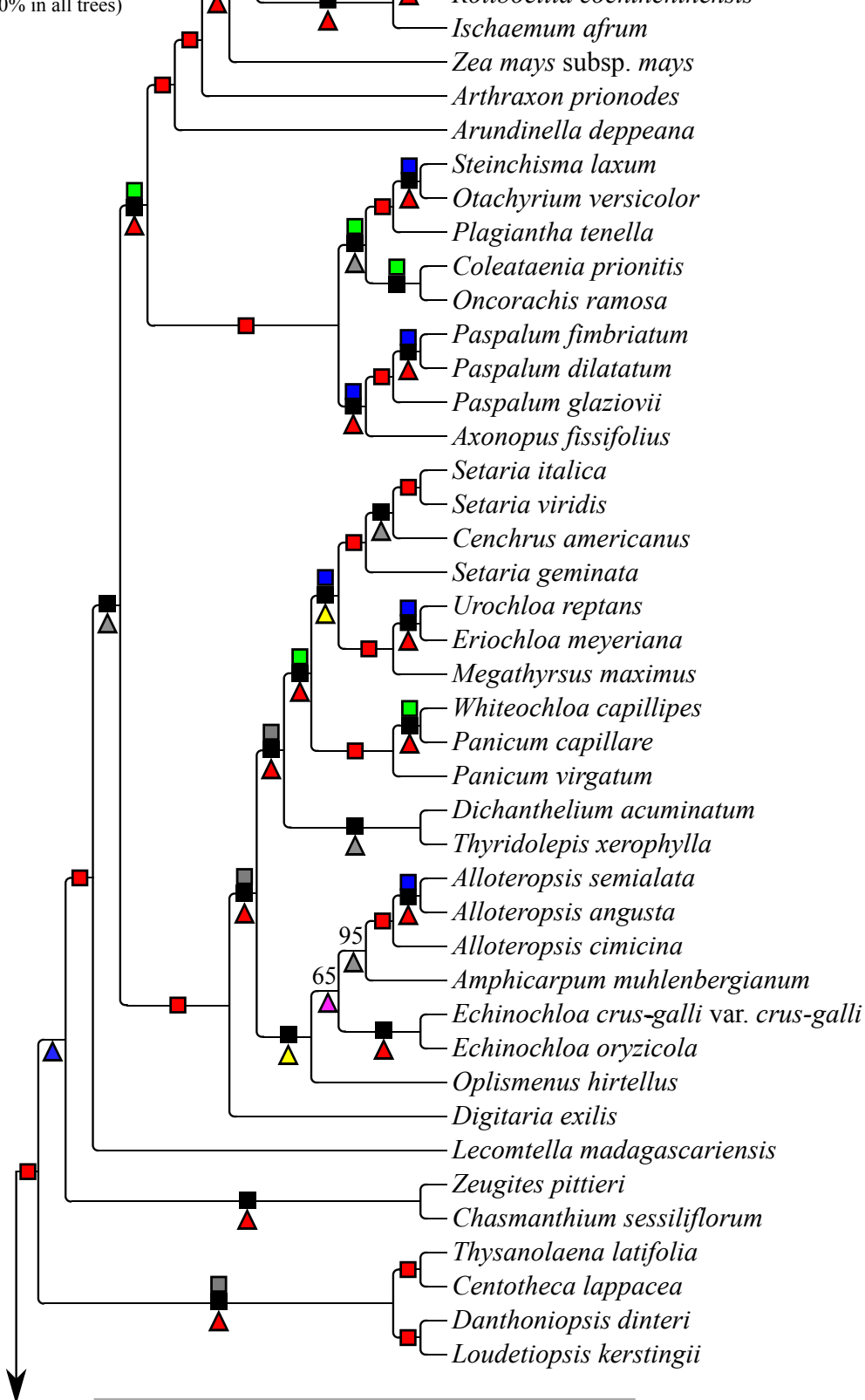

82

$\Delta$ Themeda $\mathrm{sp}$

- Hyparrhenia subplumosa

$\Delta-$ Diheteropogon amplectans

$62-$ Eulalia aurea

$\Delta \smile$ Sorghastrum nutans

- Sorghum timorense

$\triangle$ Sorghum bicolor

$98 \triangle \longrightarrow$ Saccharum hybrid cv. NCo 310

Imperata cylindrica

- Coix lacryma-jobi

$\Delta \leftarrow$ Rottboellia cochinchinensis

Ischaemum afrum

Zea mays subsp. mays

raxon prionodes

Steinchisma laxum

Otachyrium versicolor

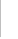

Otachyriinae

Arthropogoninae

Paspalinae

Cenchrinae

Melinidinae

Panicinae

Dichantheliinae

Neurachninae

|

Boivinellinae

Anthephorinae

Andropogoneae

Arundinelleae

Paspaleae

Paniceae

Lecomtelleae

Zeugiteae

Chasmanthieae

Thysanolaeneae

Centotheceae

Tristachyideae

to Figure geviewing PDF | (2017:08:19682:2:0:NEW 4 Jan 2018) 
Figure 8 (on next page)

Anomochlooideae, Pharoideae, Puelioideae, Arundinoideae, Chloridoideae, Danthonioideae and Micrairoideae portion of the maximum likelihood tree inferred from complete plastomes excluding gapped sites and including positively selected sites (tree $\mathrm{X})$.

Bootstrap support, when $\geq 50 \%$, for clades in this tree and clades shared among this and other trees, is summarized along branches, according to the legend. Numbers along branches are bootstrap support values in tree $X$. 


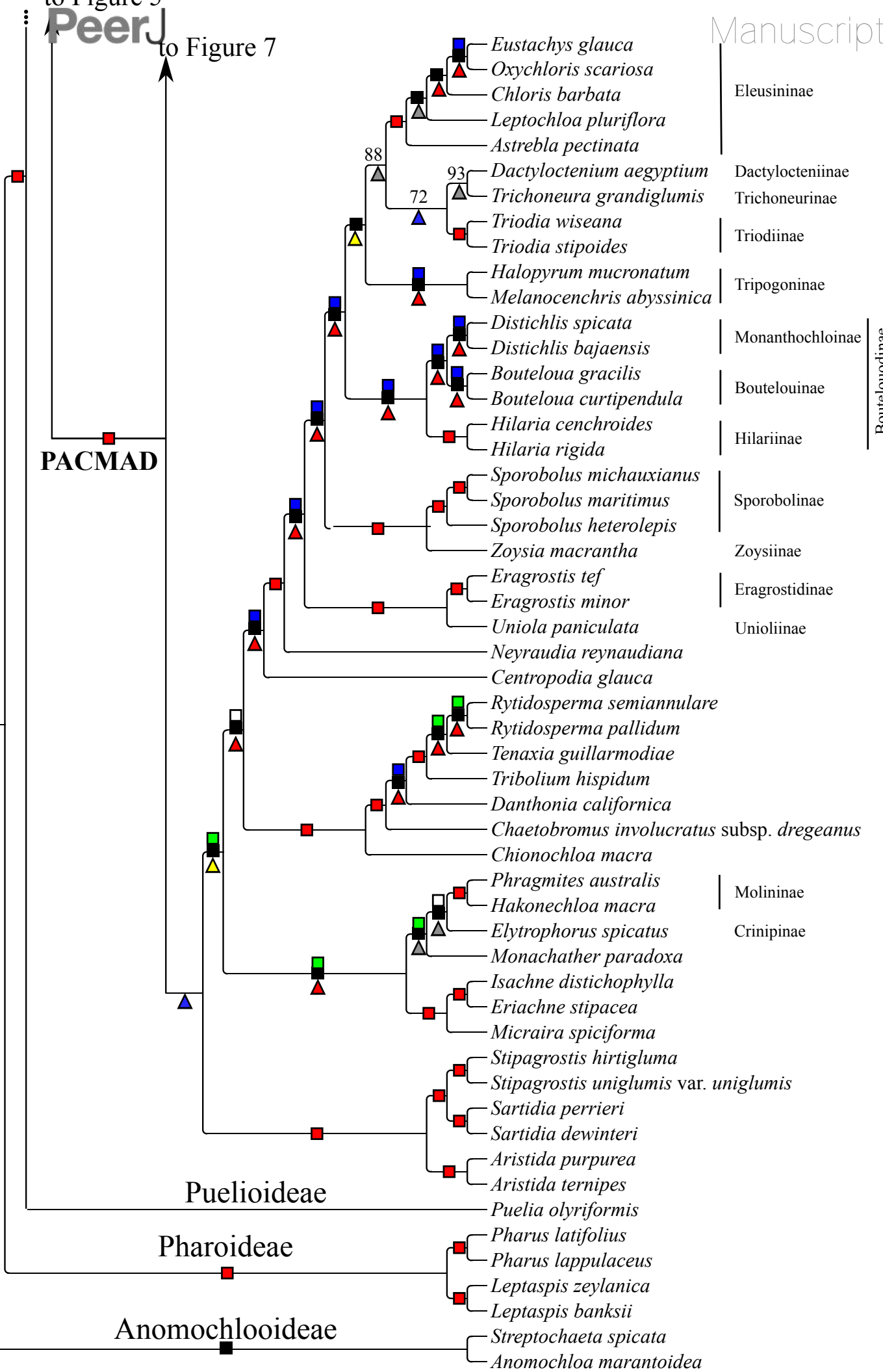

\section{Cynodonteae}

Zoysieae

Eragrostideae

Triraphideae Centropodieae

$$
\text { | }
$$

Danthonieae

Molinieae

Arundineae

Isachneae

Eriachneae

Micraireae

Aristideae

Atractocarpeae

Phareae

Streptochaeteae Anomochloeae

$\mathrm{BP}=100 \%$ in this tree $(\mathrm{X})$

(not shown if $\mathrm{BP}=100 \%$ in all trees)

$\square \mathrm{BP}=100 \%$ in all three-gene and complete plastome trees

$\mathrm{BP}=100 \%$ in all complete plastome trees

$\square \mathrm{BP}=90-100 \%$ in all complete plastome trees

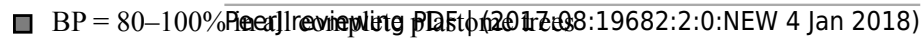

$\square \mathrm{BP}=70-100 \%$ in all complete plastome trees
Clade recovered with $\mathrm{BP} \geq \mathbf{5 0 \%}$ in:
all 14 trees
(not shown if $\mathrm{BP}=100 \%$ in all trees)
$\triangle 8-9$ trees
$\triangle 12-13$ trees
$\triangle 6-7$ trees
$\triangle 10-11$ trees
$\triangle 4-5$ trees
$\Delta 1-3$ trees 